1 Late Holocene land vertebrate fauna from Cueva de los Nesofontes, Western Cuba: stratigraphy,

2 last appearance dates, diversity and paleoecology

3

4

5

6

7

8

9

10

11

12

13

14

15

16

17

18

19

20

21

22

23

24

25 


\section{Johanset Orihuela*}

27 Department of Earth and Environment (Geosciences)

28 Florida International University

29 Miami, FL 33199

30 *Email: Paleonycteris@gmail.com

31

32 Leonel Pérez Orozco

33 City of Matanzas Conservator, Matanzas, Cuba

34 Founding member of the group Norbert Casteret

35 of the Cuban Speleological Society

36 Email: histmatanzas@ohc.cu

37

38 Jorge L. Álvarez Licourt

39 A former member of the group Combates de Moralitos

40 of the Cuban Speleological Society

41 Email: espelunca3@gmail.com

42

43 Ricardo A. Viera Muñoz

44 A former member of the group Jorge Ramon Cuevas

45 of the Cuban Speleological Society

46 Email: sancarlossanseverino@gmail.com

47

48 Candido Santana Barani

49 Member of the group Norbert Casteret

50 of the Cuban Speleological Society histmatanzas@ ohc.cu 
52 ABSTRACT

53 Here we report a Late Holocene fossil-rich cave deposit from Cueva de los Nesofontes,

54 Mayabeque Province, Cuba. The deposit's formation and its fauna were studied through a

55 multidisciplinary approach that included stable isotope analyses, radiocarbon chronology,

56 stratigraphy, sedimentology, and taphonomy. Thousands of microvertebrate skeletal remains

57 were recovered, representing a diverse land vertebrate fauna that included threatened and extinct

58 species. The deposit is characterized by profuse Nesophontes remains due to raptor predation.

59 Previously unreported last appearance dates are provided for the extinct island-shrew

60 Nesophontes major, the bats Artibeus anthonyi and Phyllops vetus. Radiocarbon $\left({ }^{14} \mathrm{C}\right.$ AMS $)$ age

61 estimates between $\sim 1960$ rcyr BP and the present were recovered. The presence of locally extinct

62 species, including the endemic parakeet Psittacara eups, the flicker Colaptes cf.

63 auratus/fernandinae, and the lipotyphlan Solenodon cubanus suggests that these species had

64 broader distributions in the near past. Isotope analyses and faunal composition indicate the

65 previous presence of diverse habitats, including palm grove savannas and mixed woodlands.

66 Isotopes also provide insight into the habitat and coexistence of the extinct bat Artibeus anthonyi

67 and extant A. jamaicensis, the diet of Nesophontes major, and local paleoenvironmental

68 conditions. Oxygen isotopes reveal an excursion suggestive of drier/colder local conditions

69 between 660 and 770 AD. Our research further expands the understanding of Cuban Quaternary

70 extinction episodes and provides data on the distribution and paleoecology of extinct taxa. It

71 supports the conclusion that many Cuban extinct species survived well into the pre-Columbian

72 late Holocene and retained wide distribution ranges until human colonization.

73

74 Keywords: Fossils; Subfossils; Microvertebrates; Cave; Cuba; Antillean; Late Holocene 


\section{INTRODUCTION}

77 Cave deposits have been, and continue to be, the richest source of extinct land vertebrate fossils in

78 the Greater Antilles. Caves harbor different kinds of bone deposits, including accumulations due to natural death of cave inhabitants and visitors, raptor-derived pellets (e.g., mostly from owls), and dietary middens created by humans. In Cuba, these forms of bone accumulation have provided a rich vertebrate record of the island's late Quaternary faunas, an essential source for understanding Antillean biogeography and extinctions (Morgan and Woods, 1986; Morgan, 1994; MacPhee et al., 1999).

Faunal deposits accumulated in Cuban caves were initially discovered during the mid-late $8519^{\text {th }}$ century and the first decades of the $20^{\text {th }}$ century. These early efforts included discoveries by José Figueroa, Fernández de Castro, and Carlos de la Torre at several localities throughout the

87 island between 1860 and 1911 (de la Torre, 1910; Nuñez, 1998; Goldberg et al., 2017). Later explorations were conducted by Barnum Brown (1913), Thomas Barbour, and other personnel from the Museum of Comparative Zoology (Cambridge), Carnegie Museum (Philadelphia), and 90 the American Museum (New York City). Gerrit S. Miller (1916) and Harold E. Anthony described

91 faunas from fossil and subfossil material found in cave deposits in eastern Cuba (Anthony, 1917, 92 1919), as did Peterson (1917) and Glover M. Allen in western Cuba (Allen, 1917, 1918), providing thereby the first micromammal fauna accounts from the island. 
the few existing radiocarbon dates from non-cultural vertebrate assemblages reported from Cuba now indicate that such faunal accumulations are often much younger in age than previously expected (MacPhee et al., 1999, 2007; Jull et al., 2004; Jiménez et al., 2005; Steadman et al., 2005; Orihuela, 2010; Orihuela and Tejedor, 2012; Orihuela, 2019). So far, only three cave deposits have yielded true Pleistocene faunas: Cueva El Abrón, in Pinar del Río province (Suárez and DíazFranco, 2003), the tar deposits of San Felipe (Jull et al., 2004) and the thermal bath deposits of Ciego Montero (Kulp, 1952). Even though the Cuban record is one of the richest and most diverse of the Greater Antilles, it remains the least understood in terms of chronology due to the lack of reliable age estimates and discrete faunal analyses.

Such lack of chronologic resolution, which can be achieved through detailed sedimentological, stratigraphically and direct "last appearance dates" (LADs), limit our understanding of the timing of loss for most of its extinct or extirpated land vertebrate fauna. So far, of the 21 extinct land mammals, including bats, currently recognized for Cuba (Silva et al., 2007), only three, plus two birds, have direct LADs (MacPhee et al., 1999; Jull et al., 2004; Steadman et al., 2005; Orihuela, 2019). Generating additional direct and indirect LADs are crucial to constrain extinction chronologies against known past human-caused environmental changes in

114 Cuba (Orihuela et al., forthcoming). northwestern Cuba. Our interpretation of the deposit's radiocarbon chronology, stratigraphy, and

117 taphonomy, in addition to analyses of stable isotopes and faunal composition, contributes to the 118 understanding of Cuban faunal diversity and biogeography by providing insight into the 119 distribution, coexistence, diet, habitat, and timing of extinction of a wide array of taxa. The 120 diversity and age of the deposit, plus new direct ${ }^{14} \mathrm{C}$ LADs for Cuban extinct or endangered 
121 endemics, provide a unique opportunity to study a faunal assemblage that spans the critical interval

122 between Amerindian arrival and European colonization, thus contributing to the overall

123 understanding of Antillean land vertebrate extinction and biogeography.

\section{MATERIALS AND METHODS}

\section{Geological and environmental settings}

Cueva de los Nesofontes is one of a number of caves located on Loma El Palenque or Palenque province but was formerly included within the Province of Matanzas (Figure 1). 
144

145

146

147

148

149

150

151

152

153

154

155

156

157

antillea, and the planktonic Globigerina spp. Heterostegina antillea is an index tax on of the upper Oligocene and lower Miocene (BouDagher-Fadel, 2008). The presence of Miogypsina at the highest level (at $265 \mathrm{~m}$ above the surface of Palenque as defined by Ducloz, 1963) supports an extension for the possible formation up to the middle Miocene (JO, unp. data).

As in the case of the rest of the Habana-Matanzas range, neotectonic uplift and differential erosion during the Pleistocene (<2.6 Ma) (Iturralde-Vinent, 1988) affected the exposure of the hillside. Two of its scarp levels (the highest is indicated by asterisks in Figure 1) have been interpreted as evidence of a late Pliocene-early Pleistocene marine terrace (Iturralde-Vinent, 1969a/b, 1977), known as the Palenque Surface (Ducloz, 1963). Thus, we consider the age of the caves found within the hill to be late Pliocene or younger in age. Decomposition of exposed limestone formed the red clay ferralitic soils and loams occurring in upper escarpments (> $250 \mathrm{~m}$ amsl). These are known as the Matanzas red soil series (Formell and Buguelskiy, 1974), now considered as the late Quaternary Villaroja Fm (Lexicon, 2014). In terms of composition, these are the same that occur at the openings and inside of caves and fractures at Palenque.

The climate in the region is today tropical, with warm temperatures between 32 and 23 $\mathrm{C}^{\circ}$ during the wet season (May-October), with average rainfall between $\sim 1300$ and $1500 \mathrm{~mm}$ (Cuban National Atlas, 1989). During the cold - dry season (November-April) temperatures range between 18 and $26 \mathrm{C}^{\circ}$ (Cuban National Atlas, 1989). We registered temperatures of $6 \mathrm{C}^{\circ}$ inside the main gallery during the night of December 24, 2003.

Premodern vegetation was comprised of semideciduous woodlands over karst terrain and mogote forests at a higher elevation (typical mesophyll, Del Risco, 1989). Today the region is covered in secondary, but well preserved, semideciduous forest surrounded by savannas and agricultural land with lakes and rivers (Figure 1). The present vegetation on the hill includes the 
167

168

169

170

171

172

173

174

175

176

177

178

179

180

181

182

183

184

185

186

187

188

189

gumbo-limbo (Bursera simaruba), oaks and mahogany (Quercus sp. and Swietenia sp.), the guao

(Comocladia dodonea), chichicate (Urtica doica), Thrinax radiata and Coccothrinax crinita

palms and Fabaceae in the upper levels. The royal palm (Roystonea regia) and other agricultural

plants spread through. Coffee (Coffea arabica) grows in the upper escarpment of the hill, and

their plant remains have been observed in Artibeus jamaicensis roosts therein. During the

colonial period, the region around the hill featured agricultural use, sugar cane, and coffee fields.

\section{Site-deposit description \& history of research}

The caves of Palenque were discovered during the late 1960s, but not fully explored or excavated until 1983-1985 by the Norbert Carteret group of the Cuban Speleological Society (Vento, 1985 in Nuñez, 1990, vol. 1: 299-304). The deposit we studied and interpret here is located inside the main gallery at Cueva de los Nesofontes, a large phreatic-vadose cave near the uppermost escarpment of Palenque (Figure1-2). The deposit is a large deposition cone situated 9 meters above the main gallery level (datum $\sim 240 \mathrm{~m}$ ), dipping at an angle of 22-28 degrees, under a $\sim 15$ meter-wide dissolution sinkhole. This sinkhole or main doline opens to other larger sinkholes with openings to the side of the hill (Figure 2). These upper caves and sinkholes are the source of the primary deposits and modern raptor roosts in which faunal remains occur or derive (Figure 2.1 and 2.3).

The deposit contains over 400 cubic meters of exceedingly rich fossiliferous sediment, which has been transported through the main sinkhole onto the cave's deposition cone (Figure 2). The sediment is rill-eroded, composed of red-ferralitic soil with redoximorphic features. It is generally colored in dusky red hues and is exceptionally rich in terrestrial mollusks and Nesophontes remains. This abundance suggested the name of the cave as the Cave of the Island 
Shrew or Cueva de los Nesofontes. This cave is alternatively known as Cueva de la Caja or the Cave of the Box (e.g., Viera, 2004; Orihuela, 2019).

The main room, where the main doline and deposit are located, is littered with roof-fall boulders, smaller rocks, fallen tree branches, and leaves. The lowest level is also covered with red-colored ferralitic soil, but much less rich in biological remains. A $1.50 \mathrm{~m}$ test pit excavated by the Norbert Casteret group in 1985 suggests that the deposit is deeper, but not nearly as rich in fauna (Figure 3.2. and both profiles denoted A).

Although conclusive archaeological evidence has not been found in this gallery or its deposits, a ceramic fragment of unknown provenance has been recovered from the cave (Hernández de Lara et al., 2013), and a cave pictograph was recently discovered in Cueva del Campamento, situated nearly a hundred meters in the escarpment above the main sinkhole of Cueva de los Nesofontes (Orihuela and Pérez Orozco, 2015). This may relate to aboriginal or maroon occupation, as the name of the hill and the region suggests, for a Palenque is an aboriginal or maroon hideout.

\section{Excavation methods}

Four test pits were excavated between 1985 and 2003. All excavations were done with a trowel and small metal shovel. The first and deepest test pit was excavated in 1985 (Figure 2.2 and 3) and measured $1 \mathrm{~m}$ length by $1 \mathrm{~m}$ width and reached over $1 \mathrm{~m}$ in depth. The second had a similar measurement, but only $50 \mathrm{~cm}$ in depth. The last two test pits (C and D on Figure 2.1) measured $50 \mathrm{~cm}$ x $50 \mathrm{~cm}$ x $50 \mathrm{~cm}$. These test pits followed $10 \mathrm{~cm}$ intervals with attention to the natural stratigraphy. The natural stratigraphy was identified from changes in soil coloration and faunal composition. Unconformities and erosional surfaces were detected from excavation 
213 profiles. All analyzed material was extracted in situ from the lateral profile into a glass vial. The

214 data presented here originate only from test pit D.

The excavated material was dry sieved with a fine screen mesh $(0.3 \mathrm{~cm})$. From each

216 sieved sample, a subsample collection was randomly placed in plastic bottles $\left(\sim 462 \mathrm{~cm}^{3}\right)$. This

217 was later softly dry brushed in the lab to remove adhered matrix and soil and material separated

218 following Silva (1974), but including juveniles and other parts of the appendicular skeleton in

219 the tallies following the method described in Orihuela (2010). This constituted the sample

220 collection from which species diversity was calculated.

221

222 Stratigraphy and Sedimentology

Stratigraphic units were defined by dry color changes and changes in clast or debris size.

224 Colors were defined using a Geologic Society of America (GSA) Geological Color Chart (2009)

225 with a Munsell color system. The grain size was determined in the lab using USA Standard

226 Sieves (no. 7, $2.80 \mathrm{~mm}$; no. 45, $0.355 \mathrm{~mm}$; no. 230, $0.0025 \mathrm{~mm}-63 \mu$ ) placed in sequence to

227 extract clasts from silt-clay size up to fine gravel. Percentages were calculated from bulk fraction

228 by weight. Interval I weighed 225.7 grams; II: 30.0 g; III: 225 g; and IV: 29.8 grams. The

229 weights were measured with an Accuris Analytical balance.

Nine levels of natural deposition (beds) were generally identified at all test pits (denoted

231 A through I, from top to bottom). Because of the dip angle of the deposit, 2 to 3 of these beds

232 were usually present within each of the $10 \mathrm{~cm}$ excavation intervals. These intervals are indicated

233 as levels I through IV, from top to bottom. Several beds pinched out or appeared laterally as

234 facies or lenses and are indicated with lower case letters (Figure 3). 
The distinctive layers had sharp contacts with changes in coloration, which graded from

236

237

238

239

240

241

242

243

244

245

246

247

248

249

250

251

252

253

254

255

256

the dark dusky yellow green-moderate reds of bed A and B (10 YR 4/2, 10 R 6/2 - 10 R 6/4) to

the reddish oranges and moderate dusky reds (5 Y 8/4 - $10 \mathrm{R} 6 / 6-5 \mathrm{R} 3 / 4)$ of beds $\mathrm{D}$ to E. Beds were generally rill eroded, poorly sorted, with poorly rounded or subangular clasts, medium-fine sand, granules, and coarse pebbles (Table 1). Bed thickness ranged between thin and thick (5 mm to $15 \mathrm{~cm}$ layers). Beds A, B, G through I were near planar, wavy non-parallel, well and grade bedded, with dip angles between 22 and 28 degrees in the main slope, but less than 3 degrees at the lowest floor level of the gallery (Figure 3).

The beds were separated by sharp contacts or boundaries (i.e., disconformity/erosional surfaces), especially between beds C, D, E, and F. Layers A, B, and G-I were generally conformant or paracomformant (i.e., of undiscernible unconformities). Bed C constituted a large first-order ash bed with fragments of charcoal, wood detritus, coarse clasts, abundant fossils and gastropod shells (ash made up > $30 \%$ composition). This layer contained exotic species such as murids and the domestic European sparrow (Passer domesticus). The beds $\mathrm{H}-\mathrm{I}$ formed the largest paracomformity with unidentifiable layers below the $\sim 50 \mathrm{~cm}$ depth (Level IV) (Figure 34).

Most beds were correlated between test pits (Figure 3). Others, such as bed E, F, and G included small lenses (e1, e2, f1, f2, and g1), that graded laterally or pinched out up-slope. Bed C also pinched out towards the higher parts of the deposition zone, where $\mathrm{H}$ also seemed to disappear, at least laterally (Figure 3.1, 3.2).

\section{Multifaceted Analytical approaches}


For elemental analysis, high-resolution imaging, and characterization of cave soils and

258

259

260

261

262

263

264

265

266

267

268

269

270

271

272

273

274

275

276

277

278

279

loams we used a JEOL JSM 5900LV scanning electron microscope (SEM) with energy dispersive spectroscopy EDS-UTW with detectors of $3.0 \mathrm{~nm}$ resolution at the Florida Center for Analytical Electron Microscopy (FCAEM) facility at Florida International University (Miami, FL). Soil or fossil fragments selected for analysis were placed in separate stages, and each sample analyzed three times. The averages are reported in weight percentage (wt \%) of those measurements. These analyses allowed for the identification of clay particles, other clasts content, and the overall elemental composition of the red clay soils. These analyses were conducted without coating, directly on dry samples kept in sterile glass vials collected in situ. For microscope and thin-section analysis, a Leica DM EP petrographic microscope was used. The samples were prepared at Florida International University. Radiocarbon dating ${ }^{14} \mathrm{C}$ AMS (accelerator mass spectrometry) and several of the isotope analyses (for nitrogen and carbon) were conducted by Beta Analytic Inc. (Miami, FL), and International Chemical Analysis Inc. (ICA, Ft. Lauderdale, FL), following each lab's standard procedure and who reported no complications (D. Wood, R. Hatfield, and B. Díaz, pers. Comm. 2014-2018). The dates and most isotope values were determined from bone collagen. These are reported using the standard notation of radiocarbon years before the present (rcyrs BP). Carbon younger in age than the modern reference standards is reported as "Percent Modern Carbon" (pMC), which indicate a date after thermonuclear testing, and date after the 1950s (Hua and Barbettii, 2004).

The conventional ${ }^{14} \mathrm{C}$ AMS dates were calibrated to calendar age-intercept solar years (Cal. yrs.) to one and two sigma ranges $( \pm 1 \sigma-2 \sigma)$ using Oxcal v4.3, on IntCal13 carbon curve for the Northern Hemisphere (Reimer et al., 2013). See also Ramsey (2017) at 

extend up to \pm 200 years due to multiple intercepts and conversion curve topography on dates during the last 2000 years (Geyh and Schleicher, 1990 in MacPhee et al., 1999). Late Quaternary epochs and time intervals discussed follow Morgan and Woods (1986), Soto-Centeno et al. (2015) and limits established by the IUGS (International Union of Geological Sciences). apatite and collagen and their rations reported in delta $(\delta)$ standard notation: ${ }^{13} \mathrm{C} /{ }^{12} \mathrm{C}=\delta^{13} \mathrm{C} \_$apt. for carbon acquired from apatite and $\delta^{13} \mathrm{C} \_$col. when acquired from bone collagen. The same

294 applies to nitrogen: ${ }^{14} \mathrm{~N} /{ }^{15} \mathrm{~N}=\delta^{15} \mathrm{~N}$ _apt. (apatite) and $\delta^{15} \mathrm{~N} \_$col. (bone collagen). The carbon 295 from apatite is reported in parts per mil (\%o) compared to the Vienna Pee Dee Belemnite (VPDB) 296 and nitrogen from atmospheric nitrogen (AIR) (Ambrose and Norr, 1993; Bocherens et al., 297 1996). Oxygen values, ${ }^{18} \mathrm{O} /{ }^{17} \mathrm{O}=\delta{ }^{18} \mathrm{O}$, were acquired from tooth apatite of Artibeus jamaicensis 298 remains, and are reported also as a ratio of VDPB parts per mil (\%o). These values likely 299 originate from available drinking water or water in the fruits consumed by the Artibeus bats, and 300 thus provides a regional paleoclimatic proxy (Bocherens et al., 1996; Ben-David and Flaherty, 301 2012). The $\mathrm{C}: \mathrm{N}$ ratio used to indicate diagenesis or alteration in the collagen sample was always 
302 below 3.4, suggesting insignificant or no diagenesis on the analyzed remains (DeNiro, 1985;

303 Bocherens et al., 1996; Ben-David and Flaherty, 2012).

304

305

306

307

308

309

310

311

312

313

314

315

316

317

318

319

320

321

322

323

324

\section{Taphonomic and fauna methodologies}

The weathering levels, based on a numerical value representative of bone erosion, flaking or fracturing due to atmospheric exposure follow Behrensmeyer (1978), Shipman (1981) and Andrews (1990). Criteria for bioturbation index follows Tylor and Goldring (1993). Estimation of taxonomic abundance, diversity and their indices follow Lyman (2008).

Anatomical terminology for birds follows Howard (1929), Olsen (1979) and for mammals Silva et al (2007). Systematic taxonomy of Cuban rodents follows Silva et al (2007). For Nesophontes we follow Rzebik-Kowalska and Woloszyn (2012) and our work in preparation in considering three valid species in Cuba. The validity of Nesophontes micrus and N. major are furthermore supported by proteomics, despite the inherent limitations of this analysis (Buckley et al. submitted). For extant Cuban birds, we followed Garrido and Kirkconnell (2000), González (2012), and for extinct birds, Orihuela (2019) and others cited in the text.

Fauna and faunal variations discussed here only pertain to test pit D. We infer that Pit D does not differ from the others, which were slightly less diverse, but similarly rich in Nesophontes spp (Author's unp. Data). Tables 3 and 4 provide a synthesis of the fauna present in the Pit D assemblage. Moreover, Table 4 provides a stratigraphic distribution of taxa within each of the levels and beds of Pit D. The fauna we will discuss ahead pertain to only species which are noteworthy or represent extralimital records.

Specimens were compared and identified with neontological and fossil collections at the American Museum of Natural History (AMNH), in New York City (USA), the Museum of Natural History 
of the University of Florida (UF-FLMNH) in Gainesville, Florida (USA), the Institute of Ecology and Systematics (IES), La Habana (Cuba), and zoological collection of Gabinete de Arqueológia, Office of the Conservator of the city of La Habana, Cuba. All the remains analyzed were extracted with permission of the Central Registry of National Cultural Goods (certification nos. 20141965; LHA-23, fol. 0162773). All the remains from these and other excavations are deposited in the collection of the Museo Nacional de Historia Natural (MNHNCu), in La Habana, Cuba. Part of the collection has been cataloged (Donation 13.18: $\mathrm{MNHNCu}-72-05.01$ and 76-156-215), but the rest remains uncatalogued (E. Aranda, persn. Comm. 2016, 2018).

Measurements were taken with a digital caliper and are reported in millimeters (mm). All statistical analyses were conducted with the software PAST v3 and STATISTICA software (1995, v5). Two-way ANOVAs and Tukey's Test for unequal sample sizes were used to compare linear measurements between species. Principal component analysis (PCA) was performed to further explore differences between Nesophontes taxa, and the first two extracted principal components were used to generate a plot. Probabilities were compared to a significance level of alpha $<0.05$, and of $<0.01$ for the PCA. These data were plotted using STATISTICA (1995).

\section{RESULTS}

\section{Radiocarbon Chronology and sedimentation rates}

Four radiocarbon dates $\left({ }^{14} \mathrm{C}\right.$ AMS $)$ were acquired from the four stratigraphic intervals of test pit D (Table 1; Figure 4). For the upper level (I), a fresh Artibeus jamaicensis adult humerus was selected from bed A. For Level II, a skull of the extinct bat Phyllops vetus from bed E. From lowermost (near interface) level III, a dentary of the extinct bat Artibeus anthonyi from bed H, 
and for level IV, a dentary of the extinct shrew Nesophontes major from bed I. These last three radiocarbon dates represent the first direct LADs reported for these Cuban species.

The uppermost bed (A) yielded a modern carbon age between 1955 and 1993 AD, and thus a very modern age for this level. The date for bed E, between BC (BCE) 40 and 90 AD (CE) revealed an inversion event in the stratigraphy or reworking of older remains since the lower levels yielded younger dates between AD 605-655 and AD 660-770 (Figure 3; Table 1).

An additional date was acquired for a domestic dog (Canis lupus familiaris) skeleton found mineralized in the floor of a small room at the entrance of the doline gallery (Figure 2.1, collection site G; Table 1). Originally, this specimen was considered Amerindian in age and was thus selected for testing. However, the age it yielded indicated its deposition within the modern period AD 1957-1993 and is likely contemporaneous with bed A of the cone deposit above. A similar surface radiocarbon date from this cave, albeit a different deposit, is provided in Orihuela (2010). All these superficial tests help support that the uppermost levels of the cave's deposit are generally modern (i.e., post-Columbian). But the presence of extinct taxa such as Nesophontes there too, suggests likely partial reworking.

All dates suggest ample hiatuses of several hundred years between beds/intervals (Figure 4). These had slow sedimentation rates that varied between $1.15 \mathrm{~mm} / \mathrm{yr}$ at the upper level (beds A-C), and slightly faster rates $>1.30 \mathrm{~mm} / \mathrm{yr}$ for the middle levels (bed C-E), and $1.28 \mathrm{~mm} / \mathrm{yr}$ for the lower III-IV, beds $\mathrm{H}$ and I.

\section{Stable isotopes}

Stable isotopes of carbon $\left(\delta^{13} \mathrm{C}\right)$ and oxygen were measured from apatite $\left(\delta^{13} \mathrm{C} \_\right.$apt. $)$and bone collagen ( $\left.\delta^{13} \mathrm{C} \_c o l.\right)$ of four adult specimens of the fruit bat $A$. jamaicensis, plus one adult 
371 specimen of the extinct bat $A$. anthonyi and a newborn Canis lupus familiaris (the same which

372 were ${ }^{14} \mathrm{C}$ dated; Table 1). Moreover, oxygen and carbon isotopic values were acquired from four

373 A. jamaicensis dental apatite samples from each interval (Table 2).

374 An additional analysis of nitrogen $\left(\delta^{15} \mathrm{~N} \_\right.$col. $)$and carbon $\left(\delta^{13} \mathrm{C} \_\right.$col. $)$isotopes were obtained

375 from the bone collagen of the ${ }^{14} \mathrm{C}$ dated $N$. major (Table 2). This specimen yielded a value of -

$37620.7 \% \delta^{13} C_{-}$col. and of $7.9 \% \delta^{15} \mathrm{~N}_{-}$col. These data help approximate the diet of these

377 vertebrates and provide insight into the paleoenvironments and taphonomy, as are interpreted in

378 the Discussion section.

379

\section{Taxon identification and fauna sample}

A total of 3932 specimens were collected from the assemblage (test Pit D), of which 2326 total, including invertebrates, represented 83 taxa (NTAXA).

390 pigeons (at least 3) and passerines (7 or 21\%), were the most abundant. 
394 These include the bats Desmodus rotundus, Chilonatalus macer and Lasiurus insularis

395 (Orihuela, 2010).

The gastropod fauna was diverse with at least 9 species preliminarily recorded. Further

397 identification of their remains will likely result in an increase in overall NTAXA count. The

398 gastropods, amphibians, and reptiles will not be discussed in detail here. These groups of

399 organisms have been poorly studied in Cuban Quaternary deposits, and thus our knowledge of

400 them in the recent past is very limited. In the case of the amphibians and reptiles, this has been

401 largely dictated by a lack of modern comparative osteological material in the Cuban zoological

402 collections (Aranda, 2019). However, those that we could identify (Table 3) will be briefly

403 commented on in the Discussion, and altogether add to the knowledge of the island's past

404 herpetofauna.

405

406 Species Accounts: noteworthy or extralimital record fauna

407

408 Aves

409 Accipitriformes

410 Cathartidae Lafresnaye, 1839

$411 \quad$ Cathartes aura (Linnaeus, 1758)

412 Material: one left femur (MNHNCu uncataloged, field no. 582a) and a complete skull

413 (MNHNCu uncataloged, field no. 582b) without mandible from bed A (level I), and one

414 incomplete premaxilla (MNHNCu uncataloged, field no. 193) from bed G (level III) (Figure

415 5.1). A complete skeleton with evidence of anthropogenic combustion was found at the lower

416 part of the main doline gallery, but not collected. 
417 Description: with the fossil fragment provided in parenthesis, the specimens measured as

418 follows: maximum skull length $91.9 \mathrm{~mm}$, maximum upper maxilla length $51.2 \mathrm{~mm}(45.2 \mathrm{~mm})$,

419 maximum nasal opening width $18.1 \mathrm{~mm}(17.1 \mathrm{~mm})$, and maximum maxillary width $14.3 \mathrm{~mm}$

420 (14.5 mm). The femur measured in maximum length (GTL) $69.4 \mathrm{~mm}$, proximal maximum width

421 (GPW) $18.9 \mathrm{~mm}$, distal maximum width (GDW) $17.6 \mathrm{~mm}$, and a maximum width of the

422 diaphysis (shaft-GSW) $18.1 \mathrm{~mm}$. The fossil premaxilla is not mineralized but showed slight

423 evidence of corrosion and weathering.

424 Taxonomic remarks: Suárez (2001) mentioned the existence of two undescribed extinct

425 vultures from Cuba. One of them is apparently referable to Cathartes but is not C. aura

426 (Orihuela, 2019). However, the specimen reported here seems indistinguishable quantitatively or

427 qualitatively from C. aura (Figure 5.1). Our specimen from layer G lacks a direct date, but it was

428 found between the dated contexts ranged between $1690 \pm 30$ and $1290 \pm 30 \mathrm{rcyr}$ BP and is thus

429 preliminarily considered late Holocene/pre-Columbian in age. This, therefore, constitutes the

430 first pre-Columbian record of the species in Cuba.

431

432 Piciformes

433 Picidae Leach, 1820

434 Colaptes sp. cf. fernandinae (Vigors, 1827) or auratus (Linnaeus, 1758).

435 Material: a single, distal tibiotarsus fragment from layer G (level III) (MNHNCu uncatalogued;

436 field number 1693) (Figure 5.2).

437 Description: This is a weathered specimen with evidence of digestion. It measures in greatest

438 distal width (GDW) $5.01 \mathrm{~mm}$ and in greatest shaft width (GSW) $2.2 \mathrm{~mm}$. 
Taxonomic remarks: This specimen is slightly larger than Melanerpes superciliaris

440 (uncatalogued from this deposit), M. radiolatus (UF 27075), GDW 4.90-4.91 mm and GSW

444 Cuba, the only two woodpeckers that fall within this size category are the endemic Fernandina's

445 flicker Colaptes fernandinae $(\sim 34 \mathrm{~cm})$ and the flicker C. auratus $(\sim 33 \mathrm{~cm})$ (Garrido and

446 Kirkconnell, 2000). Our tibiotarsus specimen (no. 1693) resembles Colaptes more than

447 Melanerpes in having marked and narrower intermuscular line and low (unflattering) fibular crest. The outer cnemial crest is more arched or circular in our specimen, as in Colaptes and not more open as in Melanerpes. However, we did not compare it directly to C. fernandinae, and

451 I (level IV) is similarly attributed to this taxon (O. Jiménez pers. Comm. 2015, 2018).

Psittaciformes

$454 \quad$ Psittacidae Rafinesque, 1815

$455 \quad$ Psittacara eups (Wagler, 1832) sensu Remsen et al. (2013).

456 Material: A complete right humerus (field number 1339) from layer G (level III) (Figure 5.3).

457 Description: Well preserved specimen, measuring in total length (TL) $28.2 \mathrm{~mm}$, GDW $5.8 \mathrm{~mm}$, 458 greatest proximal width (GPW) $9.26 \mathrm{~mm}$ and GSW $2.69 \mathrm{~mm}$.

459 Taxonomic remarks: This specimen compares in size with Psittacara parakeets such as 460 Psittacara nana from Jamaica (UF 25929): TL $29.8 \mathrm{~mm}$, GDW $6.01 \mathrm{~mm}$, DPW $10.1 \mathrm{~mm}$ and 461 GSW $2.55 \mathrm{~mm}$. Morphologically is most similar to this genus in having a shallow bicipital 
462 furrow, scarcely grooved bicipital furrow and deltoid crest, round head, poorly developed

463 external tuberosity proximally. Distally, shallow brachial depression and etepicondylar

464 prominence. It was qualitatively comparable to the endemic Cuban parakeet $P$. eups (Garrido

465 and Kirkconnell, 2000). This specimen was associated with the species aforementioned, and are

466 likely of the same age. This constitutes the first pre-Columbian record for the species.

467

468 Passeriformes

469 Hirundinidae Rafinesque, 1815

$470 \quad$ Progne sp. cf. cryptoleuca (Gmelin, 1789) or subis (Linnaeus, 1758)

471 Material: Incomplete, distal left coracoid, stained brown red (field number 1624), from layer $\mathrm{H}$

472 (level III).

473 Description: This specimen may represent a juvenile because of its porosity and rounded sternal

474 facet (Figure 5.4). Measurements: GDW $4.39 \mathrm{~mm}$ and GSW $1.75 \mathrm{~mm}$.

475 Taxonomic remarks: This coracoid represent a swallow larger than any other of the species

476 present in Cuba. In morphology, it is similar to $P$. subis but slightly smaller. The purple martin

477 (P. subis) and the Cuban martin (P. cryptoleuca) are common in Cuba. The first is a common

478 transient between August and March, whereas the second is a common resident nearly year-

479 round (Garrido and Kirkconnell, 2000, p. 168). Neither species has been previously reported 480 from the paleontological or Amerindian record of Cuba.

483 Hirundinidae Rafinesque, 1815 
485 Material: A complete left humerus (MNHNCu, uncatalogued) from layer G (level III).

486 Description: The specimen is slightly mineralized, small and delicate. It measures in GTL 15.3

487 mm, GDW $5.5 \mathrm{~mm}$, GSW $1.6 \mathrm{~mm}$, and GPW $6.6 \mathrm{~mm}$. (Figure 5.6).

488 Taxonomic remarks: This specimen is remarkably similar to the tree swallow T. bicolor, a

489 common transient in Cuba (Garrido and Kirkconnell, 2000, p. 169). Our specimen agrees well in

490 size and morphology to a male from Indian River, Florida, USA (UF 17685/30932): GTL 15.3-

$491 \quad 15.4 \mathrm{~mm}$, GDW 4.91-5.22 mm, GSW 1.62-1.64 mm, and GPW $6.44 \mathrm{~mm}$ (Figure 5.5). The

492 ectepicondylar prominence is prominent and grooved at the tip, with a slight lateral extension

493 (rome, shorter and attached in Hirundo rustica and hook-like in Progne subis). The internal

494 condyle entepicondyle is less pronounced than the external condyle, but more than the

495 intercondylar furrow, which is slightly flattened (not in $H$. rustica or very pronounced in $P$.

496 subis). The bicipital furrow and deltoid crest are poorly developed off the main shaft. The capital

497 groove is deeply excavated, unlike Hirundo, which has a double furrow (deep single furrow in

498 Progne). Thus, we refer it tentatively here to T. bicolor. A direct comparison to the Bahamian

499 tree swallow T. cyaneoviridis was not conducted. However, this taxon is a slightly larger rare

500 winter transient in Cuba (op. cit.). This represents the first paleontological and prehistoric record

501 for Cuba.

502

503 Mammalia

504 Rodentia

505 Capromyidae Smith, 1842

506 Mesocapromys Varona, 1970 
507 Material: This genus is represented by over 50 specimens, most of which are long bones,

508 representing at least 2 species and 20 individuals. The two species are represented by

509 Mesocapromys nanus and Mesocapromys kraglievichi. This genus was present at all levels and

510 in most beds, but more profusely in level III and IV (Table 4).

511 Description: Most remains showed taphonomic evidence of predation and digestion. Others

512 were mineralized or adhered to a carbonate matrix. Most were juveniles with open or incomplete 513 epiphysis and alveoli.

514 Taxonomic remarks: Although Silva et al. (2007) and M. Condis (unp. Data) provided size

515 groups for elements of the appendicular skeleton, attributing any of these long bones to a specific

516 species is problematic due to lack of complete skeletons as comparative material. Often,

517 identification and assignment are satisfactory when complete adult hemimandibles are present in

518 the assemblage, for which there are diagnostic M. nanus and M. kraglievichi. At present, the only

519 diagnostic trait distinguishing them is the lateral extension of the condyle's ascending ramus

520 process beyond the plane orientation of the angular process in M. nanus when the dentary is in

521 occlusal view (i.e., viewed from above; Silva et al., 2007 p. 176). In M. kraglievichi, the

522 ascending ramus follows the same plane as the angular process below. Most of the undetermined

523 material assigned to Mesocapromys spp. indet. Table 3 represents juveniles, just as those of the

524 extinct Geocapromys columbianus and the extant Capromys pilorides, which were well-

525 represented in the assemblage (Table 3-4).

526

527 Lipotyphla

528 Solenodontidae Gill, 1872

529 Solenodon cubanus Peters, 1861 
530 Material: A left proximal ulna fragment from layer E (level II). A complete edentulous right

531 mandible (uncatalogued) and complete left scapula (MNHNCu, field no. 2029) from a surface

532 collection near the deposition cone and under the main sinkhole. This last specimen yielded a

533 direct ${ }^{14} \mathrm{C}$ age of $650 \pm 15$ BP (UCIAMS 218808; Orihuela et al., forthcoming).

534 Description: The surface specimens likely belong to the same individual, and appeared fresh

535 (weathering level 0), with slight discoloration. The ulna was slightly mineralized and showed 536 evidence of cracking (weathering level 1) and represents another individual from the sinkhole

537 deposit above.

538 Taxonomic remarks: These specimens are indistinguishable from Solenodon cubanus. The

539 radius was associated with the bat Phyllops vetus that yielded an age of 1960 rcyr BP, thus

540 indicating a pre-Columbian, late Holocene age for that specimen, whereas those from the surface

541 may be several hundred years old, as is supported by the ${ }^{14} \mathrm{C}$ age estimate of the left scapula (no.

542 2029).

545 Nesophontidae Anthony, 1916

$546 \quad$ Nesophontes sp. cf. longirostris (sensu Anthony, 1919)

547 Material: Three specimens may represent this taxon: a near-complete skull, lacking the occipital 548 and petrosals (MNHNCu field no. 132), and two possible hemimandibles (MNHNCu, field no.

549121 and 1428). The first skull and mandible are from layer E (level II), and the last (no. 1428)

550 was from layer H (lower level III).

551 Description: Large species of Nesophontes, like N. major (Figure 6.4-6.6), but with a tubular

552 and more elongated rostrum, wider diastemata between upper and lower canine and first two 
premolars. Skull 132 and dentary 121 were slightly mineralized, and dentary 1428 partially mineralized. Measurements provided in Table 5 and plot graphs in Figure 7.

The skull of $N$. longirostris is most like that of Nesophontes major (Figure 6) but differs in being slightly larger, with a slenderer and more elongated rostrum, more parallel postorbital, with a wide diastema between the upper canine and the first two maxillary premolars (Pm1Pm3). The is also a wider separation between the last incisor and the canine. In N. major, the rostrum is broader, more U-shaped, and wider at the level of the canines. The angle of inclination of the nasal is more pronounced in $N$. longirostris than $N$. major.

$N$. longirostris shows an incipient tapering at the level of the first and second maxillary premolars not present in $N$. major (including juvenile individuals). The orientation and size of the premolars in N. micrus are nearly parallel to the axis of the toothrow and of nearly equal size. In N. major, the premolars are always crowded, oriented obliquely from the toothrow, and the first premolar is always larger than the second. In $N$. longirostris, the orientation of the premolars is slightly oblique, despite their wide separation. In $N$. longirostris the Paracone is reduced in the third upper molar (M3) but is smaller and slimmer than M1 and M2. M1 is slightly smaller than M2 and very subtriangular in shape. In N. major the M3 is more robust and wider (more quadrate), with a slightly higher Paracone, and the M1 is stubbier than the M2, with a less pronounced Metastyle (Figure 6).

In this sense, $N$. longirostris seems more akin to $N$. major than to $N$. micrus.

Quantitatively, the two species are also most similar in most cranial linear measurements. $N$. longirostris is slightly larger in skull, palatal and dental length, likely as a function of the wider spacing between the premolars. In maximum length taken from the posterior canine to the anterior premolar defined by Anthony (1919), they are significantly larger $(\mathrm{p}=0.000736)$ than 
N. major and N. micrus (Figure 7). In this measurement, they are even larger than the holotype of

577

578

579

580 discussed elsewhere.

N. edithae.

The dentary of Nesophontes major (both supposed males and females) are significantly (p $<0.050)$ larger than micrus in several linear dimensions: total length of the dentary 20.8 (18.09-

22.6), N. micrus 18.0 (16.0-19.3); maximum height of coronoid process 10.0 (8.64-11.33), $N$. micrus 7.71 (6.6-8.46); and maximum height of the mandibular ramus under m1-m2 3.09 (2.363.74), N. micrus 2.27 (6.6-8.46). In general, the dentary and lower dentition of $N$. major is more robust and marked than $N$. micrus. The dentary of $N$. major has a thicker ramus, with a more pronounced curve at the masseteric/digastric region (thinner, and much less curved in N. micrus; the muscle scar is less pronounced). The shape of the coronoid process is wider, broader, with more pronounced masseteric fossa on the lateral face, and deeper temporalis/pterygoid fossae on the medial face (subtriangular, thinner, less marked or shallow, and more restricted in N. micrus). The canine of $N$. major is an ungrooved premolaliform, with a small cingulum and more triangular cusp and smaller base (wider base and wider triangular-wider shear surface outline in $N$. micrus). In the molars, the angle between the paraconid and metaconid, as seen on lateral aspect, is more closed, with a wider commissure (more open and lower in N. micrus, with a reduction in cingulum development). The scar of the mandibular symphysis in N. major is more pronounced and longer than in $N$. micrus. In this sense, the supposed mandible of $N$. longirostris is nearly identical to $N$. major, but with the diastemata present between pm1 and pm2. Based on this qualitative and quantitative, $N$. longirostris is tentatively revalidated here but will be further 
Taxonomic remarks: H. E. Anthony described this species based on an incomplete skull

599

600

601

602

603

604

605

606

607

608

609

610

611

612

613

614

615

616

617

618

619

620

(AMNH 17626; Figure 7.3) from a cave deposit in Daiquirí, southeastern Cuba. He distinguished it from N. micrus by its longer and more slender rostrum, plus a "distinct diastemata between the canine and the first premolars" (Anthony, 1919, p. 634). Anthony also predicted that such diastema would be found in the dentary. This diastema resulted in a larger measurement of 3.2 mm taken between the posterior border of the maxillary canine and the anterior border of the premolar, in comparison to other specimens he studied (op. cit.). Since Morgan (1977) and subsequent revisors considered $N$. longirostris invalid and a synonym of $N$. micrus (Condis et al., 2005; Silva et al., 2007; Rzebik-Kowalska and Woloszyn, 2012). Despite these evaluations and considering the intra and interspecific variation of the genus (JO pers. Obs.; Buckley et al., in pub.), the characters displayed by these specimens seem to suggest otherwise.

Our specimens, both skulls, and dentaries, have the supposed diagnostic diastemata, elongated rostrum and measurements that exceed the observed variation in both $N$. micrus and $N$. major studied from multiple locations in Cuba $(n>720$ hemimandibles and $n>150$ skulls; plus over 1030 specimens from this assemblage alone) and Anthony's Daiquirí series at the AMNH. Moreover, adding the discovery of another complete skull specimen (MNHNCu, field no. 324; Figure 6.2) with similar morphology and measurements from Cueva del Gato Jíbaro, 18 km east from the assemblage described here. This last specimen is associated with the archaeological kitchen midden dated to $860 \pm 30 \mathrm{BP}$ (Orihuela et al., forthcoming).

\section{Chiroptera}

Phyllostomidae Gray, 1825

Artibeus anthonyi Woloszyn and Silva, 1977 
621 Material: eight specimens ( $\mathrm{MNHNCu}$, uncataloged), representing at least three individuals in

622 the assemblage belong to this species. These were a rostrum, three hemimandibles (no. 11, 12,

623 and 1663), and four humeri encountered within layer H (lower level III) and layer I (level IV)

624 (Figure 8.1).

625 Description: These specimens were mineralized, with a few including calcareous encrustations.

626 One of them, a slightly mineralized and robust right hemimandible (no. 1663) found at the

627 bottom of layer H (lowermost level III) yielded a direct radiocarbon date of $1290 \pm 30$ rcyrs BP

628 (Figure 8.1), providing the first direct LAD for this taxon in Cuba.

629 Taxonomic remarks: The humeri measured between 36.0 and $37.7 \mathrm{~mm}$, and the mandibles had

630 a total length greater than $18.4 \mathrm{~mm}$ and less than $22.0 \mathrm{~mm}$. These specimens were identified

631 from Artibeus jamaicensis, and the Cuban subspecies parvipes, based on size and criteria

632 published by Anthony (1919), Woloszyn and Silva (1977), Silva (1979), Balseiro et al. (2009)

633 and Orihuela (2010). Artibeus anthonyi has been reported from another deposit in Cueva de los

634 Nesofontes (Orihuela, 2010). The species seems to have been widespread in the archipelago. So

635 far, A. anthonyi has been documented from 11 localities (Borroto-Páez and Mancina, 2017).

636 Including this record and another from a paleontological layer at Cueva del Gato Jíbaro adds to

63713 localities. This last specimen yielded a middle Holocene ${ }^{14} \mathrm{C}$ direct date estimate (Orihuela et

638 al., forthcoming).

639

640 Artibeus jamaicensis Leach, 1821

641 Material: The Jamaican fruit bat was represented by 173 skulls, 254 mandibles, and 45 humeri.

642 Radii and other parts of the appendicular skeleton were not fully counted, but more than 22 
643 specimens, including scapulae and femora, represented this species. NISP of 495 and an MNI of

644 at least 165 individuals (Table 3).

645 Description: After Nesophontes micrus and N. major, this taxon was the third most common

646 taxon of the assemblage. Remains of this species displayed multiple taphonomic marks of

647 deposition, mineralization, decomposition, predation, and digestion (see Figure 10.6).

648 Taxonomic remarks: The majority of these specimens are indistinguishable morphologically

649 and metrically from the Cuban endemic subspecies A. jamaicensis parvipes. However, eight

650 crania, eight hemimandibles and four humeri (NISP of 21), indicated in Table 3 as $A$.

651 jamaicensis, were larger than the maxima of the fossil and neontological range provided by Silva

$652(1974,1979)$ and Balseiro et al (2009). These specimens slightly exceeded the upper range of $A$.

653 jamaicensis parvipes in palatal length $(>13.5 \mathrm{~mm})$, anteorbital width $(>8.5 \mathrm{~mm})$, and postorbital

654 breath (> $7.2 \mathrm{~mm}$ ) (Silva, 1979). In this last measurement, it also exceeded values reported for $A$.

655 anthonyi (> $7.4 \mathrm{~mm}$; Woloszyn and Silva, 1977; Balseiro et al., 2009) and Artibeus lituratus (>

$656 \quad 6.7 \mathrm{~mm}$ in Woloszyn and Silva, 1977). This variation may be a form of temporal or chronoclinal

657 variation but will be further explored elsewhere. Since these specimens are qualitatively

658 inseparable from A. jamaicensis, they are included within this taxon. These specimens occurred

659 exclusively in layers $\mathrm{H}$ and I (levels III and IV) where they were directly associated with $A$.

660 jamaicensis, A. anthonyi, and Phyllops vetus.

661

662 Phyllops vetus Anthony, 1917

663 Material: Taxon represented by eight fragmentary skulls, including rostra, nine dentaries, and

664 three humeri, representing at least eight individuals ( $\mathrm{MNHNCu}$, uncataloged). 
665 Description: Most remains were fragile and slightly mineralized. A skull (no. 37) found in layer

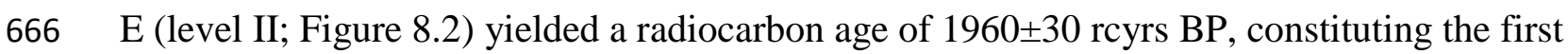

667 direct LAD for this species.

668 Remarks: This taxon appeared in association with the Cuban fig-eating bat $P$. falcatus only in 669 layer G (level III), which yielded radiocarbon ages between 1960 and 1290 rcyrs BP; Table 4.

$670 P$. vetus occurred in all levels except level I (layers A-D, in Figure 4). These age estimates are

671 further supported by radiocarbon dates now available for this level (Orihuela et al., forthcoming).

672

673 Vespertilionidae Gray, 1821

674 Antrozous koopmani Orr and Silva, 1960

675 Material: This taxon was represented by a partial skull (MNHNCu uncataloged), a fragmentary

676 braincase (MNHNCu uncataloged) and five dentaries (MNHNCu uncataloged, field no. 19, 20,

677 75, 1429, 1430), occurring in all layers between level II and IV (Figure 8.3). Three of these have

678 provided direct radiocarbon dates from beds F, G, and I, that agree with the overall Late

679 Holocene age estimates for these intervals (Orihuela et al., forthcoming).

680 Description: The specimens were well-preserved, often showing evidence of predation and

681 digestion. They did not deviate quantitatively or qualitatively from other reported specimens (Orr

682 and Silva, 1960; Silva, 1976; 1979; García and Mancina, 2011). Viera (2004) reported other

683 specimens from surface collections in the same cave.

684 Taxonomic remarks: The Cuban pallid bat is in need of a detailed revision. Although it is often

685 considered a subspecies of the continental species Antrozous pallidus from western North

686 America (Simmons, 2005), we consider that the differences in morphology and size warrant its 
1976; Silva and Vela, 2009; García and Mancina, 2011). This species was undetected in Cuba until the mid-20th century. The first, and only complete specimens preserved were two females collected by Charles T. Ramsden in 1920-21, near Bayate, Guantanamo, eastern Cuba, but misidentified as "Macrotus" (Silva, 1976). A. koopmani has been found in several "fresh" owl

692 pellets across the island, which suggest a former wide range in the island, but has not been

693 confirmed captured or observed live since 1956 (Orr and Silva, 1960; Silva, 1979; Borroto-Páez

694 and Mancina, 2017), although a questionable report exists (see comm. in Mancina, 2012).

695 Moreover, MacPhee and colleagues have shown that pellet material that is apparently "fresh" can be several hundreds of years old (1999). This species is extremely rare in collections, currently extremely endangered or already extinct.

\section{Other organisms}

Pollen, plants seeds, phytoliths, and starch grains were detected at all intervals of the deposit but remain unstudied (Figure 9).

702 Gastropods and crab remains were very common throughout the deposit. At least nine species of 703 land snails and a land crab, Gecarcinus ruricola, were present and abundant in the assemblage.

704 The land snails included the following preliminary taxa: Alcadia sp. cf. hispida, Farcimen cf.

705 procer, Chondropoma cf. vespertinum, Oleacina subulata, Opisthosiphon sp., Nescoptis sp.,

707 abundant. Unidentified plant fragments such as leaves, bark, microcharcoal, and seeds were also 708 present (Figure 9.4-9.9). 
711 when present (Figure 9). One of the pupae specimens was identified as a phorid fly pupa (Figure

712 9.3). Remains of larvae were observed directly on the bones of several specimens at the level I

713 and III.

714 Amphibians were represented by at least two genera, Eleutherodactylus, and Peltophryne

715 spp, but otherwise difficult to assign to species. The Cuban tree frog Osteopilus septentrionalis is

716 likely also present. The reptiles were identified as lizards of the Anolis group: the smaller Anolis

717 sagrei, the larger Anolis equestris, a similar large Anolis sp., and A. cf. chamaeolonides (fide

718 Nicholson et al., 2012; Rodríguez-Schettino et al., 2013), this last on Figure 9.1.

\section{Taphonomic observations}

Mineralization, coloration, and evidence of predation and digestion were the most

722 common taphonomic evidence (Figure 10). Weathering was another important factor acting on

723 the preservation of the specimens. Evidence of predation in form of scratches, claw or beak

724 marks, indentations, fractured braincases, and digestion corrosion, were much more frequent in

725 the upper levels (I and II), whereas most mineralization and maximum weathering levels (> level

726 2) were more evident in lower levels. Weathering levels or stages varied generally between 0 and

727 2, only rarely did specimens show stages higher than or equal to 3 (Figure 10.3, 10.4).

728 Scavenging evidence in the form of gnawing and tooth marks by rodents and Nesophontes

729 island-shrews (Figure 10.1, 10.2) has been documented in detail from this assemblage (Orihuela

730 et al., 2016).

732 less common (Figure 9.5), but likely related to the exposure of the pellets before and during the

733 formation of the deposit. In several cases, the soft clay of the deposit invaded the empty 
734 braincase cavities of several Nesophontes specimens, creating natural endocasts (Orihuela,

735 2014).

Skulls and mandibles were the most common of all skeletal elements, with 476 and 1359

737 specimens respectively; they contributed $14.2 \%$ and $59.1 \%$ to the osseous remains in the

738 assemblage (Pit D). Thus cranial elements, especially mandibles, dominated the assemblage at

$73979.8 \%$. Humeri (133 specimens) represented 4\%, and other elements of the appendicular

740 skeleton (398 specimens), likely constituted a total of $17.2 \%$. It is important to note, however,

741 that many radii and femora were fragmented and unidentifiable to species level, and thus, not

742 counted.

Pathologic observations

Evidence of pathologies was present in less than 1 percent of the assemblage. These were

746 evident in the bats Artibeus jamaicensis, capromyid rodents, and Nesophontes, in the form of

747 bone lesions, healed fractures, general bone deformations, and dental-alveolar lesions. Three

748 specimens of Nesophontes major were of special note: A left adult dentary showed a markedly

open premolar root with indications of an alveolar infection. Two other hemimandibles showed,

750 as supported by radiography (not illustrated here), healed fractures or deformed coronoid

751 processes. Mineralization, insect activity, and digestion often caused corrosion on the bones that

752 could be mistaken for fungal or pathologic conditions (Figure 10.5).

DISCUSSION 
The vertebrate fossils that compose this assemblage presumably mostly originated from raptor-derived primary pellet deposits located above the main sinkhole that was slowly inwashed (transported) into the cone of deposition under the sinkhole. Based on the faunal composition of the upper layer and surface samples collected around the deposit, we can infer that other organisms were included in the assemblage also from natural death, such as the

762 crustaceans, gastropods, reptiles and several birds and bats. Among the samples collected from 763 isolated non-pellet deposits included Canis, Tyto and Cathartes aforementioned, plus an 764 articulated skull and mandible of $N$. micrus found on a nearby wall. All these suggest other 765 sources for fauna in the deposit.

With the organic remains came sediments from the upper scarp levels of Palenque Hill.

767 Based on the SEM-EDS data, these soils were positively correlated $\left(R^{2}=0.8353 ; y=0.4526 x+\right.$ 1.9158) in $\mathrm{Si}, \mathrm{Fe}$ and $\mathrm{Al}$ weight percent composition with ferralitic clay soils of the Mayabeque-

769 Matanzas lowlands (Formell and Buguelskiy, 1974), and with the ferralitic-ferromagnesic red 770 soils of the upper scarp of Palenque Hill (asterisks in Figure 1). The changes in coloration are

771 redoximorphic features, indicating depletion of oxidizing/reducing Fe-Mn conditions in the 772 exposed and cave deposits. This supports the inference that both the sediments and fossils are

773 allochthonous. Thus, the red cave soils are being transported from the above scarp into the 774 cavities. Mineralization of fossils within the deposit suggest mild diagenesis through infiltrating 775 water. However, the isotope values yielded by the tested samples indicated little or no major 776 diagenesis other than slight mineralization. 
780

781

782

783

784

785

786

787

788

789

790

791

792

793

794

795

796

797

798

799

800

801

802

different erosional/depositional events and changes in sedimentation regimes (Figure 3-4). The beds were generally prograding, with the lowest layers representing lower energy (horizontal) depositions, whereas the upper-level layers were more amalgamated and inclined, suggestive of slightly higher energy flooding events resulting in more pronounced rill erosion. Several beds showed evidence of slump erosion and truncation likely caused by rill erosion (Figure 3-4). The weathering levels observed in osseous remains rarely surpassed stage 2 , which suggests that the pellets and their content were exposed for only 2 to 4 years before final deposition and diagenesis, where they decomposed exposed to the air, thus attracting insects. This is likely to have occurred in the primary pellet deposit in the upper cave levels, and much before transportation into the cone deposit below.

One of these events (layer F up to $\mathrm{C}$ ), suggested a stratigraphic inversion, mixture with a slightly faster sedimentation rate of $>1.3 \mathrm{~mm} / \mathrm{yr}^{-1}$. Together, layers $\mathrm{F}-\mathrm{C}$ may constitute a flooding event in which older fossils were transported and deposited over younger deposits, as suggested by the ${ }^{14} \mathrm{C}$ AMS date for layer F, E and D. Bioturbation also could have been a major source of reworking and stratigraphic inversion (Bosch and White, 2007; Patzkowsky and Holland, 2012). Although most exotic taxa occurred in the upper intervals, the anomalous presence of Rattus spp., Mus musculus, and Passer domesticus within the lower levels and the older ${ }^{14} \mathrm{C}$ date in level II support either mixing of diachronous fauna or a stratigraphic inversion at level II (Table 4; unp. Data from dated Antrozous and Boromys, see Orihuela et al., forthcoming). Land crabs, rodents and island-shrews are known to excavate and burrow in the sediment and for scavenging (Andrews, 1990) which can result in the mixing of diachronous remains. However, bioturbation index was low at most intervals, between 0 and 1 (i.e., $1-4 \%$ overall bioturbation), except for interval II, which had a bioturbation index of $2(>15 \%)$. 
Furthermore, the native rodent and Nesophontes tooth marks reported in the assemblage

804 (Orihuela et al. 2016), and the occurrence of a fly pupa and traces of insect activity on several of

805 the bone remains (Figure 9.3, 10.1, 10.2, and 10.5) suggest that pellets laid exposed long enough

806 to attract these scavengers before final deposition in the cone deposit. Overall, this supports the

807 mixing of fauna in the upper primary deposits, causing some of the events and specimens to

808 reach the deposition cone already mixed, or being further mixed there.

809

The large accumulation of gastropods, ash, and charcoal detritus in layer $\mathrm{C}$ suggests

810 another major deposition event. Bed C registers a probable large forest fire in the upper scarp

811 and wooded areas above the cave. In general, the material from the major events indicated by

812 beds C, E, and F, was very poorly sorted with well-preserved fossils, seeds, and plant material.

813 This suggests that these layers may represent diamicton facies of Gillieson (1986), which could

814 be interpreted as large asynchronous flooding events (McFarlane and Lundberg, 2007), although

815 in a restricted smaller scale. In turn, the slow sedimentation rates, weathering levels, and fly

816 pupae imply longer times of non-deposition, exposure, and erosion. The amalgamated mixture of

817 larger and smaller vertebrates with land gastropods suggests that deposition is largely controlled

818 by turbulent flooding events of moderate energy (Farrand, 2001; McFarlane and Lundberg,

819 2007). This is further supported by an observation. In April 2015, two of us (JO and LPO)

820 experienced a torrential rainstorm under the main doline, but it failed to bring material into the

821 deposit cone, suggesting that the transportation events must be of a more intense nature in order

822 to transport sediment and biological remains into the cave. Interestingly, some of the superficial

823 dates acquired for the upper levels ( $n=3$ : 1953-1957 AD) agree with a period of prolonged

824 rainfall and inundation in the region (Pérez et al., 2017). 


\section{Taphonomy: raptors as one of the deposit-formation processes}

827

828

829

830

831

832

833

834

835

836

837

838

839

840

841

842

843

844

845

846

847

848

Because these faunal remains are the results of raptor predation, they represent a fauna of regional or local scale, but not collected by a single raptor. Tyto furcata, the most common of Cuban nocturnal raptors today (Garrido and Kirkconnell, 2000), is a small mammal specialist with a hunting radius between 3 and $~ 16 \mathrm{~km}$ (Banks, 1965; Andrews, 1990) and is probably one of the major contributors to pellet accumulations in Cuba today (Arredondo and Chirino, 2002; Silva et al. 2007; Hernández and Mancina, 2011, López, 2012) and the major contributor to the formation of the doline deposit.

Tyto species of barn owls were formerly considered a non-preferential predator (Bunn et al. 1982). Today they are regarded as highly selective (Andrews, 1990; Kusmer, 1990;

Hernández and Mancina, 2011), with prey that range in weight between 25 and $200 \mathrm{~g}$, but of which over $95 \%$ of prey items weigh less than $100 \mathrm{~g}$ (Morris, 1979). Diet studies of T. furcata in Cuba show that bats, reptiles and birds constitute a small percentage $(<5 \%)$ in the diet, whereas rodents, especially the exotic murids, make up more than half of their diet (Silva, 1979; Suárez, 1998; Arredondo and Chirino, 2002; Hernández and Mancina, 2011; Lopez, 2012). Among the bats, those species with stationary feeding habits, such as A. jamaicensis, Brachyphylla nana, and Phyllonycteris poeyi, are the most common species present in pellets (Silva, 1979;

Hernández and Mancina, 2011; López, 2012). Other species with similar feeding such as $P$. falcatus and Erophylla sezekorni are also frequent (Silva, 1979; Arredondo and Chirino, 2002;

Hernández and Mancina, 2011).

The high preference for exotic murids (Mus sp. and Rattus spp.) is likely a post-

Columbian adaptation that replaced reliance on Nesophontes, bats, and birds in the past. Studies have shown that where rodents are not available, bats, lipotyphlans, and birds make up most of 
849

850

851

852

853

854

855

856

857

858

859

860

861

862

863

864

865

866

867

868

869

870 871 further suggested by the increased diversity and presence of predominantly larger fauna, and by

the diet (e.g. Velarde et al., 2007). This hypothesis can help explain their higher frequency in this and other Antillean deposits.

The most abundant fauna encountered in our assemblage range in body mass from $5 \mathrm{~g}$ to $\sim 1000 \mathrm{~g}(\sim 1 \mathrm{~kg})$; from the smallest bats to the small-medium sized capromyid rodents such as the Mesocapromys spp., Boromys spp., and juvenile Geocapromys columbianus (all >160g or $0.16 \mathrm{~kg}$ ), plus Capromys pilorides which is heavier (> $1 \mathrm{~kg}$ ) (supplement in Turvey and Fritz, 2011; Borroto-Páez and Mancina, 2017).

Thus, it is likely that $T$. furcata was not the sole contributor to the pellet-derived fauna reported here, for there were more strigids in Cuba's past, and at least three extinct Tyto species (Suárez and Olson, 2015; Orihuela, 2019). Indications of multiple species of raptors contributing pellets to the deposit are suggested by the taphonomic evidence. One is the dominance in the frequency of cranial elements (skulls and mandibles) over long bones and other elements of the appendicular skeleton. This ratio is common in Tyto-derived pellet deposits but also in those of strigids (Andrews, 1990; Kusmer, 1990). In this assemblage, cranial elements were represented by 476 skulls (mostly incomplete with clear evidence of predation $>45 \%$ ) and 1359 dentaries, constituting over $46 \%$ of the total (or 1835 of total 3932) and $78 \%$ of the NISP. In comparison, non-cranial elements represented $17.3 \%$ of the NISP and $10.2 \%$ of the total remains. But their lower count is likely a bias of the collection effort, as the diversity indices, discussed ahead, imply. Overall, the assemblage had well preserved post-cranial elements, but until the full study is resumed we cannot determine whether post-cranial elements were more frequent than cranial elements, which would be suggestive of other medium-sized nocturnal raptors (Andrews, 1990). Evidence that more than one raptor species was involved in the deposition of pellets is 
872 the partially mineralized large pellets found within beds $\mathrm{G}$ and $\mathrm{H}$. These two layers were

873 especially rich in juvenile capromyid rodents (> $400 \mathrm{~g})$, larger birds and bats (Table 3). These

874 raptors could include other Cuban extinct tytonids or strigids, such as larger and diverse Tyto

875 (e.g., cravesae or noeli) taxa or Pulsatrix arredondoi, based on the diversity of the faunal

876 assemblage (e.g., see Restrepo-Cardona et al., 2018). Of these, Arredondo's spectacled owl $P$.

877 arredondoi has been confirmed to have survived into the very Late Holocene (Jiménez et al., in

878 press), which can also be the case for other Cuban extinct raptors (Orihuela, 2019), and at this

879 point it cannot be excluded as contributor to the deposit formation. Pellet studies of $P$.

880

perspicillata showed a wide diversity in avian prey items, including hummingbirds and

881 migratory species (Restrepo-Cardona et al. 2018).

Extant strigids cannot also be ruled out. These may include Asio, Otus, or Margarobyas

furcata remains were also found; all either as results of raptor predation or natural death. 
natural and raptor-derived faunas widens the diversity of our record. In that sense, our subsample could be a good proxy of a past local or regional land vertebrate fauna.

\section{Fauna Diversity} evenness index varied between 1.17 and 1.21 , and 0.81 and 0.83 between interval levels, respectively. The highest being level IV $(1.21 ; 0.83)$, and the lowest level II $(1.17 ; 0.81)$ (Table Weiner index and NTAXA. These suggested, nevertheless, that the stratigraphically lower and chronologically oldest intervals II and IV were less diverse, whereas the youngest I and III were more diverse and thus less homogeneous, but better representatives of the collective fauna. The 909 Fisher á and Simpson's indices reflect the higher diversity of levels II and IV (Table 6; Figure 12). In this sense, heterogeneity could have been a result of sample recovery variation, overall

911 and between intervals, and the fauna diversity present therein. The NISP of our assemblage

912 nearly reached an NTAXA asymptote after 3000 specimens and over 70 taxa, suggesting that our

913 overall sample size approached maximum diversity in vertebrates expected for the deposit, but 914 not so each individual bed (Figure 11). 
917 de los Nesofontes and characterize the diversity of the assemblage. Even so, any comparison of

918 homogeneity, diversity and evenness indices among Cuban cave deposits is limited due to the

919 lack of comparable published assemblage details for other caves that allow for such calculations,

920 and because the deposits have a different genesis and were sampled or studied differently (e.g.,

921 concentrated on different groups of organisms, as may seem obvious). For example, the

922 assemblages reported with appropriate detail for Cueva de los Masones and Jagüey, in Sancti

923 Spíritus, represents bats (Silva, 1974), whereas other such as Cueva GEDA in Pinar del Río

924 (Mancina and García-Rivera, 2005; Condis unp. Thesis), and other cave deposits in northwestern

925 Cuba (Orihuela, 2010; Orihuela and Tejedor, 2012) included several groups of vertebrates, but

926 were less diverse in NTAXA (between 20 and 29) with smaller sample collections (between 150

927 and 430 NISP). Stratigraphic details on NTAXA and NISP variation from other faunistically-rich

928 cave deposits such as Cueva del Túnel, Cueva del Mono Fósil or Cueva de los Paredones are not

929 available.

931 deposits extend well beyond the 500 NISP but with lower NTAXA than the deposit reported

932 here. Cueva GEDAS (Condis, unp. Thesis), the kitchen midden from Cueva del Gato Jíbaro

933 (Matanzas; Orihuela and Tejedor, 2012; JO unp. data), and the other deposit reported for Cueva

934 de los Nesofontes (Orihuela, 2010) all cluster behind the 500 NISP level, and lie outside the

935 confidence intervals, which suggests under-sampling (Figure 11).

936 Our deposit was richer than that of Cuevas Blancas in NTAXA vertebrate diversity $(n=$

93783 vs. 59), even though this last had a much larger NISP sample size (i.e., 10,027 vs. 2326)

938 (Jiménez et al., 2005) (compare to B in Figure 11). Only the midden deposit from Gato Jíbaro

939 and intervals I and III of Cueva de los Nesofontes doline deposit reported here were within the 
940

941

942

943

944

945

946

947

948

949

950

951

952

953

954

955

956

\section{Chronology and fauna contemporaneity} Antillean vertebrate paleontology.

confidence interval of the curve (Figure 11). The remaining assemblages were outside and were less than the 500 NISP mark, also suggesting under-sampling.

The assemblage's diversity has been influenced by our sampling methods and differences in taphonomic aspects such as raptor preference and natural death, but also by reworking and sedimentological processes explained above. In paleontology, one can never have full access to the actual original faunal diversity. But in this sense, our calculations allowed us to quantify diversity and compare it to other important Cuban deposits to see where our assemblage fits and explore what that says about its diversity and formational history. Calculating the diversity indices for each bed and the assemblage of Pit D, has permitted us to compare the diversities of each subsample (each bed), and to infer that the high diversity observed is partially representative of the local fauna, despite limited sampling and completeness, due to the multiple origins of the biological remains. Thus, suggesting that the presence of several groups or taxa are more than taphonomically or raptor selection, but also controlled by the sedimentological history of the deposit. And moreover, that this is one of the most diverse paleontological cave deposits studied from Cuba, and its further study can provide a noteworthy contribution to Cuban and

Since the transport and deposition occurred after the deposition of pellets in the upper levels (i.e., primary deposit), the fossils transported and incorporated in the doline deposit below act as terminus post quem (TPQ) to the formation of the beds. Therefore, the depositional/erosional events indicated by the disconformities should date to a time after the age of death of the fossils. In this sense, beds I and $\mathrm{H}$ and B and A seem to follow the law of 
963 deposition, whereas the events recorded in layers C-F, may have occurred after the deposition of

964 the layers $\mathrm{H}$ and G, incorporating an older non-contemporaneous faunal assemblage (Figure 3-

965 4). This is important in the interpretation of the contemporaneity and diachrony of the fauna

966 contained on each bed as a depositional event.

968 bioturbation, mixing, layer inversion, down-slope truncation, and further reworking (Farrand,

969 2001; Bosch and White, 2007; McFarlane and Lundberg, 2007; Patzkowsky and Holland, 2012).

970 Although it is often not practical due to cost or preservation, it is preferable that many specimens

971 from a single layer or a whole stratigraphic sequence are dated (e.g., see Semken et al., 2010;

972 Stoetzel et al., 2016). Several studies have suggested that direct dating of associated specimens is

973 required to establish whether specimens in the same bed are radiometrically contemporaneous or

974 diachronous (Stafford et al., 1999; Stoetzel et al., 2016). Semken and colleagues showed that

975 diachrony is generally the norm, as they shown in several North American deposits (Semken et

976 al., 2010), this may be the case in Cuban cave deposits as well.

These issues are of great concern in the study of Cuban bone accumulation assemblages,

978 the majority which today lack ${ }^{14} \mathrm{C}$ dates. When available, they are often single dates that do not

979 follow a stratigraphic sequence or form a suite, and, as we have encountered here, may represent

980 diachronous faunas. Thus, assessing contemporaneity between important assemblages and their

981 LADs remains a key factor in the study of extinct or extirpated faunas, but is largely

982 unachievable in Cuba until more dates are available. This is a hindrance to the understanding of

983 Cuban, and thus Greater Antillean, vertebrate extinction and faunal turnover since the late

984 Pleistocene and through the Holocene. A comparison of faunas is further augmented by the lack

985 of confirmed late Pleistocene dated deposits in Cuba. Several candidate faunas have been 
postulated (e.g., Cueva del Mono Fósil, Cueva del Túnel or Cueva de los Paredones; Salgado et al., 1992; Gutiérrez et al., 2014; see Figure 1), but only three (Iturralde-Vinent et al., 2000, Breas de San Felipe, El Abrón, and Ciego Montero) have been confirmed (Kulp, 1952, Suárez and Díaz-Franco, 2003; Jull et al., 2004; Fiol, 2015). Conversely, many specimens from deposits that were originally thought to be at least late Pleistocene in age have yielded much more recent dates (mHOL-1HOL; MacPhee et al., 1999, 2007; Jiménez et al., 2005; Jull et al., 2004; Orihuela, 2010; Orihuela, 2019; Orihuela et al., forthcoming).

In our assemblage, the faunas of bed $\mathrm{G}$ and $\mathrm{H}$ (level intervals III-IV) can be interpreted as near contemporaneous, since they differ in slightly less than two sigmas $\left(2 \sigma: 100-140{ }^{14} \mathrm{C}\right.$ cal. deviation years). A deviation of a single sigma, usually between $60-70{ }^{14} \mathrm{C}$ cal. years is preferable (Semken et al., 2010), but not available for this deposit. But overall, our dated intervals (e.g., F, E, C and B) are generally longer than $1 \sigma$ or $2 \sigma$, and cannot be considered fully contemporaneous. The difference in diachronic range is between 118 and 138 cal. yrs. BP, among the faunas of intervals III and IV, and of 1958 years between I and II. The diachrony between these intervals highlights wide temporal hiatuses that support a non-continuous deposition, and likely, asynchronous faunas above bed $\mathrm{G}$ due to the processes already discussed. The use of a single date, even if from a single important individual extracted from a controlled stratigraphic unit, can conflict with or non-representative of the age of the whole fauna present in a unit or its stratigraphic association, as is suggested by the ${ }^{14} \mathrm{C}$ age of $P$. vetus from layer E. As is the case in many studies of Antillean land vertebrate paleontology, the interpretation of a single date as a representative of unit-fauna contemporaneity must be considered cautiously. Our data support the use of multiple dates, acquired directly from identifiable bone specimens, in the study of assemblage faunas. Better yet, several specimens 
should be dated within the same stratigraphic unit, or whole stratigraphic suites when possible in order to understand depositional regimes, spatial-temporal faunal change, diachrony, and bioecological turnover.

However, we consider that even though our dated individuals are not strictly contemporaneous, (as they are not expected to be in a time-averaged, slowly formed deposit), the direct LADs they provide for extinct and extirpated taxa are useful to biogeographical discussions (MacPhee et al., 1999; Silva et al., 2007; Patzkowsky and Holland, 2012). All direct

${ }^{14} \mathrm{C}$ dates provided for the extinct fruit bats $A$. anthonyi and $P$. vetus and the island island-shrews Nesophontes spp. provide evidence of their survival/existence, well into the very late Holocene of Cuba. The chronological and stratigraphic evidence suggests that the studied deposits are about 2000 years old, at least to the level excavated and thus includes fauna from well within the pre-Columbian Amerindian interval (Morgan and Woods, 1986; Cooke et al., 2017).

Furthermore, this indicates not only post-Pleistocene-early Holocene survivorship but also wider distribution ranges that persisted for several thousands of years of climate variations and human coexistence into the Late Holocene. Further supporting the time-lagged, group-specific asynchronous extinctions hypothesized by MacPhee and colleagues (1999), which have received growing support in Cuba (Jiménez et al., 2005; Steadman et al., 2005; Orihuela, 2010, 2019; Orihuela and Tejedor, 2012; Borroto-Páez and Mancina, 2017; Orihuela et al., forthcoming).

\section{Fauna temporal-spatial distribution}

Several of our fauna records indicate a wider distribution beyond current limits for several species that lasted well after 2000 years BP. These include the anole lizard Anolis cf. chamaeleonides, the woodpecker Colaptes fernandinae (or auratus), the Cuban parakeet 
1032

1033

1034

1035

1036

1037

1038

1039

1040

1041

1042

1043

1044

1045

1046

1047

1048

1049

1050

1051

1052

1053

1054

Psittacara eups, and crow Corvus which are today locally extinct in the region surrounding

Palenque. These represent past extralimital records for species whose distributions lie currently

far from the deposit (Garrido and Kirkconnell, 2000; Rodríguez-Schettino et al., 2013; Orihuela,

2013). Other remains constitute the first pre-Columbian, paleontological records for Progne cf.

subis, Tachycineta bicolor and Cathartes aura. Cathartes aura, Corvus sp, and Psittacara eups

have been reported from colonial contexts of the 16th and 18th centuries of La Habana Vieja

(Old Havana) (Jiménez and Arrazcaeta, 2008, 2015). The extralimital presence of Corvus sp. in

the colonial contexts of the old city of La Habana seems to support a recent range constriction

likely related to deforestation (Jiménez and Arrazcaeta, 2008; Orihuela, 2013). Cathartes aura

was initially reported from a supposed late Pleistocene deposit of Cueva del Túnel, in

Mayabeque province (Acevedo et al., 1975; Acevedo and Arredondo, 1982). That report was

challenged by Suárez (2001), who identified those specimen as modern (Jiménez and Arrazcaeta,

2008), thus deleting the species from the fossil record of Cuba. Moreover, Suárez (2001)

indicated the existence of an undescribed species of Cathartes. The turkey vulture was observed

and sketched by a British soldier during the siege of Havana city in the summer of 1762

(campaign journal of Henry Fletcher, 1757-1765: 255).

All of the rodent species had already been reported for the region and do not constitute new records (Jiménez et al., 2005; Silva et al., 2007; Orihuela and Tejedor, 2012). The

Mesocapromys nanus and M. kraglievichi are interesting because their fossils support a wider

late Holocene distributional range and several thousand-year survival post-Pleistocene climate

change and human inhabitancy in the island. The survival of the extinct hutia M. kraglievichi

through the pre-Columbian (Amerindian) interval is validated by the direct ${ }^{14} \mathrm{C}$ LAD obtained

from a specimen from the Solapa del Megalocnus site, Mayabeque province (Jiménez and JO 
unp. data). This specimen yielded an age of $1780 \pm 50$ rcyr BP from one of the preceramic archaeological contexts, but the specimens found between intervals III and IV of Cueva de los Nesofontes doline assemblage suggest a slightly younger LAD for this species. $M$. nanus is today likely extinct, formerly restricted only to the Zapata swamp, but in the past, it had a wider range (Silva et al., 2007; Borroto-Páez and Mancina, 2017). A similar extralimital fossil record was recently provided for Mesocapromys sanfelipensis on the mainland of Cuba (Viñola et al., 2018). This taxon is one of three highly localized and endangered pygmy hutias found today exclusively on several keys of the Cuban archipelago (Borroto-Páez, 2011; Mancina, 2012).

Bats and Nesophontes were the most abundant vertebrates in the assemblage. Yet, several of their species were rare and appeared only at specific intervals or beds, such as Nesophontes cf. longirostris. The smaller N. micrus dominated this genus' frequency, with more than 600 NISP representing at least 62 individuals (MNI) present at all intervals. But, individuals of N. major were slightly more abundant (Table 3-4). Of all Nesophontes species, $N$. cf. longirostris was the scarcest, further supporting the rarity of this species (Anthony, 1919). Over 2000 near-complete crania of Nesophontes spp. were formerly extracted from the 1985 excavation alone, making this one of the richest Nesophontes bone accumulations reported from Cuba (Vento, 1985 in Nuñez, 1990, vol. 1: 299-304).

The bats were especially numerous and diverse. The 18 taxa recorded here represent more than half of the known Cuban bat fauna. The taxonomic diversity of bats increases to 21 species if other species documented for this cave are counted (i.e., Desmodus rotundus, Lasiurus insularis and Chilonatalus macer in Orihuela, 2010).

The assemblage was particularly rich in frugivorous bats B. nana, Phyllonycteris poeyi, A. jamaicensis, and P. falcatus, whereas the insectivorous bats Eptesicus fuscus, Tadarida 

gregarious species with stationary feeding habits (phyllostomids) or species that had accessible blood-feeders (e.g., Noctilio and Desmodus) hardly ever occur in owl pellet deposits, which in part can explain their rarity in Cuba's raptor-derived bone deposits. adaptation of both M. molossus and raptors such as Tyto furcata. Molossus species are rare in the trees or crevices, which are not prone to intense preservation.

\section{Coexistence and competition}

Specimens of Artibeus anthonyi and Artibeus jamaicensis occurred in direct association

1094 within the same layer unit and throughout two intervals (level III and IV). Phyllops vetus and

1095 Phyllops falcatus occurred together only at interval level III (beds G and H). Interestingly, in bed

1096 E of interval II, which yielded the direct date for P. vetus and the oldest ${ }^{14} \mathrm{C}$ available for the

1097 assemblage, the two Phyllops species did not coincide. In the youngest interval (level I), neither

1098 the extinct $A$. anthonyi or $P$. vetus occurred, suggesting that by then they were not predated by

1099 raptors, were rare to appear in the record, or already extinct. Nonetheless, this supports a very

1100 Late Holocene extinction for these two species. Moreover, this record suggests that today's most 
1101

1102

1103

1104

1105

1106

1107

1108

1109

1110

1111

1112

1113

1114

1115

1116

1117

1118

1119

1120

1121

1122

endangered and rarest of Cuban bats, Natalus primus and Antrozous koopmani, had much better distribution in the island that lasted up to very recently.

The direct ${ }^{14} \mathrm{C}$ date on $A$. anthonyi reported for this interval suggests that it is highly probable that both Artibeus species coexisted for several thousand years. It was recently considered that these taxa did not coexist in the Holocene of Cuba for lack of direct evidence (Balseiro et al., 2009; Turvey and Fritz, 2011). In a few deposits where $A$. anthonyi occurred, $A$. jamaicensis was not found, and when found, the fossils seemed to be non-contemporaneous. But this has not been the case in others. H. E. Anthony, in the original description of the specimens from Cueva del Indio in Daiquirí, Eastern Cuba, that was later identified as Artibeus anthonyi by Woloszyn and Silva (1976), mentioned the occurrence of both Artibeus species, but these specimens have not been dated.

Until now, a direct radiocarbon date on Artibeus anthonyi was unavailable, but other evidence already suggested coexistence and survival well into the Holocene of Cuba (Jiménez et al., 2005; Orihuela, 2010; Condis unp. thesis). Recently, Condis reconsidered the temporal coexistence of several of Cuba's extinct bats in Cueva GEDA, including Cubanycteris silvai, $P$. vetus, A. jamaicensis and A. anthonyi (Condis unp. Thesis). A. anthonyi, P. vetus, $M$. megalophylla, and A. koopmani have been reported in deposits dated between the Late Pleistocene (21,474-20,050 BP) of Cueva El Abrón (Suárez and Díaz-Franco, 2003; Fiol, 2015), the early-mid Holocene of Cuevas Blancas (7044-6504 BP) in Jiménez et al. (2005) or further in the very Late Holocene (Orihuela, 2010; Orihuela and Tejedor, 2012; Orihuela et al., forthcoming). This supports their somewhat continuous presence in the fauna since the LGM and throughout most of the Holocene up to the colonial period. 

competition, as may also be the case for $P$. vetus and $P$. silvai. However, this hypothesis lacks

1125 confirmatory evidence (Balseiro et al., 2009). With the stable isotope values acquired from the

1126 bone collagen and tooth apatite from A. jamaicensis in comparison to A. anthonyi specimens, we

1127 are in a better position to discuss the competition hypothesis. The carbon isotopes do not indicate

1128 a substantial trophic variance between the species (Table 2; Figure 12). Artibeus anthonyi and A.

1129 jamaicensis had a similar diet and occupied a similar niche, as suggested by their values: $A$.

1130 anthonyi $\left(\delta^{13} \mathrm{C} \_c o l .-21.1 \%\right.$ and $\delta^{13} \mathrm{C} \_$apt. $\left.-11.0 \%\right)$ and $A$. jamaicensis $\left(\delta^{13} \mathrm{C} \_c o l .-20.1\right.$ and -

$113120.7 \%$, plus $\delta^{13}$ C_apt. -8.1 and $-9.9 \%$ ). These values suggest that the component of diet could

1132 have been an important source of competition; the intensity of the competition depending on

1133 their level of resource partitioning or difference in foraging strategies is yet unknown, and only

1134 here incipiently investigated and requiring further data.

1135 Moreover, our Artibeus $\delta^{13}$ C_col. values were lower than those reported by Rex and

1136 colleagues for $A$. jamaicensis $(-25.6 \pm 0.55 \mathrm{SD}, n=17)$ and A. lituratus $(-25.2 \pm 0.46 \mathrm{SD}, n=29)$

1137 (Rex et al., 2011, p. 221). The slightly smaller isotopic yield of A. lituratus could suggest a slight

1138 vertical stratification in niche partitioning between these two species in Neotropical forests,

1139 following the hypothesis that smaller bats prefer understory resources, whereas larger species

1140 prefer larger fruits of the canopy (Findley, 1993; Bonaccorso et al., 2007; Pereira et al., 2010). A.

1141 jamaicensis generally feed in the forest understory, commonly at ground level, whereas $A$.

1142 lituratus preferred a higher canopy level (McNab, 1971; Herrera et al., 2001; Rex et al., 2011;

1143 Silva et al., 2008). However, this was not supported overall for phyllostomids (Rex et al. (2011).

1144 Rex and colleagues reported that there could be up to $\sim 6.8 \%$ carbon isotope variation between

1145 syntopic species and concluded that there was no vertical stratification for these and other South 
American forest phyllostomids (Rex et al., 2011). This $6.8 \%$ value is much greater than the one we report for A. jamaicensis and A. anthonyi (Table 2, Figure 12). Thus, it is likely that syntopic phyllostomids such as $A$. jamaicensis and $A$. anthonyi explored all vertical forest levels and niches. The same phenomenon could have occurred among other extinct phyllostomids in Cuba. The size difference between $A$. jamaicensis and $A$. anthonyi is not considerable, and both can be classified as large short-faced fruit consumers (Silva, 1979). Therefore, their sympatry and minor

1152 habitat partitioning probably lead to more competition in foraging for the same resources in the 1153 same habitats. nectarivorous phyllostomids, in which species presented differences in feeding apparatus, wing

1156 morphology, flight patterns, foraging behavior, and spatial segregation, probably facilitated

1157 resource partitioning (McNab, 1971; Herrera et al., 2001; Mancina and Herrera, 2010; Mancina

1158 et al., 2012; Soto-Centeno et al., 2014), and thus could have decreased competition. a similar diet and occupied similar habitats. In that sense, it is probable that $A$. anthonyi and $A$.

1161 jamaicensis, as for Phyllops spp., shared similar habitats and diets, because differences between

1162 the carbon and oxygen isotope values are likely not reflective of significant spatial segregation or

1163 foraging strategy. A higher level of competition in foraging habitats between these taxa could

1164 have pushed the $\operatorname{rarer} A$. anthonyi and P. vetus/silvai to become extinct. A similar situation could 1165 help explain the coexistence of several extinct Cuban bats for a few thousand years and provide a 1166 window into their interaction and extinction We consider $A$. anthonyi rarer because in the cases 1167 in which both species occur, A. jamaicensis is by far the most common species of the two, as is 1168 the case in assemblages from Cueva de los Nesofontes (Orihuela, 2010; this work), Cueva 
1169 GEDA (Balseiro et al., 2009; Condis, unp. Thesis.) and Cuevas Blancas (Jiménez et al., 2005).

1170 Although, this apparent variation in abundance could be a taphonomic artifact, such as raptor

1171 preference, and not reflective of their natural abundance. However, further isotopic analyses are

1172 required to corroborate these preliminary observations.

\section{Paleoenvironmental reconstruction gleaned from fauna and isotopes}

1176 Colaptes woodpeckers suggest the presence of savannas and grasslands and nearby dry

1177 semideciduous forests. These are habitats which are today reduced, but still available over the

1178 karst terrain. Similar findings were reported for Cuevas Blancas, several dozen kilometers to the

1179 southwest of Palenque (Jiménez et al., 2005). The dove Geotrygon chrysia suggests dry forests

1180 with little undergrowth, and Psittacara eups undisturbed forests and palm grove savannas

1181 (Garrido and Kirkconnell, 2000). The regular transient woodpeckers Sphyrapicus varius,

1182 swallow Tachycineta sp. and the martin Progne sp. support the presence of seasonal transient

1183 species in the assemblage. This mosaic of available habitats agrees with the former vegetation

1184 hypothesized for the region (Marrero, 1972; Del Risco, 1989). The pollen, spores, and seeds

1185 registered from this deposit are yet to be studied but can provide a better record of vegetation

1186 change in the area when available (Figure 9).

1187 The carbon and oxygen isotopes aid in the interpretation of past habitats and

1188 microenvironments (Bocherens et al., 1996; Lee-Thorp et al., 1989; MacFadden et al., 1996).

1189 Habitats with a greater proportion of C4 vegetation, such as grasslands and savannahs, generally

1190 yield higher $\delta^{13} \mathrm{C}$ (more positive) values, whereas habitats with higher tree cover (riverine

1191 woodlands) tend to have lower (more negative) values. Mixed habitats yield intermediate values 
1192 (Leichliter et al. 2016; Keicher et al., 2017). The $\delta^{13} \mathrm{C}$ values we obtained from the analyzed 1193 remains of Artibeus sp. and N. major are intermediate (Figure 11), suggest that these species

1194 lived in riverine woodlands and mixed woodland habitats. In this sense, the slight $\delta^{13} \mathrm{C}$ variation

1195 between the Cuban Artibeus spp. $\left(\delta^{13} C_{-}\right.$col. -21.1 and $-20.1 \%$ \% $)$ discussed above suggests that $A$.

1196 jamaicensis and A. anthonyi probably preferred similar forest microhabitats within mixed

1197 woodlands and riverine woodlands. major observed in our assemblage. Even though N. micrus is smaller, it would have been easier individual fed on millipedes, earthworms, maybe fungi and fruits (see similar interpreted signals

1209 in Reid et al., 2013; Eckrich et al., 2018). Based on this we hypothesize that Nesophontes species 1210 were probably omnivores, occasionally feeding on beetles or millipedes attracted to

1211 decomposing pellets accumulated at the raptor roosts. Their tooth marks have been identified on 1212 the bones present on owl pellet biological remains (Orihuela et al., 2016; this paper). However, 1213 the carrion signal acquired from scavenging is not clear in our isotope data. Our isotope signals 
1214 for Nesophontes could be masked by enrichment from feeding on necrophagic arthropods

1215 (Hocking et al., 2007).

1216 Once more, many more analyses are needed to explore habitat segregation and diet of

1217 these vertebrates. Thus, is probable that niche overlap could have also existed between these

1218 sympatric taxa. Other sources of variation could include metabolic and isotope fractionation

1219 differences (enrichment fluctuations) among taxa, body mass, trophic level, and individual

1220 habitat preferences, as has been shown for soricid shrews (Baugh et al., 2004; Keicher et al.,

1221 2017) could further mask the isotope signals. Nevertheless, the isotopes provide an additional,

1222 here incipiently explored, source of insight that can explain Nesophontes spp. habitat preference,

1223 diet, and competition to better explain their extinction.

1224 The presence of mormoopid and vampire bats suggests an overall warm climate during

1225 the time of deposition since these species do not inhabit boreal regions and their distribution in

1226 the Neotropics is limited by temperature (Vaughan and Bateman, 1970; McNab, 1973;

1227 Bonaccorso et al., 1992). This is supported by the oxygen stable isotopes acquired from bone

1228 hydroxyapatite and collagen from remains of the bats A. jamaicensis, A. anthonyi and from $N$.

1229 major in several intervals of the deposit (Table 2). Our record suggests a wetter, warmer climate

1230 around $\mathrm{BC} 40-90 \mathrm{AD}$ and $\mathrm{AD}$ 605-655, which agrees with the large, slowly deposited but

1231 amalgamated bed sets of interval IV and III (beds I to H), expressive of large flooding

1232 depositional events.

1233 A - $0.4 \%$ positive oxygen isotope excursion occurred at AD 660-770, suggestive of drier,

1234 colder local conditions, with a subsequent progressive return to warmer, wetter conditions after

1235 and up to the present (Figure 13). This profile is comparable to conditions gleaned from the Late

1236 Pleistocene speleothem record of Río Secreto, Yucatan (Mexico) between 23 and $23.5 \mathrm{ka}$ 
1237 (Medina et al., 2017) and the temperature deviations (anomalies in Celsius degrees from modern

1238

1239

1240

1241

1242

1243

1244

1245

1246

1247

1248

1249

1250

1251

1252

1253

1254

1255

1256

1257

1258

1259

temperature) in the order of -0.6 to -0.2 in Moberg et al. (2005) and Abrantes et al. (2017). The

wetter, warmer period that followed also agrees with the data presented by these researchers.

A similar positive excursion, although larger in magnitude, is recorded from lacustrine deposits from Punta Laguna, Lake Chichancanab and Lake Coba (Hodell et al., 1995; HigueraGundy et al., 1999; Curtis et al., 2001, p. 4). These records indicated a major drought between 1500 and 1100 years BP (op. cit.), which can help interpret our positive excursion as a similar, concomitant dry-cold spell.

Paleoclimatic records throughout the Caribbean and circum-Caribbean show a shift from wetter, more mesic conditions during the early-middle Holocene to drier, more xeric conditions during the late Holocene, between 3000 and 1300 year BP (Hodell et al., 1995; Curtis et al., 2001; Peros et al., 2007). Our data do not agree with the overall tendency towards drier conditions after 2000 cal yr. BP interpreted from Cuban coastal lacustrine deposits (Peros et al., 2007; Peros et al., 2015; Gregory et al., 2015), and instead agree with those acquired from cave speleothem records (Pajón et al., 2001; Pajón, 2012; Fensterer et al., 2013) which indicate the inverse. Since our oxygen isotope values were acquired from bat dental apatite, they likely represent the bat's life oxygen record acquired from the local diet and water source (Bocherens et al., 1996; Lee-Thorp et al., 1989; MacFadden et al., 1996). These, in turn, provide us with a very local environmental record. Nevertheless, our contrasting results could also be obscured by the complicated fractionation of oxygen in the sampled bats, bone mineralization, or deposit diagenesis (Bocherens et al., 1996; Lachniet, 2009).

The large accumulation of charcoal and ash of bed $\mathrm{C}$ suggest either a natural forest fire or anthropogenic activity in the area; with the charcoal remains brought in by a fast flooding event. 
1260 Direct ${ }^{14} \mathrm{C}$ date estimates from this level (bed $\mathrm{C}$ in Figure 4) indicates it includes fauna younger

1261 than 1960 cal. yrs. BP (BC 40 - 90 AD), but older than 1000 BP (from Boromys torrei and

1262 Antrozous koopmani specimens in Orihuela et al., forthcoming). By then Amerindians, both pre-

1263 Arawak "archaic" and Arawaks (Taino) were already well-established in the area (Tabío and

1264 Rey, 1979; Roksandic et al., 2015; Chinique et al., 2016), thus human-caused forest fires cannot

1265 be ruled out. Although, based on the lack of archaeological evidence, we consider this as a result

1266 of a natural fire on the upper escarpment of the hill. Natural fires are commonly ignited by

1267 lightning, as is the case in Cuba (Medina and Alfonso, 2000; Ramos, 2002). Microcharcoal

1268 deposits in Cuba (Jiménez et al., 2005) and other parts of the Greater Antilles, although common

1269 in some cave and lacustrine deposits, have been difficult to attribute to human action (Burney et

1270 al., 1994; Haug et al., 2001; Lane et al., 2013; Caffrey and Horn, 2014). Furthermore, we did not

1271 find any archaeological evidence (e.g., tool cut marks) at the doline deposit that could suggest

1272 human involvement in these localized fires.

1273

1274

1275

1276

1277

1278

1279 Holocene of Cuba. Through a multidisciplinary and multiproxy approach, we access the

1280 formational history and source of the deposit, including the survivorship and coexistence of

1281 fauna on a millennial-scale. From these data, we infer that the cone deposit in the main doline

1282

\section{CONCLUSIONS}

The deposit reported and interpreted here from Cueva de los Nesofontes, in northeastern

Mayabeque province, provides a rich source of biogeographical and paleoecological information with which to understand the pre-Columbian (Amerindian) environmental history of the late gallery is a secondary repository of primarily amalgamated, multisource deposit located in the 
1283 upper levels of the main sinkhole. Although the deposit is mostly pellet-derived, it was slightly

1284

1285

1286

1287

1288

1289

1290

1291

1292

1293

1294

1295

1296

1297

1298

1299

1300

1301

1302

1303

1304

mixed over time with organisms by sedimentation and reworking.

The stratigraphic architecture (disconformities and erosional surfaces) that suggest

flooding events helped transport sediments and organic remains into the deposition cone below

the sinkhole. The deposition was controlled by the slope's incline and is marked by a slow

sedimentary regime (slow sedimentary rates), suggesting that it was slow to form and time-

averaged. The oxygen isotopes suggest a change in the tendency from wet and warm conditions

during BC 40 - AD 90 to slightly wetter and warmer conditions thereafter. A positive excursion

was registered during $\mathrm{AD} 660-770$, before the medieval warm period, that suggests drier and

colder local conditions, which does not agree with most other circum-Caribbean records.

The radiocarbon dates yielded by faunal bone collagen indicate that the sampled portion

of the deposit is less than 2000 years old, and thus within the pre-Columbian Amerindian interval

of the Late Holocene. Direct radiocarbon dates from extinct fauna provide last occurrence dates

for the extinct fruit bats Artibeus anthonyi and Phyllops vetus, plus the extinct island-shrew

Nesophontes major, previously without direct LAD dates. These dates support the inference that

some Cuban extinct land mammal taxa, formerly believed to have disappeared during the late

Pleistocene-early Holocene, survived well into the late Holocene, and several thousands of years

of human presence in the archipelago (MacPhee et al., 1999; Jiménez et al., 2005; Orihuela,

2010; Orihuela and Tejedor, 2012). The association of these species within the dated intervals of

the deposit also provides new records supporting a wider distribution for species that are either

extinct or severely endangered, such as the bats Natalus primus and Antrozous koopmani. Other

taxa, such as Psittacara eups, Corvus, Colaptes, and Solenodon cubanus are locally extinct or no 
1305

longer occur in the region, but their presence in the deposit support their existence in the surrounding habitats up to the very late Holocene.

The integration of isotopic data as a proxy for dietary preferences with evidence of niche partitioning may serve to better elucidate unexplored causes of extinction of Antillean land mammals, which we have only recently begun to explore (e.g., Cooke and Crowley, 2018; this work). The information that can be gleaned with simultaneous analyses of assemblage structure and resource partitioning can help elucidate aspects of competition and trophic guilding, which when coupled to climatic and anthropogenic factors, can provide a more naturalistic (realistic) explanation to the asynchronous and taxon-specific extinction of land vertebrates during the Antillean Late Holocene.

\section{REFERENCES}

Abrantes, F., Rodríguez T., Rufino M., Salgueiro E, et al. 2017. The climate of the Common Era off the Iberian Peninsula. Climate of the Past, 13:1901-1918.

Acevedo González, M., Arredondo, O., and González, N. 1975. La Cueva del Túnel. Editorial Pueblo y Educación, La Habana.

Acevedo González, M., and Arredondo O. 1982. Paleozoografía y geología del cuaternario de Cuba: Características y distribución geográfica de los depósitos con restos de vertebrados, P. 54-70. In IX Jornada Científica del Instituto de Geología y Paleontológica de la Academia de Ciencias de Cuba, La Habana, Cuba. Acevedo González, M. 1992. Geografía Física de Cuba. Editorial Pueblo y Educación, La Habana, Cuba. 
Allen, G.M. 1917. New fossil mammals from Cuba. Bulletin of the Museum of Comparative Zoology, 61:3-12.

Allen, G.M. 1918. Fossil mammals from Cuba. Bulletin of the Museum of Comparative Zoology, $62: 133-148$.

Andrews, P. 1990. Owls, Caves and Fossils. University of Chicago Press, Chicago.

Anthony, H.E. 1917. New rabbit and a new bat from Neotropical regions. Bulletin of the American Museum of Natural History, 37:335-337.

Anthony, H.E. 1919. Mammals collected in Eastern Cuba. Bulletin of the American Museum of Natural History, 41:625-643.

Arredondo, O. 1970. Nueva especie de ave Pleistocénica del Orden Accipitriformes (Accipitridae) y nuevo género para las Antillas. Ciencias Biológicas, 4:1-19.

Arredondo, C. and Chirino, V.N. 2002. Consideraciones sobre la alimentación de Tyto alba furcata (Aves: Strigiformes) con implicaciones ecológicas en Cuba. El Pitirre, 15:16-24.

Balseiro, F., Mancina, C.A., and Guerrero, J.A. 2009. Taxonomic status of Artibeus anthonyi (Chiroptera: Phyllostomidae), a fossil bat from Cuba. Journal of Mammalogy, 90:14871494.

Balseiro, F. 2011. Los murciélagos extintos p. 170-177. In Borroto-Páez, R., and Mancina C.A. (eds.), Mamíferos en Cuba. UPC Print Vaasa, Finland.

Banks, R.C. 1965. Some information from barn owl pellets. Auk, 82:506.

Baugh, A.T., West, A.G., Rickart, E.A., Cerling, T.E., Ehleringer, J.R., Dearing, M.D. 2004. Stable isotope ratios $(\delta 15 \mathrm{~N}$ and $\delta 13 \mathrm{C})$ of syntopic shrews (Sorex). Southwestern Naturalist, 49:493-500.

Behrensmeyer, A.K. 1978. Taphonomic and ecologic information from bone weathering. 
Paleobiology, 4:150-162.

1352

1353

1354

1355

1356

1357

1358

1359

1360

1361

1362

1363

1364

1365

1366

1367

1368

1369

1370

1371

1372

1373

Ben-David, M., and Flaherty, E.A. 2012. Stable isotopes in mammalian research: a beginner's guide. Journal of Mammalogy, 93:312-328.

Bocherens, H., Koch, P.L., Mariotti, A., Geraads D., and Jaeger J.J. 1996. Isotopic biogeochemistry $\left({ }^{13} \mathrm{C},{ }^{18} \mathrm{O}\right)$ of mammalian enamel from African Pleistocene Hominid Sites. Palaios, 11:306-318.

Bonaccorso, F.J., Arends, A., Genoud, M., Cantoni, D., and Morton T. 1992. Thermal ecology of Mustached and Ghost-Faced Bats (Mormoopidae) in Venezuela. Journal of Mammalogy, $73: 365-378$.

Bonaccorso, F.J., Winkelmann, J.R., Shin, D., Agrawal, C.I., Aslami, N., Bonney, C., HSU, A., Jekielek, P.E., Knox, A., Kopach, S.J., Jennings, T.D., Lasky, J.R., Menesale, S.A., Richards, J.H., Rutland, J.A., Sessa, A., Zhaurov, L., and Kunz, T.H. 2007. Evidence for exploitative competition: comparative foraging behavior and roosting ecology of shorttailed fruit bats (Phyllostomidae). Biotropica, 39:249-256.

Borroto-Páez, R. 2011. Los mamíferos invasores o introducidos, p. 220-241. In Borroto-Páez, R., and Mancina, C.A. (eds.), Mamíferos en Cuba. UPC Print, Vaasa, Finland.

Borroto-Páez, R. and Mancina C.A. 2017. Biodiversity and conservation of Cuban mammals: past, present, and invasive species. Journal of Mammalogy, 98:964-985.

Bosch, R.F. and White, W.B. 2007. Lithofacies and transport of clastic sediment in karstic aquifers, p. 1-22 . In Sasowsky I.D., and Mylroie J. (eds), Studies of Cave Sediments. Springer, Dordrecht.

Boudagher-Fadel, M.K. 2008. Evolution and Geological Significance of Larger Benthic Foraminifera. Developments in Paleontology and Stratigraphy 21. Elsevier, Amsterdam. 
1374

1375

1376

1377

1378

1379

1380

1381

1382

1383

1384

1385

1386

1387

1388

1389

1390

1391

1392

1393

1394

1395

1396

Brown, B. 1913. Some Cuban fossils: a hot spring yields up the bones of animals that lived before the advent of Man. The American Museum Journal, 13:221-228.

Buckley, N., Harvey, V.L., Orihuela, J., Mychajliw, A.M., Hadly, E.A., Almonte Milan, J.N., Lawless, C., Chamberlain, A.T., Egerton, V.M. and Manning P.L. (in press, submitted Nov. 2018). Collagen sequence analysis reveals evolutionary history of extinct West Indies island-shrews.

Bunn, D.S., Washburton A.B., and Wilson R.D.S. 1982. The Barn Owl. A. D. Poyser, Calton.

Burney, D.A., Pigott Burney L., and MacPhee, R.D.E. 1994. Holocene charcoal stratigraphy from Laguna Tortuguero, Puerto Rico, and the timing of human arrival on the island. Journal of Archaeological Science, 21:273-281.

Caffrey, M. and Horn S.P. 2014. Long-term fire trends in Hispaniola and Puerto Rico from sedimentary charcoal: a comparison of three records. The Professional Geographer, 67:229-241. DOI: $\underline{10.1080 / 00330124.2014 .922017}$

Cooke S.B., Dávalos, L.M., Mychajliw, A.M., Turvey, S.T., and Upham, N.S. 2017. Anthropogenic extinction dominates Holocene declines of West Indian mammals. Annual Review Ecology Evolution and Systematics, 48:301-27. https://doi.org/10.1146/annurevecolsys-110316-022754

Cooke, S.B. and Crowley, B.E. 2018. Deciphering the isotopic niches of new-extinct Hispaniolan rodents. Journal of Vertebrate Paleontology, e1510414. DOI: https://doi.org/10.1080/02724634.2018.1510414

Condis Fernández, M.M., Jiménez Vázquez, O., and Arredondo, C. 2005. Revisión taxonómica del género Nesophontes (Insectivora: Nesophontidae) en Cuba: análisis de los caracteres diagnósticos, p. 95-100. In Alcover, J. A., and Bover, P. (eds.), Proceedings of the 
International Symposium "Insular Vertebrate Evolution: the Paleontological Approach". Monografies de la Societat d'Història Natural de les Balears, 12.

Condis Fernández, M.M. (n/d). Inferencias paleoecológicas sobre especies de la mastofauna cuaternaria cubana, conservadas en el depósito superficial de la Caverna GEDA, Pinar del Rio, Cuba. Unpublished PhD dissertation, Universidad de Pinar del Río, Cuba.

Cuban Geological Lexicon, Collective de authors. 2003. Léxico Estratigráfico de Cuba. Habana.

Cuban National Atlas, Collective of authors. 1989. Nuevo Atlas Nacional de Cuba. Instituto de Planificación Física, La Habana, Cuba.

Curtis, J.H., Brenner, M., and Hodell, D.A. 2001. Climate change in the Circum-Caribbean (Late Pleistocene to Present) and implication for regional biogeography, p. 35-54. In Woods,

de la Torre y Huerta, C. 1910. Excursión a la Sierra de Jatibonico: osamentas fósiles de C.A. \& Sergile, F. (eds.), Biogeography of the West Indies (Second Edition). CRC Press, Megalocnus rodens o Myomorphus cubensis: comprobación de la naturaleza continental de Cuba a principios de la época Cuaternaria. Anales de la Academia de Ciencias In Nuevo Atlas Nacional de Cuba. Instituto de Planificación Física, La Habana, Cuba.

DeNiro, M.J. 1985. Postmortem preservation and alteration of in vivo bone collagen isotope ratios in relation to palaeodietary reconstruction. Nature, 317:806-809.

Ducloz, C. 1963. Etude géomorphologique de la région de Matanzas, Cuba. Archives de Sciense, 
1421

1422

1423

1424

1425

1426

1427

1428

1429

1430

1431

1432

1433

1434

1435

1436

1437

1438

1439

1440

1441

1442

Eckrich, C.A. Flaherty, E.A., and Ben-David M. 2018. Functional and numerical responses of shrews to competition vary with mouse density. PlosOne, 13:e0189471. DOI: https://doi.org/10.1371/journal.pone.0189471

Farrand, W.R. 2001. Sediments and stratigraphy in rockshelters and caves: A personal persepective on principles and pragmatics. Geoarchaeology: An International Journal, $16: 537-557$.

Fensterer, C., Scholz, D., Hoffman, D.L., Spötl, C., Schröder-Ritzrau, A., Horn, C., Pajón, J.M., And Mangini, A. 2013. Millenial-scale climate variability during the last $12.5 \mathrm{ka}$ recorded in a Caribbean speleothem. Earth Planet Science Letters, 361:143-151.

Fiol González, S. 2015. La fauna de mamíferos fósiles del depósito paleontológico "El Abrón” (Nivel IX) Pinar del Río, Cuba. Unpublished thesis, Universidad de La Habana, Facultada de Biología, La Habana, Cuba.

Findley, J.S. 1993. Bats: A Community Perspective. Cambridge Studies in Ecology, Cambridge University Press, Cambridge.

Fletcher, Henry (1757-1765) Seven Year's War journal of the $35^{\text {th }}$ regiment on foot (unedited manuscript). John Carter Brown Library, Rhode Island.

Formell Cortina, F., and Buguelskiy, Y.R. 1974. Sobre la existencia en Cuba de lateritas ferroniquelíferas redepositadas sobre calizas, p.117-139. In Contribución a la Geología de Cuba. Publicación Especial Numero 2, Academia de Ciencias de Cuba, La Habana, Cuba.

García Rivera, L., and Mancina C.A. 2011. Murciélagos insectívoros, p: 140-165. In BorrotoPáez, R. and Mancina, C.A. (eds), Mamíferos en Cuba. UPC, Vasa, Finland. 
1443 Garrido, O.H., and Kirkconnell A. 2000. Field Guide to the Birds of Cuba. Cornell University

$1444 \quad$ Press, Ithaca.

1445 Geologic Society of America. 2009. Geological Rock-Color Chart with Genuine Munsell Color

1446 Chips. Rocl-Color Chart Committee, Munsell Color, Grand Rapids.

1447 Geyh, M.A. and Schleicher, H. 1990. Absolute Age Determination: Physical and Chemical

1448 Dating Methods and their Applications. Springer-Verlag, New York

1449 Gillieson, D. 1986. Cave sedimentation in the New Guinea highlands. Earth Surface Processes

$1450 \quad$ Landoforms, 11:533-543.

1451 Goldberg, S.L., Novacek, M.J. and Alayón, G. 2017. The History of Scientific Relations between Cuba and the American Museum of Natural History (AMNH): 160 Years of Collecting and Collaborating (1857-2017). American Museum of Natural History Special Publication, New York City, USA.

González Alonso, H. 2012. Aves, p. 207-267. In González Alonso, H., Rodríguez, L., Rodríguez, Editorial Academia, La Habana.

Gregory, B.R.B., Peros, M., Reinhardt E.G., and Donnelly, J.P. 2015. Middle-late Holocene

\section{2} two Cuban lagoons. Palaeogeography, Palaeoclimatology and Palaeoecology, 426:229241. DOI: $\underline{\text { https://doi.org/10.1177/0959683615585844 }}$ 
Haug, G.H., Hughen, K.A., Sigman, D.M., Peterson, L.C., and Röhl, U. 2001. Southward migration of the Intertropical Convergence Zone through the Holocene. Science, 293:1304-1308.

Hernández-Muñoz, A. and Mancina C.A. 2011. La dieta de la lechuza (Tyto alba) (Aves: Strigiformes) en hábitats naturales y antropogénicos de la región central de Cuba. Revista mexicana de biodiversidad, 82:217-226.

Hernández de Lara, O., Rodríguez Tápanes, B., and Arredondo, C. 2013. Esclavos y Cimarrones en Cuba: Arqueología Histórica en la Cueva El Grillete. Aspha, Buenos Aires.

Herrera, L., Hobson, K.A., Mirón, L., Nicte Ramírez, P., Méndez, G., and Sánchez-Cordero, V. 2001. Source of protein in two species of phytophagous bats in seasonal dry forest: evidence from stable-isotope analysis. Journal of Mammalogy, 82:352-361.

Higuera-Gundy A., Brenner, M., Hodell, D.A., Curtis, J.H., Leyden, B.W., and Binford, M.W. 1999. A 10,300 14C record of climate and vegetation change in Haiti. Quaternary Research, 52:159-170.

Hodell, D.A., Curtis, J.H., and Brenner, M. 1995. Possible role of climate in the collapse of Classic Maya civilization. Nature, 375:391-394.

Howard, H. 1929. The avifauna of Emeryville shellmound. University of California Publications in Zoology, 32:301-396.

Hua, Q. and Barbettii, M. 2004. Review of the tropospheric bomb 14C data for carbon cycle modeling and age calibration porpuses. Radiocarbon, 46:1273-1298.

Iturralde-Vinent, M. 1969a. Principal characteristics of Cuban Neogene stratigraphy. American Association Bulletin of Petroleum Geologists, 53:1938-1955.

Iturralde-Vinent, M. 1969b. El Neógeno en la provincia de Matanzas, Cuba. Parte General. 
Publicación Especial del Instituto Nacional de Recursos Hidráulicos, 7:3-30.

1490

1491

1492

1493

1494

1495

1496

1497

1498

1499

1500

1501

1502

1503

1504

1505

1506

1507

1508

1509

1510
Iturralde-Vinent, M. 1977. Los movimientos tectónicos de la etapa de desarrollo platafórmico en Cuba. Informe Científico-Técnico Academia de Ciencias de Cuba, 20:1-24.

Iturralde-Vinent, M. 1988. Naturaleza Geológica de Cuba. Editorial Científico-Técnica, La Habana, Cuba.

Iturralde-Vinent, M., MacPhee, R.D.E., Díaz-Franco, S., Rojas-Consuegra, R. Suárez, W., and Lomba, A. 2000. Las breas de San Felipe, Quaternary asphalt seep near Martí (Matanzas Province, Cuba). Caribbean Journal of Science, 36:300-313.

Jiménez Vázquez, O. 1997. Seis nuevos registros de aves fósiles en Cuba. El Pitirre, 10:49.

Jiménez Vázquez, O. 2001. Registros ornitológicos en residuarios de dieta de los aborígenes precerámicos cubanos. El Pitirre, 14:120-126.

Jiménez Vázquez, O., Condis, M.M., and García Cansío E. 2005. Vertebrados Post-glaciales en un residuario fósil de Tyto alba Scopoli (Aves: Tytonidae) en el Occidente de Cuba. Revista Mexicana de Mastozoología, 9:80-101.

Jiménez Vázquez, O. and Arrazcaeta, R. 2008. Las aves en la arqueología histórica de La Habana Vieja. Boletín del Gabinete de Arqueología, 7:17-29.

Jiménez Vázquez, O., and Arrazcaeta, R. 2015. Las aves y su relación con las culturas precolombinas de Cuba. Boletín del Gabinete de Arqueología, 11:141-157.

Jiménez Vázquez, O., Arrazcaeta, R., and Orihuela, J. (in press; 2019). Nuevos hallazgos paleobiológicos de aves extintas o en peligro crítico endémicas de cuba, géneros Ara (Psittacidae), Pulsatrix (Strigidae) y Campephilus (Picidae). Novitates Caribaea.

Jull, A.J.T., Iturralde-Vinent, M., O’Malley, J.M., MacPhee, R.D.E., McDonald, H.G., Martin, 
P.S., Moddy, J., and Rincón, A. 2004. Radiocarbon dating of extinct fauna in the Americas recovered from tar pits. Nuclear Instruments and Methods in Physics Research, B 223/224:668-671.

Keicher, L., O’Mara, M.T., Voigt, C.C., and D. Dechmann, K.N. 2017. Stable carbon isotopes in breath reveal fast incorporation rates and seasonably variable but rapid fat turnover in the common shrew (Sores araneus). Journal of Experimental Biology: jeb.159947 doi:10.1242/jeb.159947.

Koopman, K.F. and Williams, E.E. 1951. Fossil chiroptera collected by H. E. Anthony in Jamaica 1919-1920. American Museum Novitates, 1519:1-30.

Kulp, J.L., Tryon, L.E., Eckelman W.R., and Snell W.A. 1952. Lamont Natural Radiocarbon Measurements, II. Science, 116(3016):409-414.

Kusmer, K.D. 1990. Taphonomy of owl pellet deposition. Journal of Paleontology, 64:629-637.

Lachniet, M.S. 2009. Climatic and environmental controls on speleothem oxygen-isotope values. Quaternary Science Reviews, 28:412-432.

Lane, C.S., Clark, J.J., Knudsen, A., and McFarlin, J. 2013. Late-Holocene paleoenvironmental history of bioluminescent Laguna Grande, Puerto Rico. Palaeogeography, Palaeoclimatology Palaeoecology, 369:99-113.

Leichliter, J.N., Sponheimer, M., Avenant, N.L., Sandberg P.A., et al. 2016. Small mammal insectivore stable carbon isotope compositions as habitat proxies in a South African savanna ecosystem. Journal of Archaeological Science: Reports, 8:335-345.

Lee-Thorp, J.A., Sealy, J.C., and Van Der Merwe, N.J. 1989. Stable carbon isotope ratio differences between bone collagen and bone apatite, and their relationship to diet. Journal of Archaeological Science, 16:585-599. 
1534

1535

1536

1537

1538

1539

1540

1541

1542

1543

1544

1545

1546

1547

1548

1549

1550

1551

1552

1553

1554

1555

López Ricardo, Y. 2012. Alimentación de la lechuza (Tyto alba furcata) en Cuba central: presas introducidas y autóctonas. Unpublished thesis, Facultad de Biología de la Universidad de La Habana, La Habana, Cuba.

Lyman, R.L. 2008. Quantitative Paleozoology. Cambridge University Press, Cambridge.

MacPhee, R.D.E., Flemming, C., and Lunde D.P. 1999. "Last Occurrence” of the Antillean insectivoran Nesophontes: new radiometric dates and their interpretations. American Museum Novitates, 3261:1-20.

MacPhee, R.D.E., Iturralde-Vinent, M.A., and Jiménez Vázquez O. 2007. Prehistoric sloth extinctions in Cuba: Implications of a new "Last" appearance date. Caribbean Journal of Science, 43:94-98.

MacFadden, B.J., Cerling, T.E., and Prado, J. 1996. Cenozoic terrestrial ecosystem evolution in Argentina: Evidence from Carbon isotopes of fossil mammal teeth. Palaios, 11:319-327.

McNab, B.K. 1971. The structure of tropical bat faunas. Ecology, 32:352-358.

McNab, B.K. 1973. Energetics and the distribution of vampires. Journal of Mammalogy 54:131144

Mancina, C.A. 2012. Mamíferos, p. 268-291. In González Alonso, H. et al (eds), Libro Rojo de los Vertebrados de Cuba. Editorial Academia, La Habana, Cuba.

Mancina, C.A. and García-Rivera, L. 2005. New genus and species of fossil bat (Chiroptera: Phyllostomidae) from Cuba. Caribbean Journal of Science, 41:22-27.

Mancina, C.A. and Herrera, L.G. 2010. Disparate feeding strategies used by syntopic Antillean nectarivorous bats to obtain dietary protein. Journal of Mammalogy, 9: 960-966.

Mancina, C.A., García-Rivera, L., and Miller B.W. 2012. Wing morphology, echolocation, and 
resource partitioning in syntopic Cuban mormoopid bats. Journal of Mammalogy,

1558 Marrero, L. 1972. Cuba: Economía y Sociedad Vol. 1. Editorial Playor, S. A., Madrid

1559 McFarlane D.A. and Lundberg J. 2007. Reliquia Diluviave Alter: Las interglacial flood d eposits 1560 in the caves of the West Indies. In Sasowsky I.D., and Mylroie J. (eds), Studies of Cave $1561 \quad$ Sediments. Springer, Dordrecht.

1562 Medina Elizalde, M., Burns, S.J., Polanco Martínez, J., Lases Hernández, F., Bradley, R., Wang, Hao-Cheng, and Chuan-Chou Shen. 2017. Synchronous precipitation reduction in the American tropics associated with Heinrich 2. Scientific Reports DOI: 10.1038/s41598017-11742-8.

Medina, T.N. and Alfonso F.A. 2000. Los incendios forestales causados por descargas eléctricas en Cienaga de Zapata, Matanzas, Cuba. Ciencia Forestal en México, 25:105-113.

1568 Miller, G.S. 1916. Bones of mammals from Indian sites in Cuba and Santo Domingo. Smithsonian Miscellaneous Collection, 66:1-10.

1570 Moberg A., Sonechkin D.M., Holmgren K., Datsenko N.M., and Karlen W. 2005. Highly variable Northern hemisphere temperatures reconstructed from low- and high-resolution proxy data. Nature, 433:613-617.

1573 Morgan, G.S. 1977. Late Pleistocene fossil vertebrates from the Cayman Islands, British West Indies. Unpublished M.S. thesis, University of Florida, Gainesville.

1575 Morgan, G.S. and Woods, C.A. 1986. Extinction and zoogeography of the West Indian land mammals. Biology Journal of the Linnaean Society, 28:167-203.

1577 Morgan G.S. 1994. Late Quaternary fossil vertebrates from the Cayman Islands, p. 465-508. In 
Morris, P. 1979. Rats in the diet of the Barn owl (Tyto alba). Journal of Zoology, 189:540-545.

1581 Nicholson, K.E., Crother, B.I., Guyer, C., and Savage, J.M. 2012. It is time for a new classification of anoles (Squamata: Dactyloidea). Zootaxa, 3477:1-108.

Nuñez Jiménez, A. 1989. Medio Siglo Explorando a Cuba (Tomo 1). Imprenta Central de las FAR, La Habana, Cuba.

Nuñez Jiménez, A., and et al. 1984. Cuevas y Carsos.Editorial Militar, La Habana, Cuba.

Nuñez Jiménez, A. 1998. Geología. Ediciones Mee Graphic Ltd., La Habana, Cuba.

Olsen, S.J. 1979. Osteology for the archaeologist. Papers of the Peadbody Museum of Archaeology and Ethnology: Harvard University, 56: 1-186. Columbian occurrence of the Vampire Bat Desmodus rotundus (Phyllostomidae: Desmodontinae). Caribbean Journal of Science, 46:297-312.

Orihuela, J. and Tejedor A. 2012. Peter's ghost-faced bat Mormoops megalophylla (Chiroptera: Mormoopidae) from a pre-Columbian archeological deposit in Cuba. Acta

Orihuela, J. 2013. Fossil Cuban crow Corvus cf. nasicus from a Late Quaternary cave deposit in northern Matanzas, Cuba. Journal of Caribbean Ornithology, 26:12-16.

Orihuela J. 2014. Endocranial morphology of the extinct Antillean shrew Nesophontes (Lipotyphla: Nesophontidae) from natural and digital endocasts of Cuban taxa. Palaeontologia Electronica, 17:1-12.

1600 Orihuela, J. and Pérez Orozco, L. 2015. Descubrimiento de posible arte rupestre en cueva de la 

Arqueológica, 9:13-36. Neotropical, 30: 57-67. Vázquez, O., and Lorenzo, L. (forthcoming). The role of humans on Greater Antillean

Orr, R.T. and Silva Taboada G. 1960. A new species of bat of the genus Antrozous from Cuba. land vertebrate extictions: new insights from Cuba.

Pajón, J.M. 2012. Paleoclimas y paleohuracanes en el Gran Caribe. Potencialidades de investigación-cooperación científica. LASA, San Francisco May 23-27.

1618 Patzkowsky, M.E. and Holland, S.M. 2012. Stratigraphic Paleobiology: Understanding the Distribution of Fossil Taxa in Time and Space. University of Chicago Press, Chicago,

1621 Pereira, M.J.R., Marques, J.T., and Palmeirim, J.M. 2010. Vertical stratification of bat assemblages in flooded and unflooded Amazonian forests. Current Zoology, 56:469-478.

1623 Pérez Orozco, L., González Arestuche, L.R., Orihuela León, J., and Viera Muñoz, R. 2017. 
Matanzas en el Visor del Tiempo. Editorial Boloña, La Habana.

1625

1626

1627

1628

1629

1630

1631

1632

1633

1634

1635

1636

1637

1638

1639

1640

1641

1642

1643

1644

1645

1646

Peros, M.C., Reinhardt, E.G., Schwarcz, H.P. and et al. 2007. High-resolution paleosalinity reconstruction from Laguna de la Leche, north coastal Cuba, using $\mathrm{Sr}, \mathrm{O}$, and C isotopes. Palaeogeography, Palaeoclimatology, Palaeoecology, 245:535-550.

Peros, M., Gregory, B. Matos, F., Reinhardt, E., and Desloges J. 2015. Late-Holocene record of lagoon evolution, climate change, and hurricane activity from southeastern Cuba. The Holocene, 25:1483-1497.

Peterson, O.A. 1917. Report upon a fossil material collected in 1913 by the Messrs. Link in a cave in the Isle of Pines. Annals of the Carnegie Museum, 11:359-361.

Ramsey, C.B. 2017. OXCAL-4.3.2: https://c14.arch.ox.ac.uk/oxcal/OxCal.html.

Reid, R.E.B, Greenwald, E.N., Wang, Y., and Wilmers C.C. 2013. Dietary niche partitioning by sympatric Peromyscus boylii and P. californicus in a mixed evergreen forest. Journal of Mammalogy, 94:1248-1257.

Remsen, J.V., Schirtzinger, E.E., Ferraroni, A.., and Silveira, L.F. 2013. DNA-sequence data require revision of the parrot genus Aratinga (Aves: Psittacidae). Zootaza, 3641:296-300.

Restrepo-Cardona, J.S., Marín, D., Sánchez-Bellaizá, D.M., Rodriguez-Villamil, D.R., Berrio, S. Vargas, L., and Mikkola, H. 2018. Diet of Barn owl (Tyto alba), Spectacled owl (Pulsatrix perpicillata) and Rufous-Banded owl (Strix albitarsis) in the Western Andes of Columbia. Ornitología Neotropical, 29:193-198.

Rex, K., Michener, R., Kunz T.H., and Voight, C.C. 2011. Vertical stratification of Neotropical leaf-nosed bats (Chiroptera: Phyllostomidae) revealed by stable carbon isotopes. Journal of Tropical Ecology, 27:211-222.

Rivero, M. and Arredondo, O. 1991. Paralouatta varonai, a new Quaternary platyrrhine from 
Cuba. Journal of Human Evolution, 21:1-11.

1648

1649

1650

1651

1652

1653

1654

1655

1656

1657

1658

1659

1660

1661

1662

1663

1664

1665

1666

1667

1668

1669

Rodríguez-Schettino, L., Mancina, C.A., and Rivalta González, V. 2013. Reptiles of Cuba:

Checklist and Geographic Distributions. Smithsonian Herpetological Information Service, 144:1-92.

Rzebik-Kowalska, B. and Woloszyn B.W. 2012. New data on Nesophontes subfossil populations from Cuba and Isla de la Juventud (Cuba). N. Jb. Geol. Palaont. Abh., 263/2:155-166.

Salgado, E.J., Calvache, D.G., MacPhee, R.D.E., and Gould, G.C. 1992. The monkey caves of Cuba. Cave Sciences, 19:25-28.

Semken, H.A. Jr., Graham, R.W., and Stafford Jr., T.W. 2010. AMS14C analysis of Late Pleistocene non-analog faunal component from 21 cave deposits in southeastern North America. Quaternary International, 217:240-255.

Silva Taboada, G. 1974. Fossil Chiroptera from cave deposits in central Cuba, with a description of two new species (genera Pteronotus and Mormoops) and the first West Indian record of Mormoops megalophylla. Acta Zoologica Cracoviensia, 19:33-73.

Silva Taboada, G. 1976. Historia y actualización taxonómica de algunas especies antillanas de murciélagos de los géneros Pteronotus, Brachyphylla, Lasiurus, y Antrozous. Poeyana, $153: 1-24$.

Silva Taboada, G. 1979. Los Murciélagos de Cuba. Editorial Academia, La Habana.

Silva Taboada, G. and Vela Rodríguez, H. 2009. Actualización taxonómica y distribucional de los murciélagos de Cuba (1). El Explorador, 61: 1-5.

Silva Taboada, G., Suárez, W., and Díaz-Franco, S. 2007. Compendio de los Mamíferos terrestres autóctonos de Cuba vivientes y extinguidos. Ediciones Boloña, La Habana. 
Silva, A.G., Gaona O., and Medellín, R.A. 2008. Diet and trophic structure in a community of fruit-eating bats in lacandon forest, México. Journal of Mammalogy, 89:43-49

Simmons, N.B. 2005. Order Chiroptera. In Wilson, D.E. and Reeder, D.M. (eds), Mammal species of the world: A Taxonomic and Geographic reference, $3^{\text {rd }}$. ed. Smithsonian Institution Press, Washington D.C.

Shipman, P. 1981. Life History of a Fossil: An Introduction to Taphonomy and Paleocology. Harvard University Press, Cambridge.

Short, L.L. 1965. Variation in West Indian Flickers (Aves: Colapters). Bulletin of the Florida State Museum, 10:1-42.

Soto-Centeno, J.A., Phillips, D.L., Kurta, A., and Hobson, K.A. 2014. Food resource partitioning in nectar feeding bats on Puerto Rico. Journal of Tropical Ecology, 30:359-369.

Soto-Centeno, J.A., O'Brien, M., and Simmons, N.B. 2015. The importance of late Quaternary climate change and karst on distributions of Caribbean mormoopid bats. American Museum Novitates, 3847:1-32.

Stafford, T.W., Semken, H.A., Graham, R.W., Klippel, W.F., Markova, A., Smirnov, N.G., and Southon, H. 1999. First accelerator mass spectrometry 14C dates documenting contemporaneity of nonanalog species in the late Pleistocene mammal communities. Geology, 27:903-906.

Steadman, D.W., and et al. 2005. Asynchronous extinction of late Quaternary sloths on continents and islands. Proceedings of the National Academy of Science, 102:1176311768.

Stoetzel, E., Royer, A., Cochard, D., Lenoble, A. 2016. Late Quaternary changes in bat 
paleodiversity and paleobiogeography under climatic and anthropogenic pressure: new insights from Marie-Galante, Lesser Antilles. Quaternary Science, 143:150-174.

Suárez, W.S.1998. Lista preliminar de las aves cubanas depredadas por Tyto alba furcata (Aves: Tytonidae). El Pitirre, 11:12-13.

Suárez, W.S. 2001. A reevaluation of some fossils identified as vultures (Aves: Vulturidae) from Quaternary cave deposits of Cuba. Caribbean Journal of Science, 37:110-111. Quaternary cave deposit in Cuba. Caribbean Journal of Science, 39:371-377.

1700

1701

1702

1703

1704

1705

1706

1707

1708

1709

1710

1711

1712

1713

1714

Suárez, W.S. and Olson, S.L. 2015. Systematics and distribution of the giant fossil barn owls of the West Indies (Aves: Strigiformes: Tytonidae). Zootaxa, 4020:533-553.

Tylor, A.M. and Goldring, R. 1993. Description and analysis of bioturbation and ichnofabric. Journal of the Geological Society, 150:141-148.

Turvey, S.T. and Fritz, S.A. 2011. The ghosts of mammals past: biological and geographical patterns of global mammalian extinction across the Holocene. Philosophical Transactions of the Royal Society B, 366: 2564-2576. doi:10.1098/rstb.2011.0020.

Vaughan, T.A., and Bateman, G.C. 1970. Functional morphology of the forelimb of Mormoopid bats. Journal of Mammalogy, 51:217-235

Velarde, E., Avila-Flores, R., and Medellín, R.A. 2007. Endemic and introduced vertebrates in the diet of the Barn Owl (Tyto alba) on two islands in the Gulf of California, Mexico. The Southwestern Naturalist, 52:284-290.

Vento Canosa, E. 1985. Nuestra sociedad y la defensa de la patria (capitulo 32), p. 299-304. In Nuñez Jiménez, A. 1990. Medio Siglo Explorando a Cuba (Tomo I). Imprenta Central de las FAR, La Habana. 
1715 Viera, R.A. 2004. Aportes a la quiropterofauna nacional. 1861 Revista de Espeleología y

1716

1717

1718

1719

1720

1721

1722

1723

1724 Figures

1725

1726

1727

1728

1729 Cueva del Túnel, Mayabeque. 4, Cuevas Blancas, Mayabeque. 5, Cueva del Gato Jíbaro,

1730

1731

1732

1733

1734

1735

1736

1737

Arqueología, 5:21-23.

Viñola López, L.W., Garrido, O.H., and Bermúdez A. 2018. Note on Mesocapromys sanfelipensis (Rodentia: Capromyidae) from Cuba. Zootaxa, 4410:164-176.

Woloszyn, B. W. and Silva Taboada, G. 1977. Nueva especie fósil de Artibeus (Mammalia: Chiroptera) de Cuba, y tipificación preliminar de los depósitos fosilíferos Cubanos contentivos de mamíferos terrestres. Poeyana, 161:1-17.

\section{CAPTIONS}

Figure 1: Location of Loma del Palenque and Cueva de los Nesofontes in northwestern Cuba.

The asterisks $(*)$ indicate a flat scarp at $\sim 260 \mathrm{~m}$ where red-clay soils have formed, are the main source of the allochthonous sediment inside the cave. Other important localities are indicated: $\mathbf{1}$, Cueva El Abrón, GEDA, and Mono Fósil, Pinar del Río. 2, Cueva de Paredones, Artemisa. 3,

Matanzas. 6, Cueva Calero, Matanzas. 7, Breas de San Felipe, and Cuevas de Hato Nuevo,

Matanzas. 8, Cueva de los Masones and Jagüey, Trinidad, Las Villas. 9, Cueva del Indio,

Daiquirí, Santiago de Cuba.

Figure 2: Cueva de los Nesofontes indicating geological, stratigraphic and deposition features. 1, a gallery with main doline or sinkhole indicating areas of fauna collection: A-D pertain to the upper deposits described here. E-F are two test pits conducted on the lower level. G is the source location for the ${ }^{14} \mathrm{C}$-dated domestic dog mentioned in the text. 2, the upper area where the main test pits described are located: A is the test pit from 1985, B-C was dug between April 1995 and 
1738 December 2003. The cross-section a-a' is the approximate sources for the stratigraphic profiles

1739 illustrated in following figures. 3, cross-section (indicated b-b' on 1). Arrows indicate areas of

1740 sediment and raptor-derived pellet deposits and roost.

1741 Figure 3: Stratigraphic profile composite, including all test pit excavations from cross-section a-

1742 a' illustrated in Figure 2. 1, indicates a graphic correlation of the stratigraphic units (A-I) and

1743 their lenses (e-f). The figure below shows the southern wall profile of the excavation of 1985

1744 (A), whereas A, on the extreme lower right, shows the east wall profile. Profiles B-C pertains to

1745 the other test pits. Each Roman numeral indicates the arbitrary $10 \mathrm{~cm}$ intervals.

1746 Figure 4: Lateral profile of test pit D with source radiocarbon dates, oxygen stable isotopes and

1747 NTAXA diversity by intervals. The fauna and multi-proxy analyses described in the text are

1748 from this excavation. The red lines indicate the major disconformities/erosional surfaces.

1749 Figure 5: Aves. Fossil and subfossil bird remains from test pit D. 1, Cathartes aura maxilla in

1750 lateral and dorsal view. 2, proximal tibiotarsus of Colaptes cf. fernandinae. 3, the humerus of

1751 Psittacara eups. 4, distal coracoid of Progne cf. cryptoleuca or subis. 5, humerus of Tachycineta

1752 bicolor (FLMN 17685). 6, humerus of Tachycineta cf. bicolor. 7, humerus of Geotrygon cf.

1753 chrysia. 8, humerus of Sphyrapicus varius. 9, humerus of Melanerpes superciliaris. 10,

1754 tarsometatarsus (left) and humerus of Margarobyas lawrencii. 11, humerus of Saurothera

1755 merlini. Each scale bar represents $10 \mathrm{~mm}$.

1756 Figure 6: Comparison of tentatively identified Nesophontes cf. longirostris specimens (1-3

1757 skulls, 3 is the holotype AMNH 17626, 7-8 tentative mandibles) and Nesophontes major (4-6).

1758 Small lines indicate discrete characters discussed in the text. Note the more elongated rostrum

1759 and wider gap between upper premolars in N. longirostris and the crowding in N. major. 
1760 Figure 7. Plot graph of principal component analysis (PCA), above, shows the loading of root 1

1761 and 2 for several Nesophontes species. Note the distinctive separation of $N$. longirostris from $N$.

1762 major, N. micrus and N. edithae, used as an outgroup, ( $<<0.10)$. Plot graph from 2-Way

1763 ANOVA with Tukey's post hoc test $(\mathrm{p}<0.05)$, indicating the quantitative range of variation in

1764 the maximum length between posterior canine to anterior third maxillary premolar in N. micrus,

$1765 \quad$ N. major, N. longirostris from Pit D, and N. longirostris holotype.

1766 Figure 8: Bats. 1, left hemimandible of Artibeus anthonyi (no, 1663, lower Level III). 2, the

1767 incomplete skull of Phyllops vetus, on the ventral view (no. 37, Level II). Both specimens

1768 radiocarbon-dated $\left({ }^{14} \mathrm{C}\right) .3$ hemimandibles of Antrozous koopmani (no. 20, 75, 1429, 1430 from

1769 Levels II and IV, also ${ }^{14} \mathrm{C}$ dated). The scale bar $=10 \mathrm{~mm}$.

1770 Figure 9: Plant, invertebrate and reptile remains. 1-1.2, Anolis cf. chamaleolis (no. 606), scale

1771 bar $10 \mathrm{~mm}$ (Level I). 2, unidentified insect extremity $1 \mathrm{~mm}$ (Level IV). 3, photid fly pupa,

1772 scale $10 \mathrm{~mm}$ (Level IV). 4-5, plant seeds, scale $5 \mathrm{~mm} .6$ fungus spore (?), scale $\sim 50 \mu \mathrm{m}$ (All

1773 from level II and III). 7-8, seeds, scale $5 \mathrm{~mm}$. 9, leaf fragment, scale $\sim 50 \mu \mathrm{m}$ (Level II). 10 plant

1774 spores, likely a conifer, Pinus? (Level IV), scale $\sim 50 \mu \mathrm{m}$.

1775 Figure 10: Taphonomic evidence. 1-2, images are SEM microphotographs of Nesophontes sp.

1776 tooth marks on small capromyid long bones. Note the well-rounded edges, microfractures

1777 radiating from the cortex. 3-4, show stage 3 weathering on an $N$. major left hemimandible (left)

1778 and stage IV on another (right). 5, shows microscopic striae and notching associated with insect

1779 scavenging on the bone. The main depression is likely a tooth mark made on the bone while still

1780 fresh (note the gradual peeling features). 6, is an A. jamaicensis adult skull with evidence of

1781 raptor predation and digestion (corrosion). 
1782 Figure 11: Rarefaction curve of Cueva de los Nesofontes doline test pit D (Levels I-IV) in

1783 relation to other Cuban deposits (A-G). A is Cueva GEDA, Pinar del Río. B is Cuevas Blancas,

1784 Mayabeque. D is the Desmodus deposit described in Orihuela (2010). G is from Gato Jíbaro

1785 archaeological deposit described in Orihuela and Tejedor (2012).

1786 Figure 12: Carbon stable isotopes signals from Nesophontes and Artibeus spp. (from bone

1787 collagen).

1788 Figure 13: Approximation of paleoenvironment conditions through oxygen stable isotopes from

1789 Cueva de los Nesofontes test pit D, compared to other circum Caribbean deposits (modified from

1790 Curtis et al., 2001). The grey areas indicate the timeframe of our deposit and its graphical

1791 correlation to our data.

1792

1793 Tables

1794 Table 1: Stratigraphic units, levels, and chronology from Cueva de los Nesofontes, Mayabeque,

1795 Cuba. Results and source of radiocarbon-dated (AMS ${ }^{14} \mathrm{C}$ ) material with lab numbers is

1796 provided.

1797 Table 2: Results of stable isotope analysis with source material from deposits at Cueva de los

1798 Nesofontes.

1799 Table 3: Cueva de los Nesofontes fauna list, providing a number of individual specimens (NISP),

1800 the minimum number of individuals (MNI), and the number of total taxa (NTAXA) counts.

1801 Table 4: Stratigraphic distribution of taxa throughout each interval and their individual count.

1802 Grey-filled boxes indicate the presence and empty absence. A total by interval is provided.

1803 Table 5: Nesophontes craniomandibular measurements, including the specimens tentatively

1804 identified here as $N$. longirostris. All specimens are from Cueva de los Nesofontes, except two 
1805 N. longirostris (one is the AMNH holotype, and the other a specimen from Cueva del Gato

1806 Jíbaro referenced in the text). * ${ }^{*} \mathrm{p}<0.050$.

1807 Table 6: Diversity indices, evenness, dominance, and chronology for each stratigraphic interval.

1808 Overall values are not the averages of each column, but the overall index calculated for the

1809 whole fauna. $\mathrm{R}=$ recent.

1810

1811

1812

1813

1814

1815 

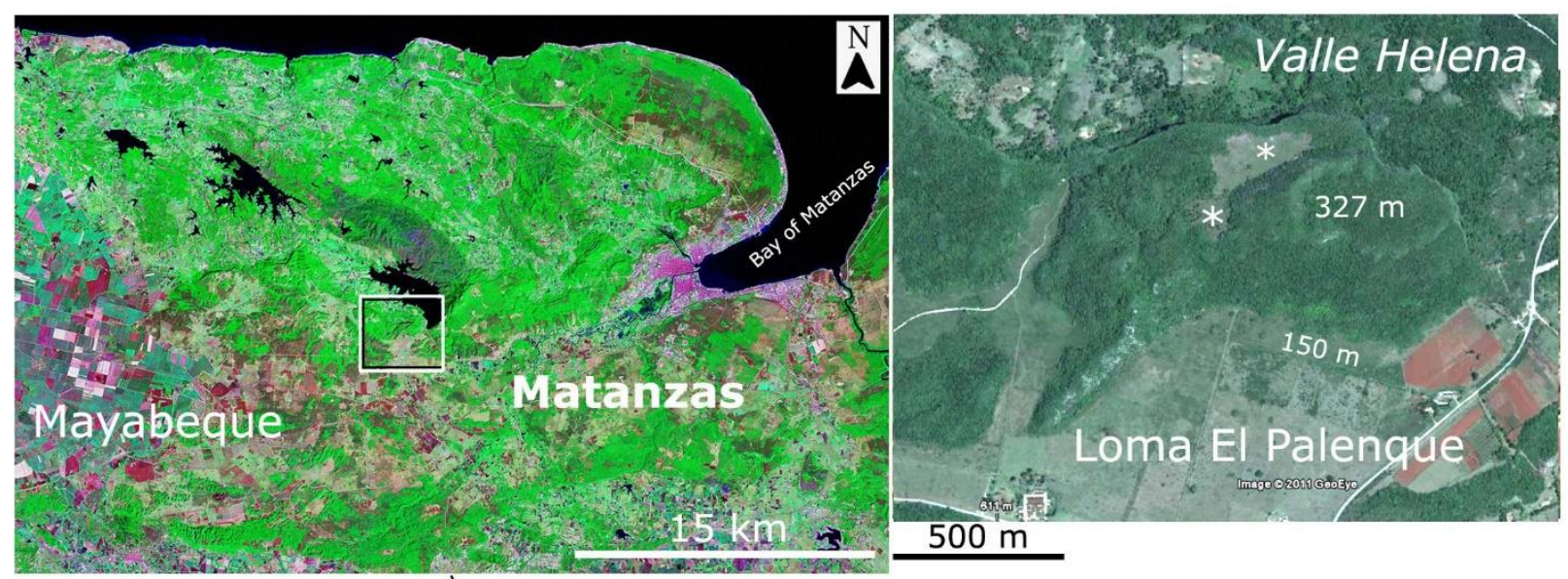
$500 \mathrm{~m}$

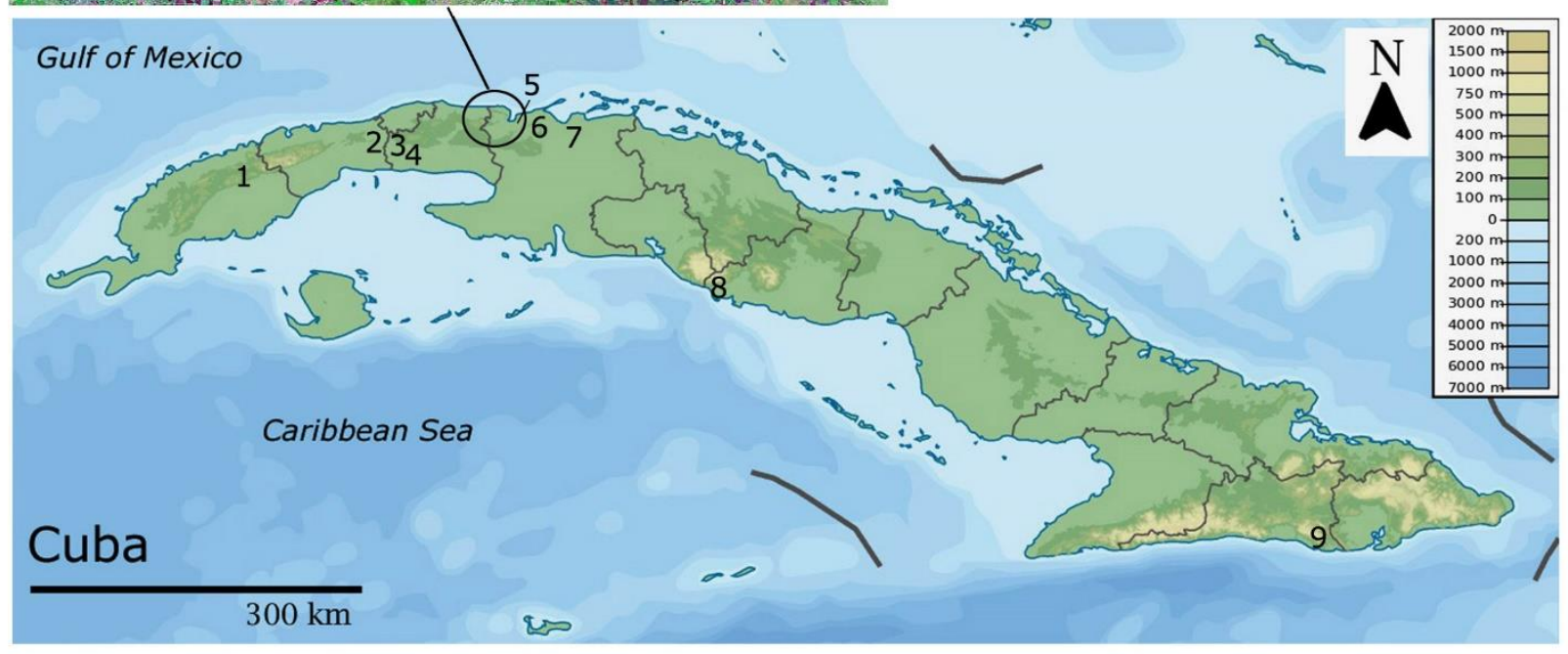

1817 Figure 1. 
bioRxiv preprint doi: https://doi.org/10.1101/2020.01.17 909663: this version posted January 17 2020. The copyright holder for this preprint (which was not certified by peer review) is the author/funder, who has granted bioRxiv a license to display the preprint in perpetuity. It is made available under aCC-BY-NC-ND 4.0 International license.
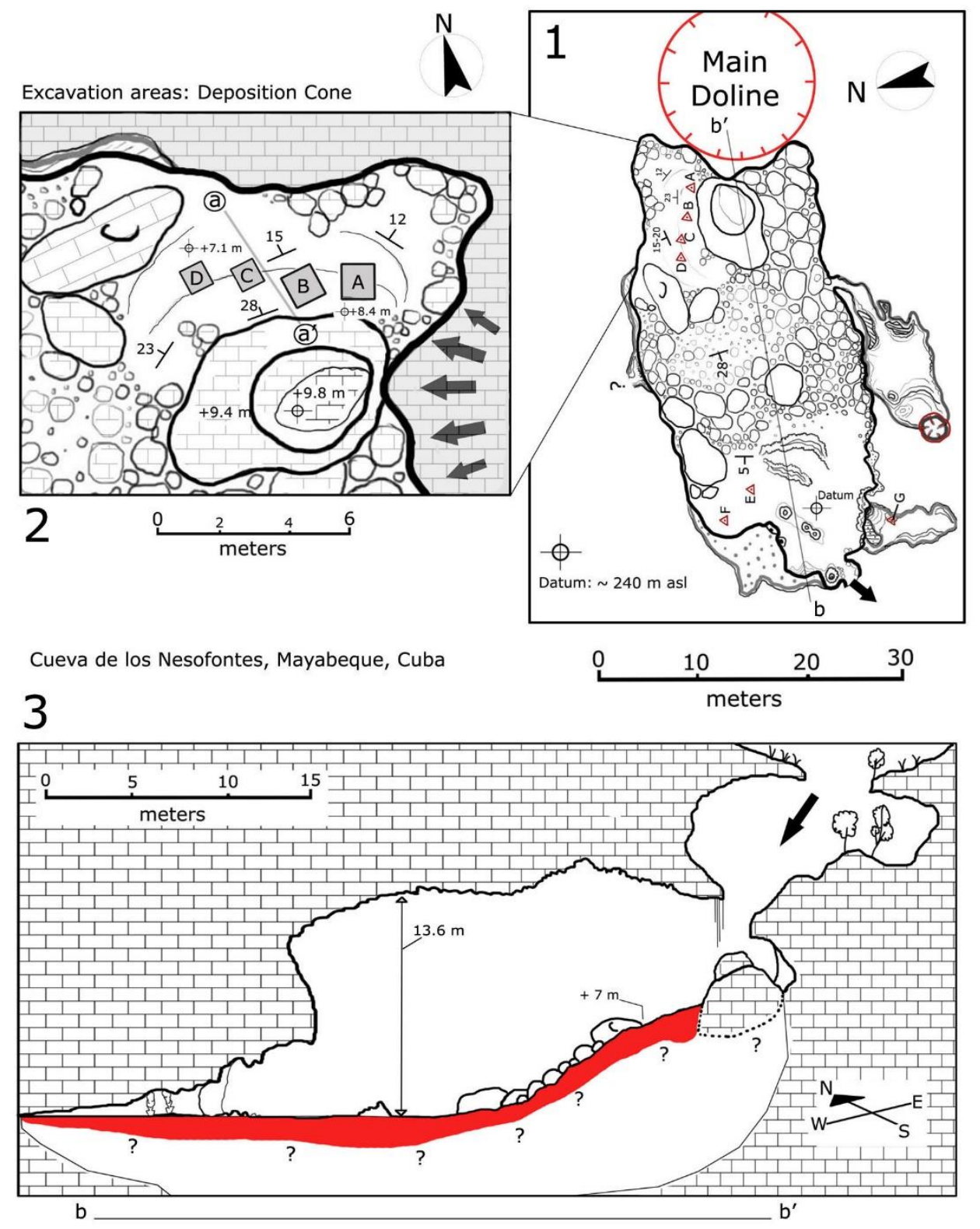

1828 Figure 2. 
bioRxiv preprint doi: https://doi.org/10.1101/2020.01.17.909663; this version posted January 17,2020 . The copyright holder for this preprint (which was not certified by peer review) is the author/funder, who has granted bioRxiv a license to display the preprint in perpetuity. It is made available under aCC-BY-NC-ND 4.0 International license.
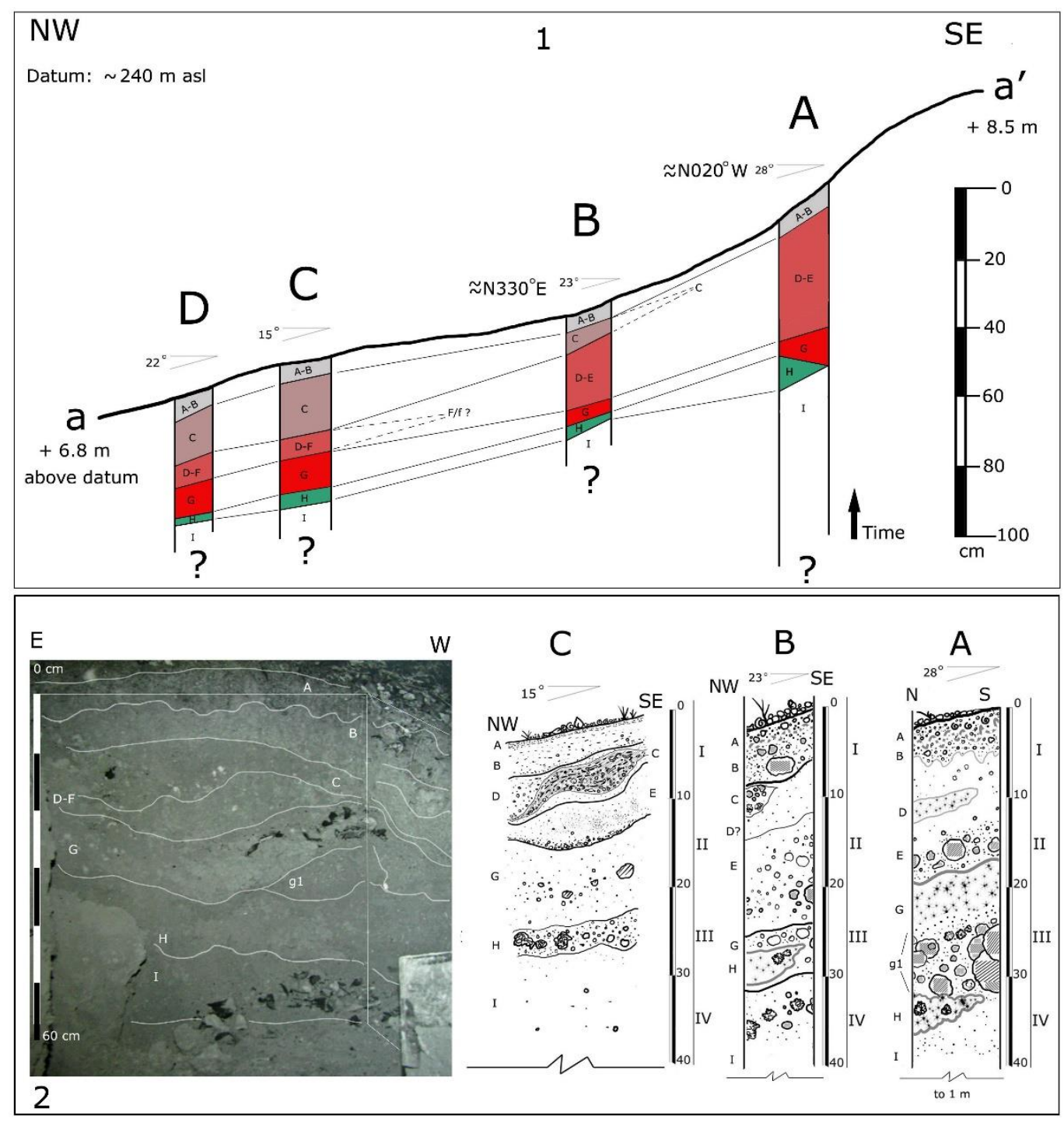

1830

1831

Figure 3.

1832

1833

1834 
bioRxiv preprint doi: https://doi.org/10.1101/2020.01.17.909663; this version posted January 17,2020. The copyright holder for this preprint (which was not certified by peer review) is the author/funder, who has granted bioRxiv a license to display the preprint in perpetuity. It is made available under aCC-BY-NC-ND 4.0 International license.

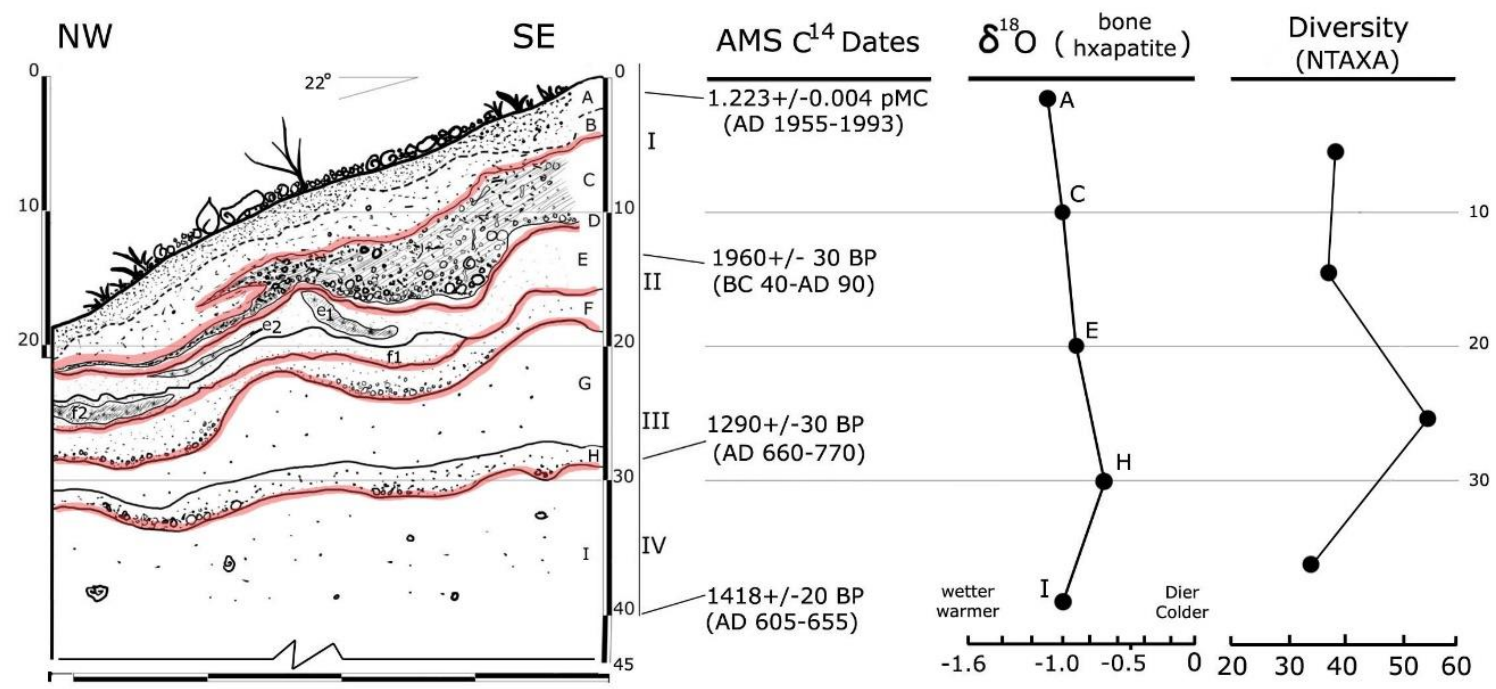

1837 Figure 4.

1838

1839

1840

1841

1842

1843

1844

1845

1846

1847

1848

1849 

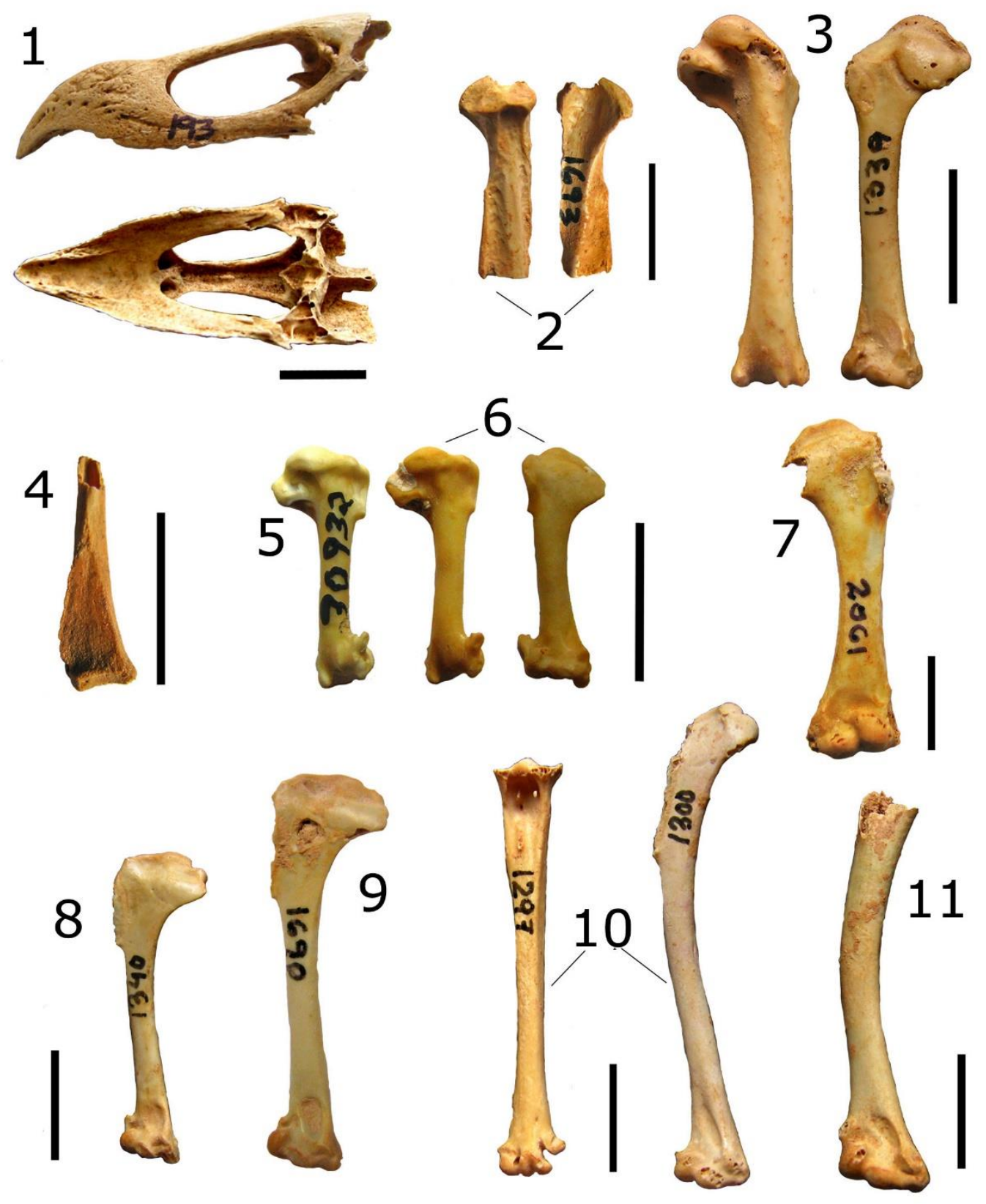

1851 Figure 5. 
bioRxiv preprint doi: https://doi.org/10.1101/2020.01.17.909663; this version posted January 17, 2020. The copyright holder for this preprint (which was not certified by peer review) is the author/funder, who has granted bioRxiv a license to display the preprint in perpetuity. It is made available under aCC-BY-NC-ND 4.0 International license.
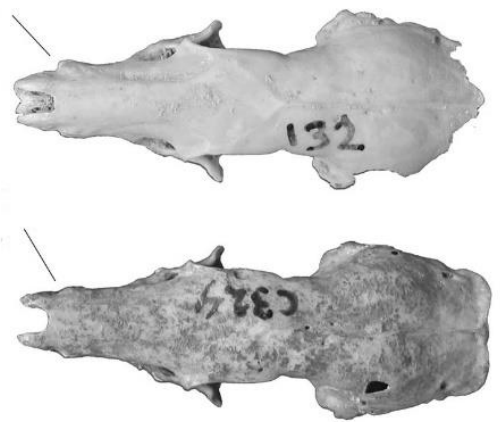

1
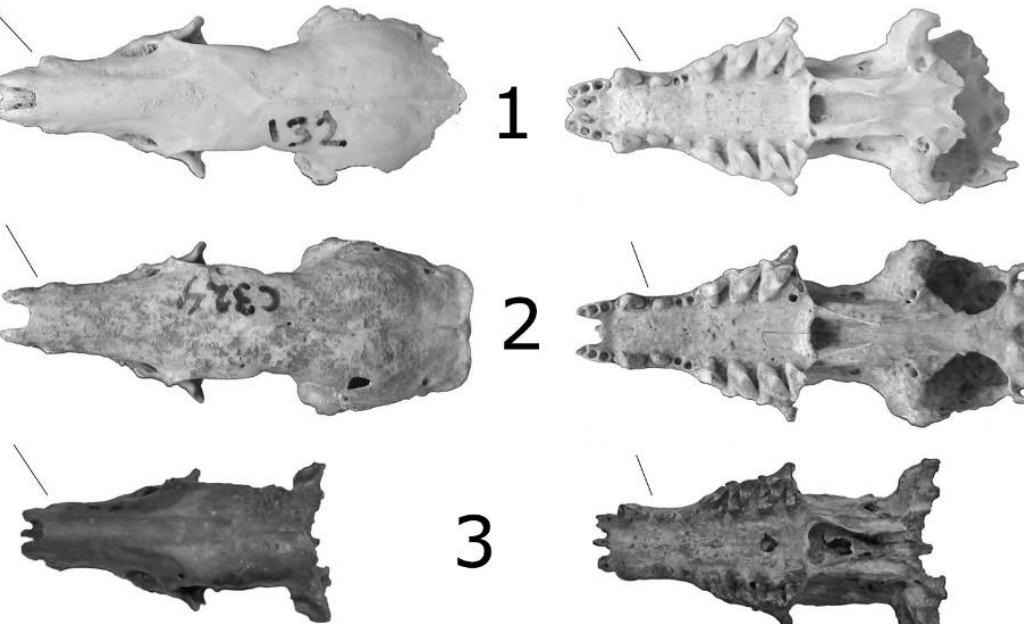

3
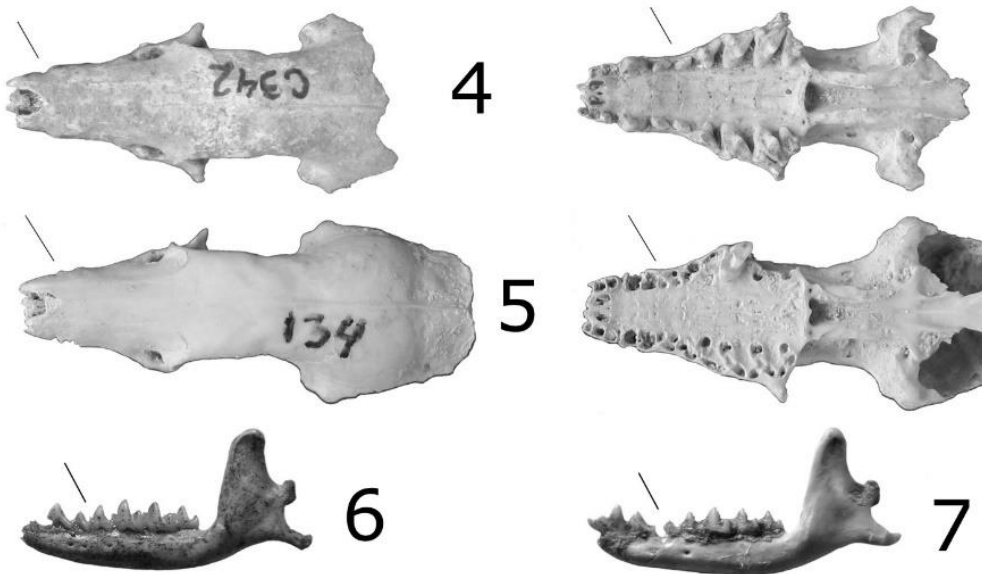
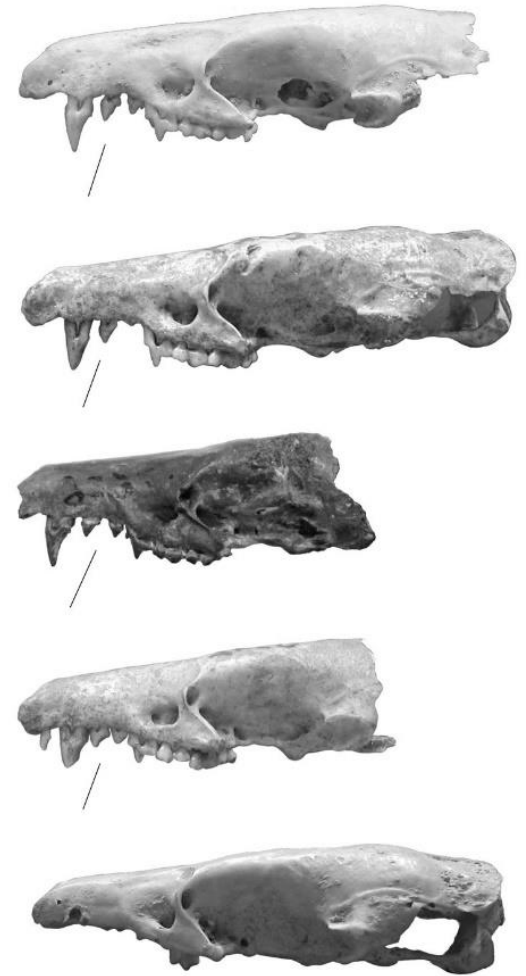

$10 \mathrm{~mm}$

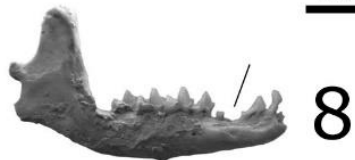

1853

Figure 6. 
bioRxiv preprint doi: https://doi.org/10.1101/2020.01.17.909663; this version posted January 17,2020. The copyright holder for this preprint (which was not certified by peer review) is the author/funder, who has granted bioRxiv a license to display the preprint in perpetuity. It is made available under aCC-BY-NC-ND 4.0 International license.

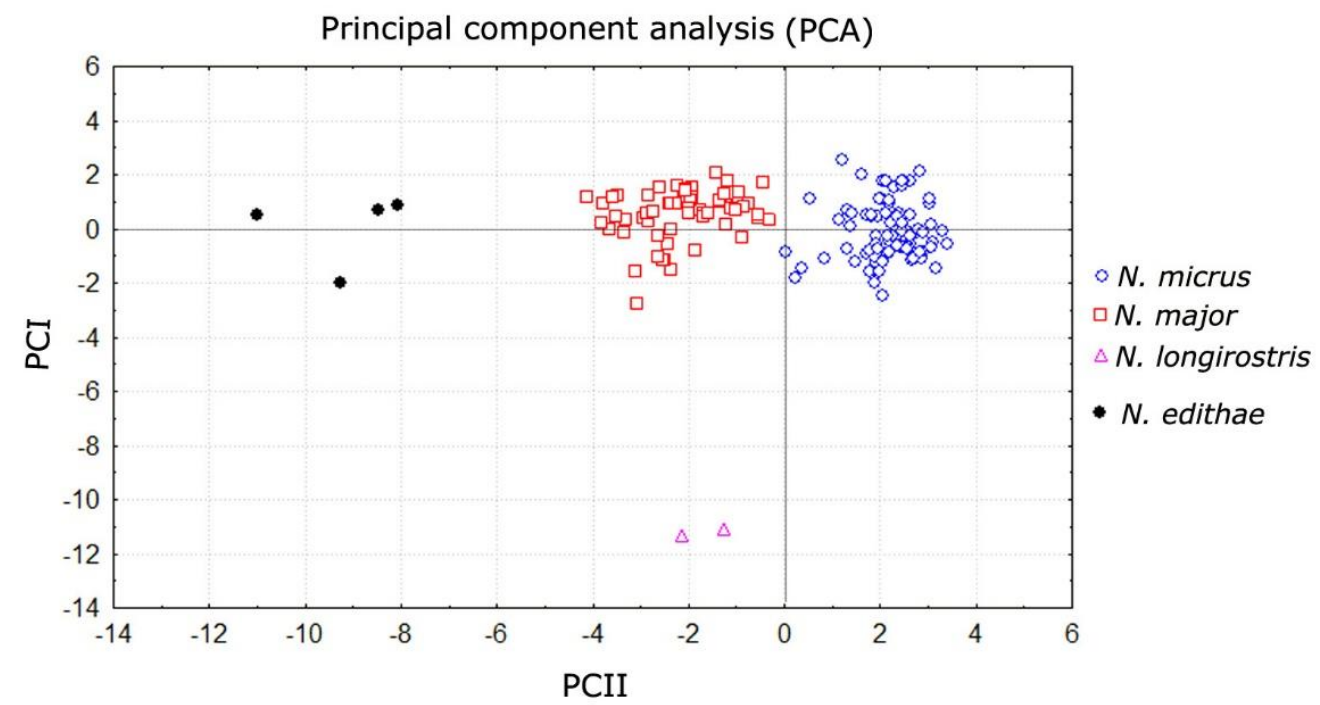

Maximum length between canine and last premolar

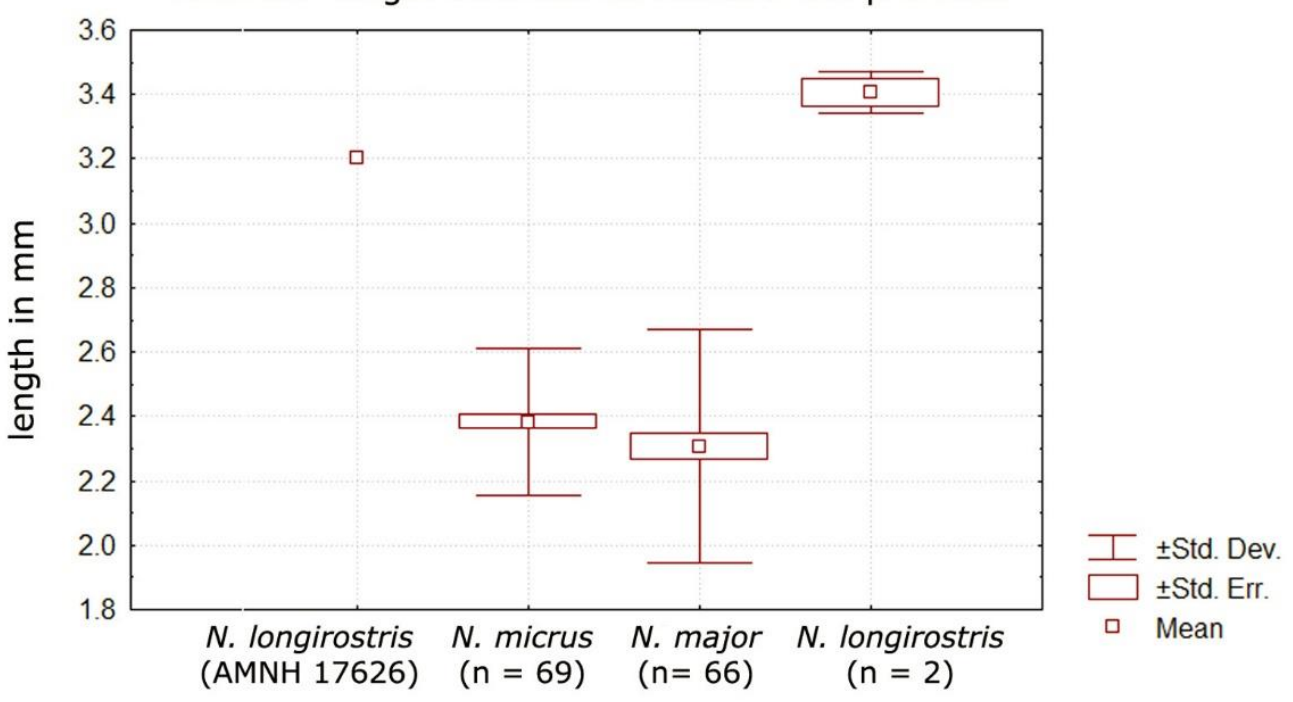

1866 Figure 7. 
bioRxiv preprint doi: https://doi.org/10.1101/2020.01.17.909663; this version posted January 17, 2020. The copyright holder for this preprint (which was not certified by peer review) is the author/funder, who has granted bioRxiv a license to display the preprint in perpetuity. It is made available under aCC-BY-NC-ND 4.0 International license.

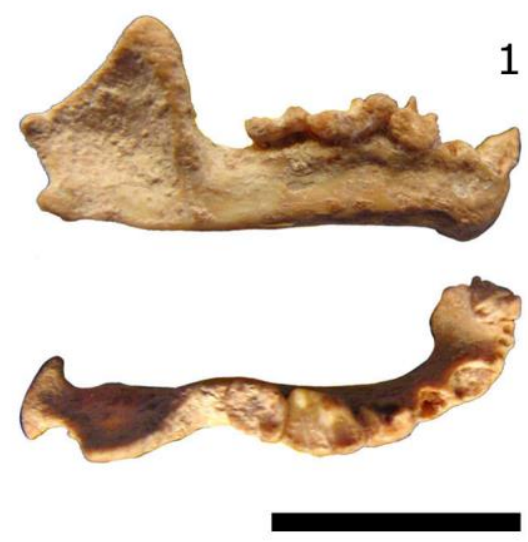

1
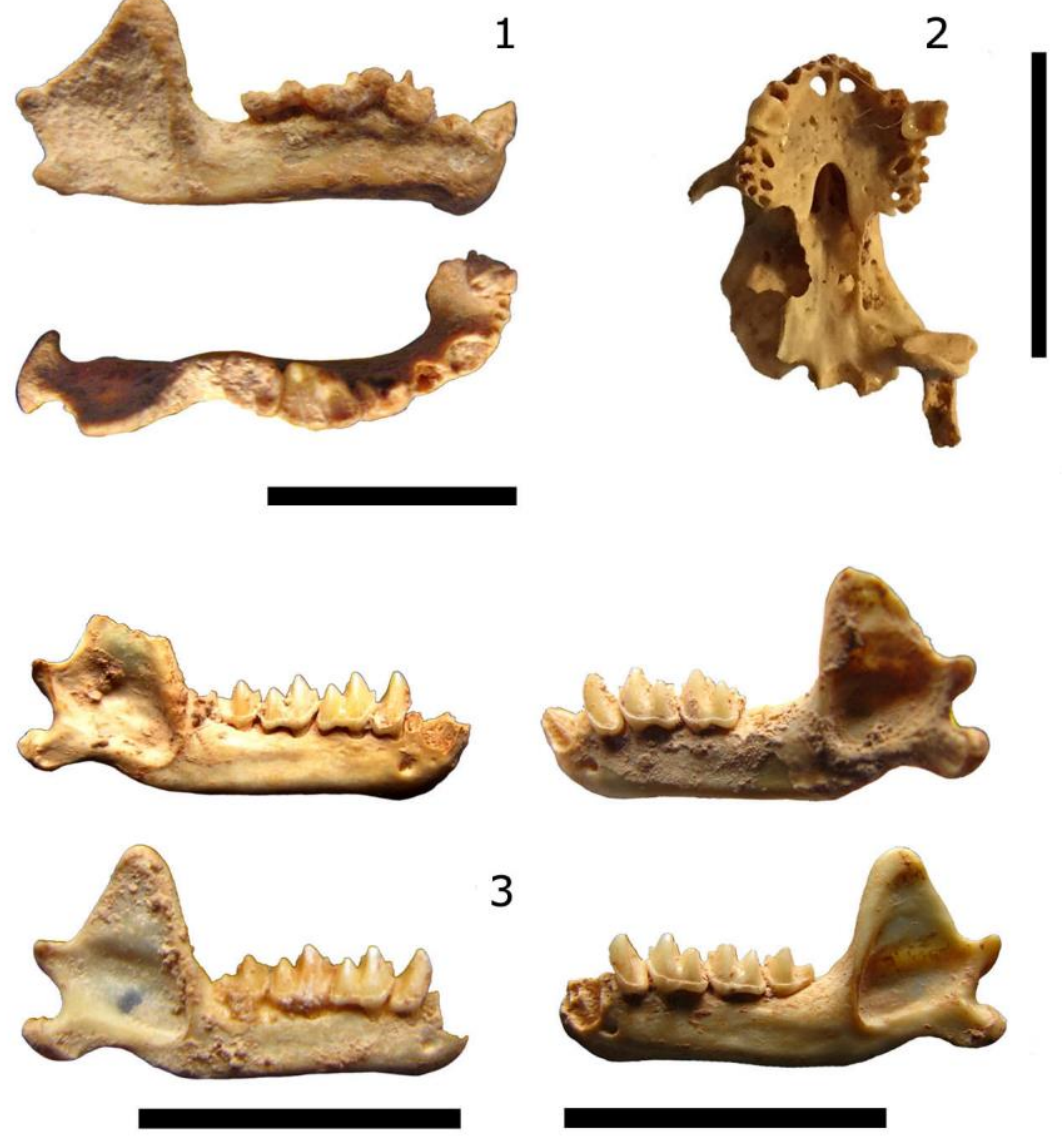

3

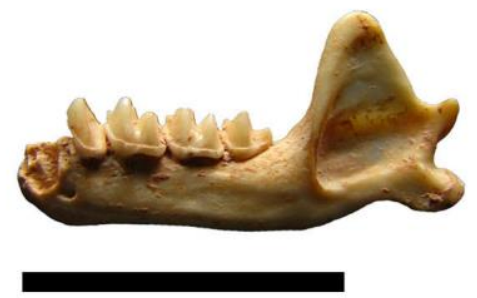

1867

1868

1869

Figure 8.

1870

1871

1872

1873

1874

1875 
bioRxiv preprint doi: https://doi.org/10.1101/2020.01.17.909663; this version posted January 17,2020 . The copyright holder for this preprint (which was not certified by peer review) is the author/funder, who has granted bioRxiv a license to display the preprint in perpetuity. It is made available under aCC-BY-NC-ND 4.0 International license.
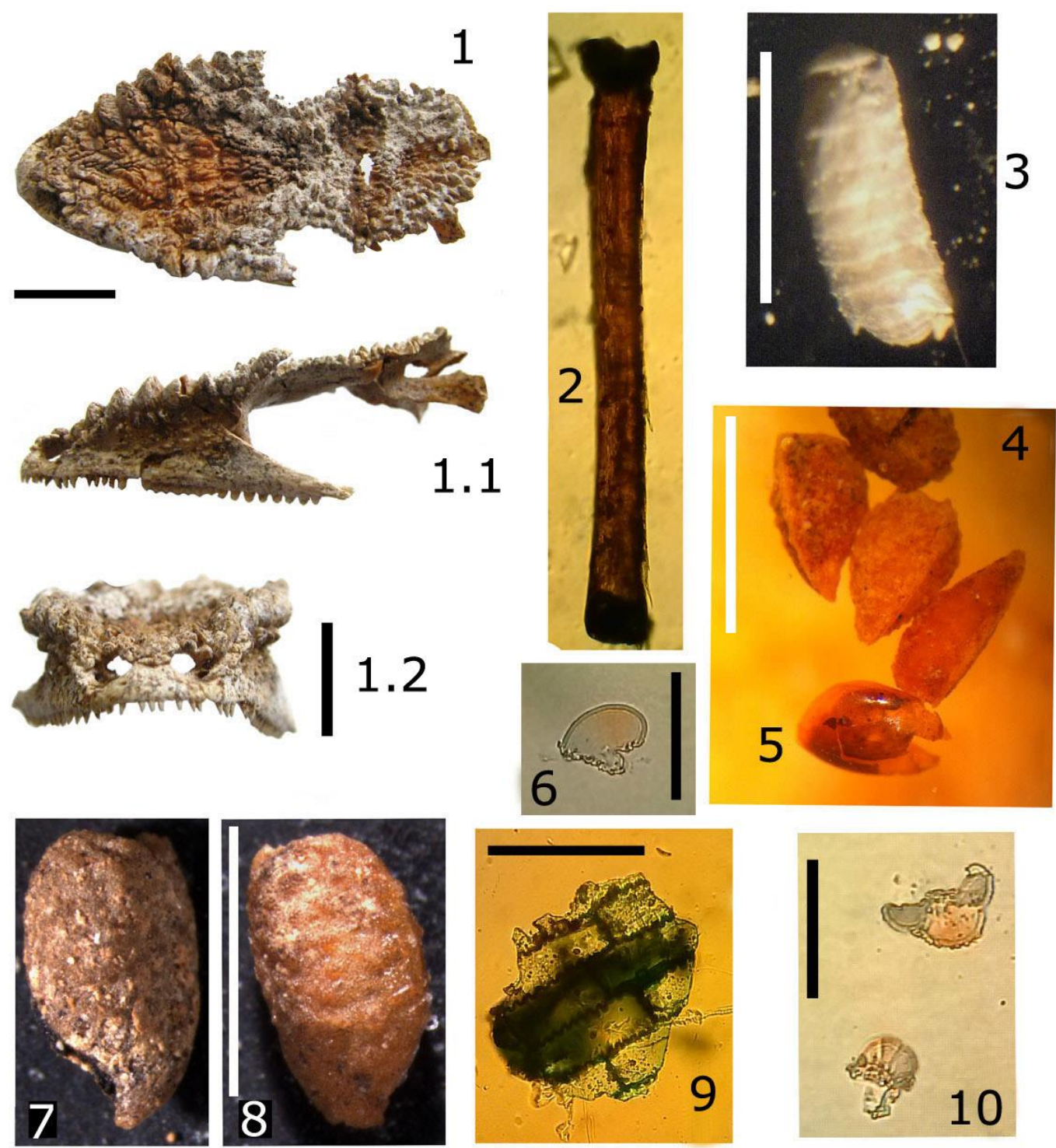

1877 Figure 9. 
bioRxiv preprint doi: https://doi.org/10.1101/2020.01.17.909663: this version posted January 17, 2020. The copyright holder for this preprint (which was not certified by peer review) is the author/funder, who has granted bioRxiv a license to display the preprint in perpetuity. It is made available under aCC-BY-NC-ND 4.0 International license.
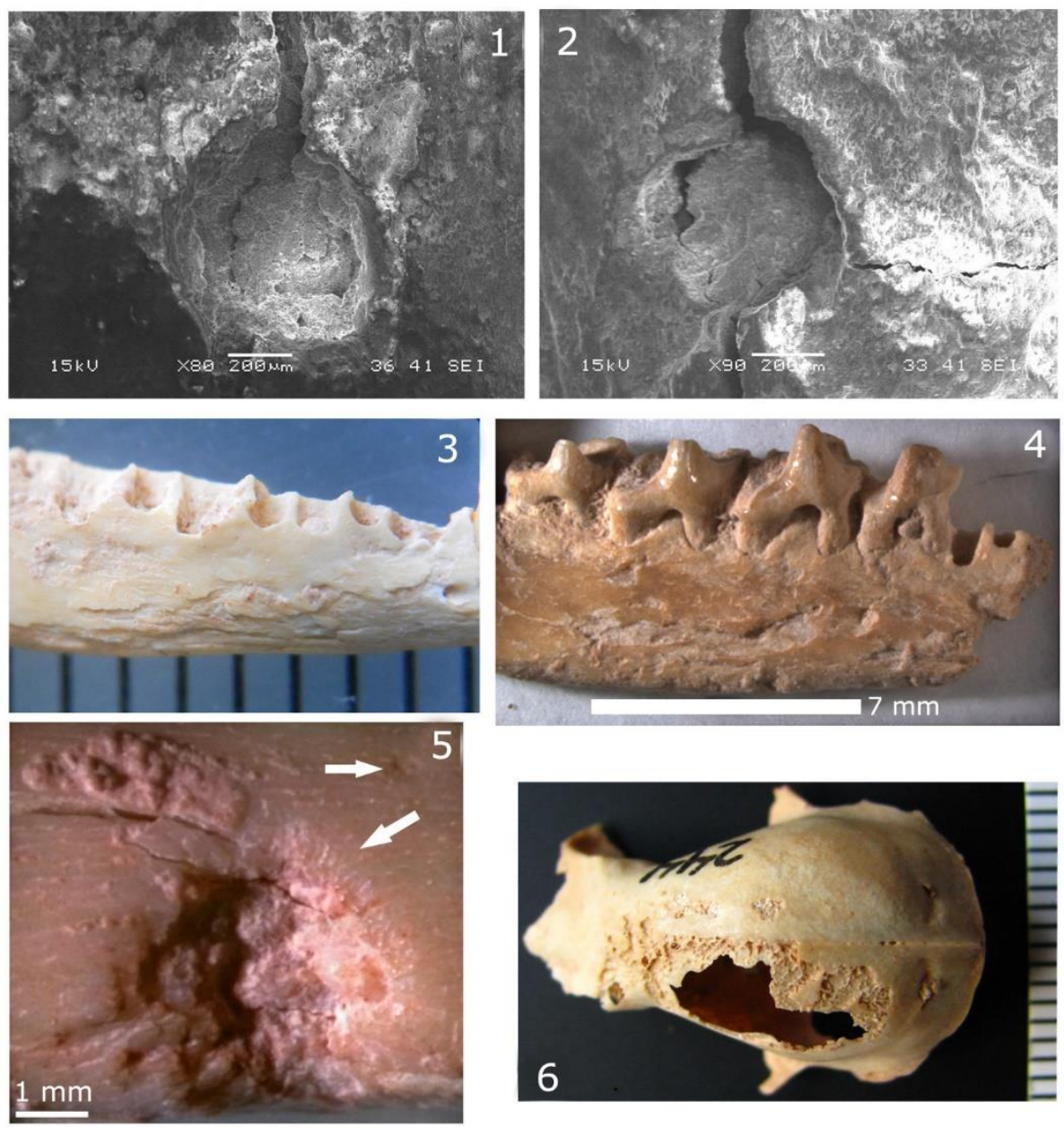

1882

1883 Figure 10.

1884

1885

1886

1887 
bioRxiv preprint doi: https://doi. org/10.1101/2020.01.17.909663; this version posted January 17,2020 . The copyright holder for this preprint (which was not certified by peer review) is the author/funder, who has granted bioRxiv a license to display the preprint in perpetuity. It is made available under aCC-BY-NC-ND 4.0 International license.

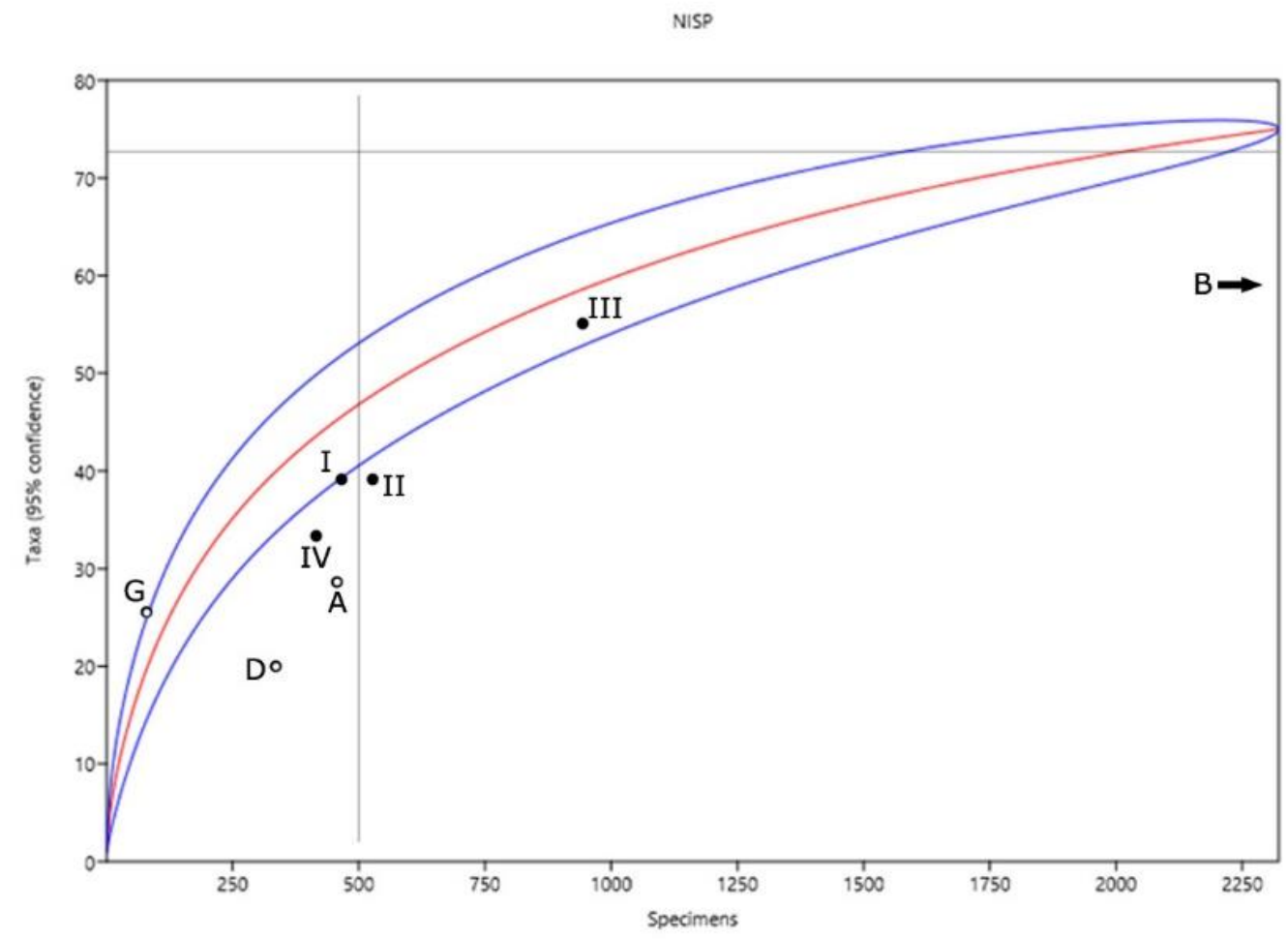

1888

1889

Figure 11.

1890

1891

1892

1893

1894

1895

1896

1897

1898

1899 
bioRxiv preprint doi: https://doi.org/10.1101/2020.01.17.909663; this version posted January 17, 2020. The copyright holder for this preprint (which was not certified by peer review) is the author/funder, who has granted bioRxiv a license to display the preprint in perpetuity. It is made available under aCC-BY-NC-ND 4.0 International license.

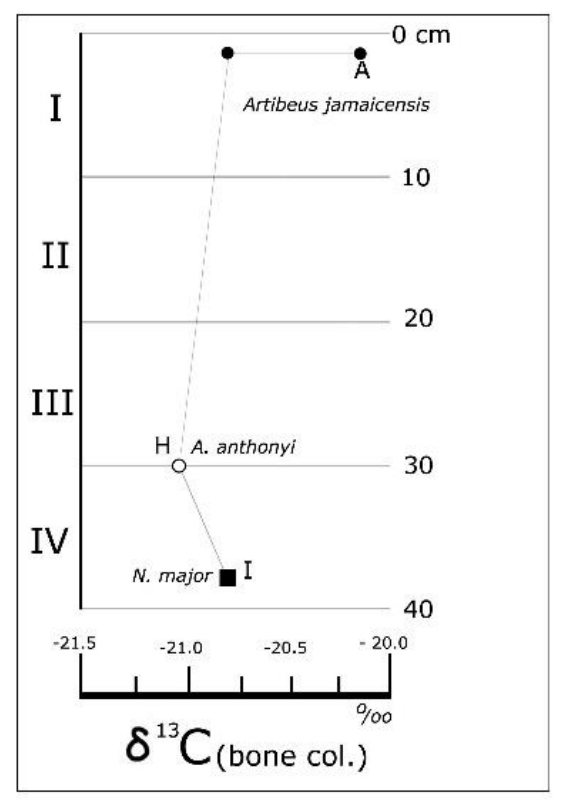

1900

1901

Figure 12.

1902

Oxygen isotopic ratios $\delta^{19} \mathrm{O}(\% \mathrm{VPDB})$

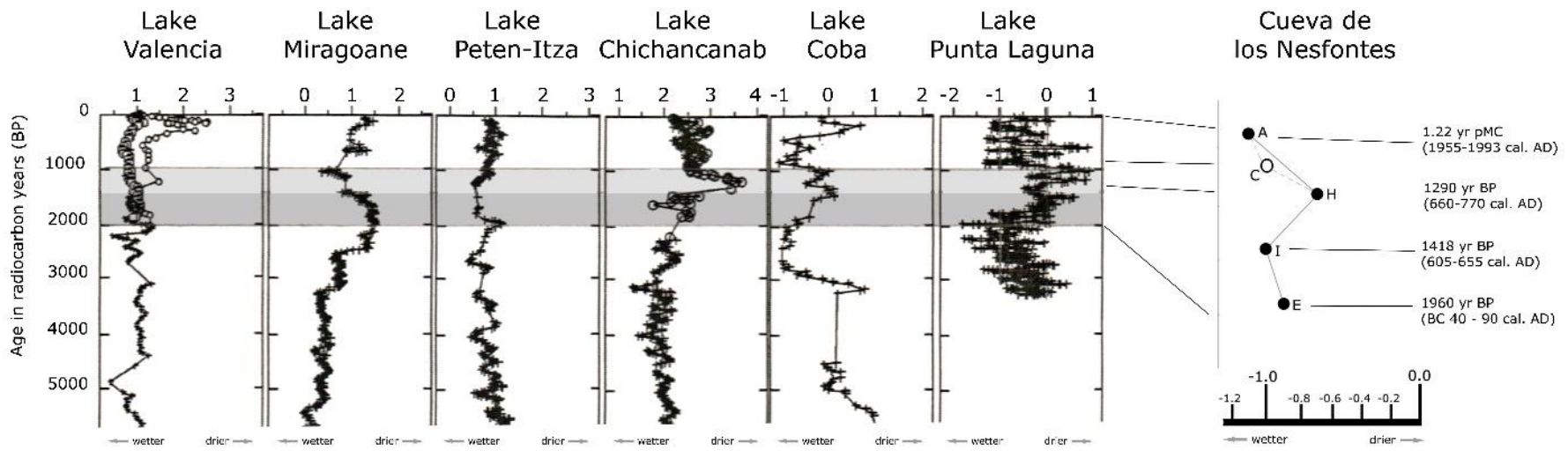

\section{Figure 13.}


bioRxiv preprint doi: https://doi.org/10.1101/2020.01.17.909663; this version posted January 17, 2020. The copyright holder for this preprint (which was not certified by peer review) is the author/funder, who has granted bioRxiv a license to display the preprint in perpetuity. It is made available under aCC-BY-NC-ND 4.0 International license.

1910 Table 1.

\begin{tabular}{|c|c|c|c|c|c|c|c|}
\hline Interval level & Depth (cm) & Strat. Unit & Granulometry & ${ }^{14} \mathrm{C}$ Cal yrs BP & Cal yrs & Source & Number \\
\hline 1 & $0-9 \mathrm{~cm}$ & $A$ & $40.9 \%$ med sand & $1.223 \pm 0.004 \mathrm{pMC}$ & 2б: $1955-1993 \mathrm{AD}$ & Artibeus jamaicensis humerus & ICA 15B/0116 \\
\hline II & $10-19 \mathrm{~cm}$ & $\mathrm{E}$ & $>50 \%$ med san & $1960 \pm 30 \mathrm{BP}$ & $2 \sigma: B C 40-90 A D$ & Phyllops vetus skull & ICA 18B/0845 \\
\hline III & $20-29 \mathrm{~cm}$ & $\mathrm{H}$ & $52.4 \%$ fine sand & $1290 \pm 30 \mathrm{BP}$ & $2 \sigma: 660-770 \mathrm{AD}$ & Artibeus anthonyi dentary & ICA 14B/1102 \\
\hline IV & $30-45 \mathrm{~cm}$ & 1 & $49.8 \%$ fine sand & $1418 \pm 20 \mathrm{BP}$ & $2 \sigma: 605-655 A D$ & Nesophontes major dentary & Beta 392022 \\
\hline & & & & & & & \\
\hline 1 & $0-2 \mathrm{~cm}$ & $n / a$ & Fine sand/detritus & $115.9 \pm 0.6 \mathrm{pMC}$ & $2 \sigma: 1957-1993 A D$ & A. jamaicensis scapula & Beta 210380 \\
\hline 1 & Surface & $\mathrm{n} / \mathrm{a}$ & cave floor & $1.014 \pm 0.004 \mathrm{pMC}$ & $2 \sigma: 1955-1956 \mathrm{AD}$ & Canis lupus familiaris vertebra & ICA15B/0115 \\
\hline
\end{tabular}

1911

1912

1913 Table 2.

\begin{tabular}{|c|c|c|c|c|c|c|}
\hline Interval & Depth $(\mathrm{cm})$ & Strat. Unit & $\delta^{18} 0 \_a p t$ (dental) & $\delta^{13} \mathrm{C}_{-}$ & Source & Number \\
\hline 1 & 0 & $\mathrm{~A}$ & -1.1 & -9.9 & A. jamaicensis skull & USF 15314 \\
\hline I & 0 & A & $n / a$ & $-20.1 \mathrm{col}$. & A. jamaicensis humerus & ICA 15B/0116 \\
\hline $\mid-11$ & $\sim 14$ & c & -1 & -8.1 & A. jamaicensis humeri & USF 15316 \\
\hline II & $\sim 18$ & $\mathrm{E}$ & -0.9 & -10 & A. jamaicensis skull & USF 15313 \\
\hline III-IV & $29-31$ & $\mathrm{H}$ & -0.7 & -11.0 & A. anthonyi dentary & USF 15315 \\
\hline III-IV & $29-32$ & $\mathrm{H}$ & $n / a$ & $-21.1 \mathrm{col}$. & A. anthonyi dentary & ICA 14B/1102 \\
\hline IV & $>32$ & 1 & -1 & $-20.7 \mathrm{col}$. & N. major dentary & Beta 392022 \\
\hline 1 & $0-2 \mathrm{~cm}$ & $\mathrm{n} / \mathrm{a}$ & $\mathrm{n} / \mathrm{a}$ & $-20.7 \mathrm{col}$. & A. jamaicensis scapula & Beta 210380 \\
\hline 1 & Surface & $n / a$ & n/a & $-10.9 \mathrm{col}$. & C. lupus familiaris vertebra & ICA15B/0115 \\
\hline & & & & & & \\
\hline
\end{tabular}

1914 
bioRxiv preprint doi: https://doi.org/10.1101/2020.01.17.909663; this version posted January 17, 2020. The copyright holder for this preprint (which was not certified by peer review) is the author/funder, who has granted bioRxiv a license to display the preprint in perpetuity. It is made available under aCC-BY-NC-ND 4.0 International license.

1927 Table 3.
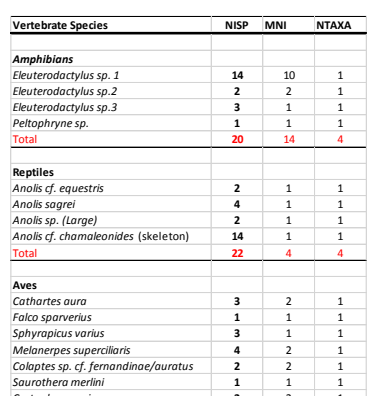
Colaptes sp. cf. fermo
Sourothera merini
Coriti Sourothera merlini
Crotophaga ani

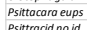
Tyto furcata
Glaucidium siju Glacididium siju
Margarobovas lawrenci
Medium Strigid sp Medium Strigid sp.
Lorge Strigid sp. Zenoida asiatica/macrura Zenoida aurita
Geotrygonct. chrys Geotryon nf. chrysia Corvus sp.
Tyrannus sp. cf. dominicenss
Turdus plumbeus Turdus plumbeus
Dumetella? Mimus polygottos Progne sp. Tachycineta bicolor
Dives atroviolasceous Quiscalus niger
Icterus sp. Agelaius sp.
small cterid s. Sturnella magna
Passer domesticus Passer domes
Aves indet. Rodents
Rattus rattus Rattus rattus
Rattus norvegicus
Mus musculus Mus muscalus
Boromys torreil Boromys storein
Boromys offella Geocapromys columbian us capromys pilorides Mesoccapromys kraglieviof Mesocapromys sp. indet.

Eulipotyphla
Solenodon cubanus Nesophontes micrus Nesophontes major

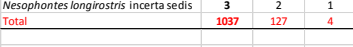

Chiroptera Pteronotus parmellii
Brochyphylla nona Erophylla sezekorni Artibeus anthonyi Phyllops falcatios Antrozous koopman Molossus molossis

Total Bats

Total identified counted 2326 NISP Total vert fauna
Total fauna

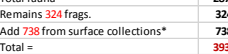

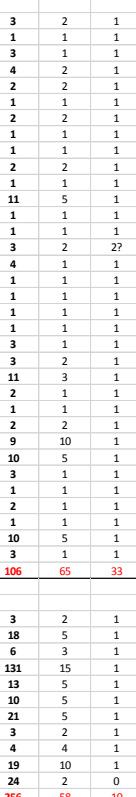

1928

1929

1930

1931

1932

1933 
bioRxiv preprint doi: https://doi.org/10.1101/2020.01.17.909663; this version posted January 17, 2020. The copyright holder for this preprint (which was not certified by peer review) is the author/funder, who has granted bioRxiv a license to display the preprint in perpetuity. It is made available under aCC-BY-NC-ND 4.0 International license.

1934 Table 4.

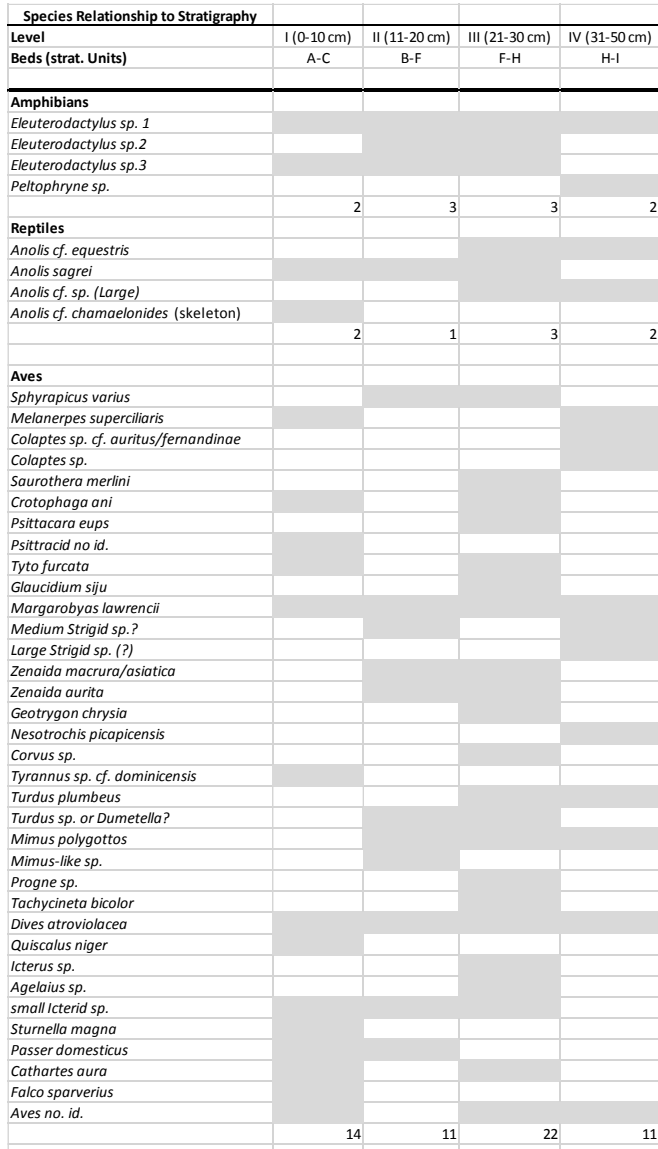

Rodents
Rattus rattus

Rattus rattus
Rattus norvegicus

Rattus norvegicus

Mus musculus

Boromys offella

Geocapromys columbianus

Capromys pilorides

Mesocapromys nanus

Mesocapromys kraglievich

Mesocapromidae no id.

Eulipotyphla

Solenodon cubanus

Nesophontes micrus

Nesophontes major

Nesophontes longirostris incertae cedis

Chiroptera

Mormoops blainvillei

Pteronotus parnelli

Brachyphylla nana

Monophyllus redma

Erophylla sezekorn

Phyllonycteris poeyi

Macrotus waterhouse

Artibeus anthonyi

Artibeus jamaicensis (Large)

Artibeus jamaicensis (parvipes)

Phyllops falcatus

Phyllops vetus

Natalus primus

Antrozous koopman

Eptesicus fuscus

Tadarida brasiliensis

Molossus molossus

Chiroptera No id

Total per interval

1935

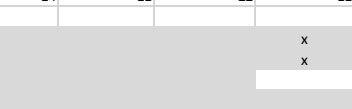

Including Gastropods and Crustaceans

1936 
bioRxiv preprint doi: https://doi.org/10.1101/2020.01.17.909663; this version posted January 17,2020 . The copyright holder for this preprint (which was not certified by peer review) is the author/funder, who has granted bioRxiv a license to display the preprint in perpetuity. It is made available under aCC-BY-NC-ND 4.0 International license.

1937 Table 5.

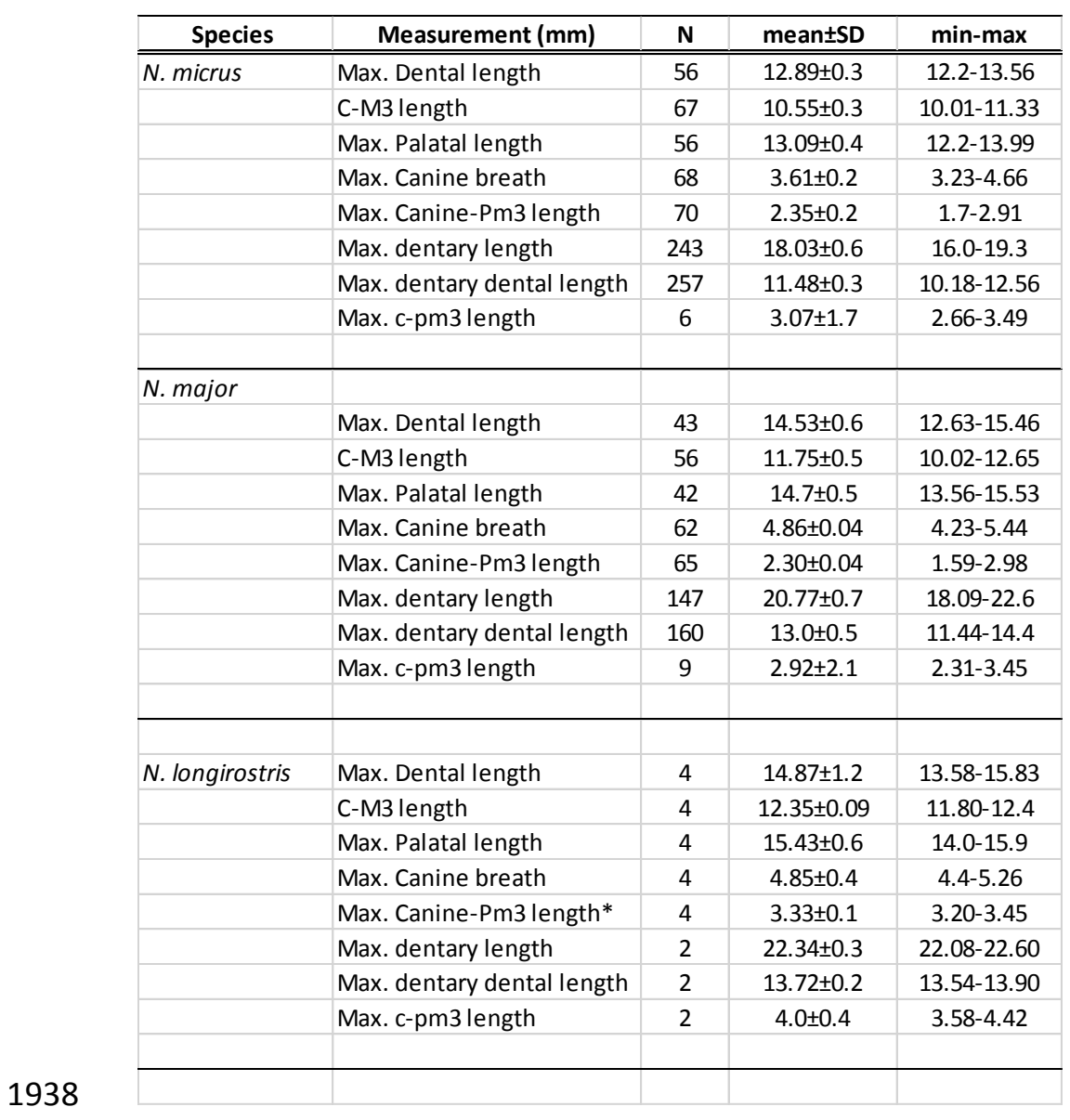

1939

1940 Table 6.

1941

\begin{tabular}{|c||c|c|c|c|c|c|c|c|}
\hline Interval & NTAXA & NISP & Shannon-Weiner & Simpson's & Fisher-a & Eveness & Dominance & Chronology \\
\hline \hline I & 39 & 469 & 1.18 & 0.653 & 1.12 & 0.814 & 0.525 & AD 1953-1993 \\
\hline \hline II & 38 & 519 & 1.17 & 0.649 & 1.14 & 0.805 & 0.572 & AD 660-770 \\
\hline III & 55 & 929 & 1.18 & 0.653 & 0.99 & 0.812 & 0.481 & AD 605-655 \\
\hline IV & 34 & 409 & 1.21 & 0.664 & 1.18 & 0.839 & 0.545 & BC 40-90 AD \\
\hline Overall & $\mathbf{7 3}$ & $\mathbf{2 3 2 6}$ & $\mathbf{2 . 8 2}$ & $\mathbf{0 . 6 9 8}$ & $\mathbf{1 . 1 0 7 5}$ & $\mathbf{0 . 2 3 3}$ & 0.53075 & R-2000 BP \\
\hline
\end{tabular}

